\title{
On the quality of MIPAS kinetic temperature in the middle atmosphere
}

\author{
M. García-Comas ${ }^{1,2}$, B. Funke ${ }^{1}$, M. López-Puertas ${ }^{1}$, D. Bermejo-Pantaleón ${ }^{1}$, N. Glatthor ${ }^{3}$, T. von Clarmann ${ }^{3}$, \\ G. Stiller ${ }^{3}$, U. Grabowski ${ }^{3}$, C. D. Boone ${ }^{4}$, W. J. R. French ${ }^{5}$, T. Leblanc ${ }^{6}$, M. J. López-González ${ }^{1}$, and M. J. Schwartz ${ }^{7}$ \\ ${ }^{1}$ Instituto de Astrofísica de Andalucía-CSIC, Granada, Spain \\ ${ }^{2}$ Dpto. Física Aplicada, Universidad de Granada, Granada, Spain \\ ${ }^{3}$ Karlsruhe Institut für Technologie, Institut für Meteorologie und Klimaforschung, Karlsruhe, Germany \\ ${ }^{4}$ University of Waterloo, Waterloo, Ontario, Canada \\ ${ }^{5}$ Australian Antarctic Division, Kingston, Tasmania, Australia \\ ${ }^{6}$ California Institute of Technology, Jet Propulsion Laboratory, Wrightwood, CA, USA \\ ${ }^{7}$ California Institute of Technology, Jet Propulsion Laboratory, Pasadena, CA, USA
}

Correspondence to: M. García-Comas (maya@iaa.es)

Received: 15 July 2011 - Published in Atmos. Chem. Phys. Discuss.: 30 August 2011

Revised: 12 April 2012 - Accepted: 12 June 2012 - Published: 13 July 2012

\begin{abstract}
The kinetic temperature and line of sight elevation information are retrieved from the MIPAS Middle Atmosphere (MA), Upper Atmosphere (UA) and NoctiLucentCloud (NLC) modes of high spectral resolution limb observations of the $\mathrm{CO}_{2} 15 \mu \mathrm{m}$ emission using the dedicated IMK/IAA retrieval algorithm, which considers non-local thermodynamic equilibrium conditions. These variables are accurately derived from about $20 \mathrm{~km}$ (MA) and $40 \mathrm{~km}$ (UA and NLC) to $105 \mathrm{~km}$ globally and both at daytime and nighttime. Typical temperature random errors are smaller than $0.5 \mathrm{~K}$ below $50 \mathrm{~km}, 0.5-2 \mathrm{~K}$ at $50-70 \mathrm{~km}$, and $2-7 \mathrm{~K}$ above. The systematic error is typically $1 \mathrm{~K}$ below $70 \mathrm{~km}, 1-3 \mathrm{~K}$ from 70 to $85 \mathrm{~km}$ and $3-11 \mathrm{~K}$ from 85 to $100 \mathrm{~km}$. The average vertical resolution is typically $4 \mathrm{~km}$ below $35 \mathrm{~km}, 3 \mathrm{~km}$ at $35-50 \mathrm{~km}, 4-6 \mathrm{~km}$ at $50-90 \mathrm{~km}$, and $6-10 \mathrm{~km}$ above. We compared our MIPAS temperature retrievals from 2005 to 2009 with co-located ground-based measurements from the lidars located at the Table Mountain Facility and Mauna Loa Observatory, the SATI spectrograph in Granada (Spain) and the Davis station spectrometer, and satellite observations from ACE-FTS, Aura-MLS and TIMED-SABER from $20 \mathrm{~km}$ to $100 \mathrm{~km}$. We also compared MIPAS temperatures with the high latitudes climatology from falling sphere measurements. The comparisons show very good agreement, with differences smaller than $3 \mathrm{~K}$ below $85-90 \mathrm{~km}$ in midlatitudes. Differences over the poles in this altitude range are
\end{abstract}

larger but can be generally explained in terms of known biases of the other instruments. The comparisons above $90 \mathrm{~km}$ worsen and MIPAS retrieved temperatures are always larger than other instrument measurements.

\section{Introduction}

The accurate knowledge of the atmospheric kinetic temperature is necessary to understand the dynamics, the chemistry and the energy balance of the atmosphere because it both reflects and affects the behavior of the atmosphere. Also, the kinetic temperature is required to derive the abundance of atmospheric species should they be retrieved from measurements of their infrared emission. If the latter applies, both implications make the availability of temperature measurements and their accuracy essential for atmospheric studies.

This is the case of the Michelson Interferometer for Passive Atmospheric Sounding (MIPAS), which measures the atmospheric infrared emission from which profiles of temperature and abundance of atmospheric species are derived (Fischer et al., 2008). MIPAS provides day and nighttime global measurements in the $4.3-14.6 \mu \mathrm{m}$ spectral range with a high spectral resolution (its optimized-resolution is $0.0625 \mathrm{~cm}^{-1}$, unapodized). Since its launch on 1 March 2002 onboard the European Space Agency's Environmental

Published by Copernicus Publications on behalf of the European Geosciences Union. 
Satellite (ESA's EnviSat), MIPAS usually scans the limb in its nominal mode (NOM). This mode covers the atmosphere from about 6 to $70 \mathrm{~km}$ in 27 steps (every $1.5 \mathrm{~km}$ from 6 to $21 \mathrm{~km}$, every $2 \mathrm{~km}$ from 21 to $31 \mathrm{~km}$, every $3 \mathrm{~km}$ from 31 to $46 \mathrm{~km}$, and every $4 \mathrm{~km}$ from 46 to $70 \mathrm{~km}$ ). MIPAS also uses special modes of observations: the Middle Atmosphere (MA), the NoctiLucent-Cloud (NLC) and the Upper Atmosphere (UA) modes. The MA, NLC and UA modes are observations in which MIPAS extends its vertical coverage up to the thermosphere, measuring the limb atmospheric spectra every $3 \mathrm{~km}$ from about 18 to $102 \mathrm{~km}$ in the MA mode, every $3 \mathrm{~km}$ from 40 to $102 \mathrm{~km}$ and every $5 \mathrm{~km}$ from 102 to $170 \mathrm{~km}$ in the UA mode, and every $3 \mathrm{~km}$ from 39 to $102 \mathrm{~km}$ (except for the vertical step from 78 to $87 \mathrm{~km}$, which is $1.5 \mathrm{~km}$ ) in the NLC mode. Observations in the MA and UA modes started in 2005, when full day measurements in these modes were done sporadically, and since 2007 they are taken regularly (approximately each mode is used one day every 10 days). The NLC mode observations, also starting in 2005, are only used in the NLC season (solstices) and usually last 2-3 days per solstice and year. Hence, MIPAS operates in these modes in approximately $20 \%$ of its orbits since 2005 . These features make MIPAS the first limb instrument measuring IR mesospheric and thermospheric emission with high spectral resolution on a periodic and prolongued basis.

ESA provides operational retrievals of the NOM mode measurements as described in Ridolfi et al. (2000) and Raspollini et al. (2010). Complementarily, the retrievals are also done off-line for the analysis of scientific cases in which a better accuracy is more desirable than the immediacy of data availability. The IMK-IAA retrieval processor (von Clarmann et al., 2003), using consolidated L1B spectra (complete orbits with more accurate gain calibration), was designed for this purpose. The advantages of the IMKIAA retrievals compared to the operational products are the extended NOM altitude coverage, the extended number of species retrieved, less stringent approximations in radiative transfer modeling, the ability to consider non-LTE conditions and, as a consequence, the possibility of application to the MA, UA and NLC mode measurements.

The difficulty of the retrieval of atmospheric variables from the MIPAS infrared spectra in the MA, UA and NLC modes is that the emission originating in the mesosphere and the lower thermosphere (MLT) is very often affected by nonLocal Thermodynamic Equilibrium (non-LTE). This is because the density at these altitudes is very low and collisions are not frequent enough to take the population of the emitting ro-vibrational levels to a Boltzmann distribution (LópezPuertas and Taylor, 2001). This is the case of the $\mathrm{CO}_{2}$ emission at $15 \mu \mathrm{m}$, from which kinetic temperature can be retrieved. Under that situation, a sophisticated modeling of the emitting vibrational levels considering the excitation mechanisms (thermal and non-thermal collisions, exchange of energy between atmospheric layers, solar absorption, chemical processes) is required for accurate retrievals. The IMK-IAA retrieval processor has that ability since it can be coupled to the Generic RAdiative traNsfer AnD non-LTE population Algorithm (GRANADA) (Funke et al., 2009), which calculates the non-LTE population of the ro-vibrational levels of atmospheric molecules.

Observations of the MLT $15 \mu \mathrm{m}$ non-LTE emission from the limb started back in the seventies, with the launch of several rockets, like the High Resolution Interferometer Spectrometer (HIRIS) in 1976 (Stair et al., 1983) and the Spectral Infrared Rocket Experiment (SPIRE) in 1977 (Nadile et al., 1977). The Cryogenic Infrared Radiance Instrumentation for Shuttle (CIRRIS-A), onboard the space shuttle for 9 days, was the first instrument measuring this non-LTE emission from space and the Improved Stratospheric And Mesospheric Sounder (ISAMS), flying onboard UARS, was the first observing it with an almost global latitudinal coverage $\left(34^{\circ} \mathrm{S}-\right.$ $80^{\circ} \mathrm{N}$ alternating with $80^{\circ} \mathrm{S}-34^{\circ} \mathrm{N}$ ) for an extended period (9 months), both in 1991. Their $15 \mu \mathrm{m}$ kinetic temperature retrievals assumed LTE (Dudhia and Livesey, 1996; Miller et al., 1999), justified by the fact that they only extended up to $70 \mathrm{~km}$, where the non-LTE effects on the main $\mathrm{CO}_{2}$ isotope $v_{2}$ fundamental band used are not significant. This is usually the case unless strong inversion layers in the lowermid mesosphere are present (García-Comas et al., 2008). The CRyogenic Infrared Spectrometers and Telescopes for the Atmosphere experiment, CRISTA, was mounted on the free-flying ASTRO-SPAS satellite. It was launched with the US Space Shuttle in November 1994 (CRISTA-1) and August 1997 (CRISTA-2), yielding about one week of atmospheric measurements each (Grossmann et al., 2002). Initially, the standard temperature retrievals were performed up to $90 \mathrm{~km}$ in altitude, covered $60^{\circ} \mathrm{S}-60^{\circ} \mathrm{N}$ and assumed LTE (Riese et al., 1999). The re-processing of measurements extended to $110 \mathrm{~km}$ and $74^{\circ} \mathrm{S}-74^{\circ} \mathrm{N}$ considered, for the first time, non-LTE and revealed retrieved temperatures up to $30 \mathrm{~K}$ smaller than the standard results (LTE) at the cold high latitude mesopause (Gusev et al., 2006).

Besides MIPAS, there are currently two other instruments onboard satellites observing the limb $15 \mu \mathrm{m}$ emission in the MLT: the Sounding of the Atmosphere using Broadband Emission Radiometry (SABER), launched in 2001 onboard TIMED and the HIgh Resolution Dynamics Limb Sounder (HIRDLS), launched in 2004 onboard Aura. Temperature retrievals of HIDRLS measurements reach up to $65 \mathrm{~km}$ (Khosravi et al., 2009) and assume LTE. SABER temperatures retrievals extend up to $110 \mathrm{~km}$ and include non-LTE (Mertens et al., 2004) using the formalism described in López-Puertas and Taylor (2001). Its temperatures are obtained continuously and up to $110 \mathrm{~km}$, covering $52^{\circ} \mathrm{S}-82^{\circ} \mathrm{N}$ and alternating every two months with $82^{\circ} \mathrm{S}-52^{\circ} \mathrm{N}$. Although, as we mentioned above, MIPAS observes the MLT one fifth of the time, it provides a complete global coverage, being able to monitor the atmosphere above the two poles within one hour. Its emission measurements at $15 \mu \mathrm{m}$ are affected by non-LTE and, hence, require a retrieval taking this into account. 
This paper describes how non-LTE kinetic temperature profiles are derived from MIPAS measurements covering the MLT and assesses their quality. In Sect. 2, we describe the temperature retrieval technique used, the non-LTE model behind it and evaluate the systematic and random errors for versions 511, 611 and 711, corresponding to the MA, UA and NLC modes measurements, respectively. In Sect. 3, we give details on seven ground-based and space-borne instruments that, besides MIPAS, provide kinetic temperature in the mesosphere or/and the lower thermosphere and compare them with co-located MIPAS measurements. We also compare our measurements with a climatology for the northern high latitude summer constructed from measurements from falling spheres taken over about ten years. Out of these instruments, only SABER limb measurements uses the same technique as MIPAS. The other space-borne instruments use a different spectral region or observe in absorption and, hence, are not significantly affected by non-LTE. This is also the case for all the ground-based instruments. In the final section, we also discuss the differences found, explain their possible reasons, and give a summary of the results.

\section{MIPAS temperature and line of sight non-LTE retrievals}

Temperature profiles, line of sight (LOS) altitude information and temperature horizontal gradients are retrieved with the "state-of-the-art" MIPAS level 2 research processor developed and operated by the Institute of Meteorology and Climate Research (IMK) in Karlsruhe together with the Instituto de Astrofísica de Andalucía (IAA) in Granada. The retrieval strategy, which is a constrained multi-parameter non-linear least squares fitting of measured and modeled spectra, is described in detail in von Clarmann et al. (2003). It has been successfully applied to nominal MIPAS observations taken during 2002-2004. Several improvements have been incorporated to the temperature and LOS retrieval from nominal MIPAS optimized resolution data after an instrument failure in 2005 (von Clarmann et al., 2009), including the joint retrieval of horizontal gradients in latitudinal and longitudinal directions from single scans. This approach, also applied to the MA, UA and NLC retrievals described here, avoids significant retrieval errors due to temperature inhomogenities along the line of sight (Kiefer et al., 2010). Additional modifications of the retrieval setup for nominal observations are required, however, in order to account for the extended altitude range of MA, UA and NLC observations. These include (i) the inclusion of non-LTE of the $\mathrm{CO}_{2}$ vibrational populations emitting near $15 \mu \mathrm{m}$; (ii) an extension of spectral intervals (microwindows) used in the retrieval, (iii) a modified altitude grid of the retrieval parameter vector; and, (iv) modified a priori information on temperature and its horizontal gradients.
The general approach for retrievals under consideration of non-LTE is described in Funke et al. (2001). Non-LTE vibrational populations of $\mathrm{CO}_{2}$ are modeled with the GRANADA algorithm (Funke et al., 2009) within each iteration of the retrieval. A brief description of the non-LTE modeling in the temperature and LOS retrievals is provided in Sect. 2.1.

Temperature and LOS elevation pointing information are retrieved from the $15 \mu \mathrm{m}$ spectral region, covered by the MIPAS band A (685-970 $\left.\mathrm{cm}^{-1}\right)$, using ro-vibrational emissions of the $\mathrm{CO}_{2}$ principal isotope. The retrievals are performed using selected spectral microwindows with a typical width of $0.1-0.5 \mathrm{~cm}^{-1}$ and which vary with tangent altitudes in order to account for the variability of the sensitivity of $\mathrm{CO}_{2}$ lines to temperature, to optimize computation time, and to minimize systematic errors (Echle et al., 2000). The selected microwindows are listed in Table 1, also showing the altitude range where they are used. This microwindow set is an extension of those used in the nominal retrieval $(6-68 \mathrm{~km})$ that includes very strong emission lines in order to achieve a good signal-to-noise ratio at higher tangent heights. Three additional microwindows include fundamental band $(01101 \rightarrow 00001)$ R-branch lines in the 686$703 \mathrm{~cm}^{-1}$ range, used principally at mesospheric and lower thermospheric tangent heights. Particular care has been taken to avoid saturated line center regions at lower mesospheric tangent heights in order to minimize vertical crosstalk. Additionally, strong Q-branch emissions located at $720 \mathrm{~cm}^{-1}$ $(10001 \rightarrow 01101), 740 \mathrm{~cm}^{-1}(11101 \rightarrow 02201)$, and $791 \mathrm{~cm}^{-1}$ $(11101 \rightarrow 10002)$ are exploited also at lower tangent heights, resulting in an improved temperature and pointing sensitivity compared to the microwindow selection used in the nominal retrievals. The inclusion of $\mathrm{CO}_{2}$ Q-branches, however, requires the modeling of line-mixing effects in spectral simulations. The "Karlsruhe Optimized and Precise Radiative transfer Algorithm" (KOPRA) (Stiller et al., 2002), included in the retrieval scheme, allows to account for line mixing as described by Funke et al. (1998). In our retrieval of temperature and LOS from MA observations, we have chosen the approach proposed by Rosenkranz (1975) which provides accurate results at tangent height higher than $20 \mathrm{~km}$ for the Q-branches of interest (Funke et al., 1998).

As in the nominal setup described in von Clarmann et al. (2009), the temperature retrieval is performed on a $0-120 \mathrm{~km}$ altitude range with a grid of $1 \mathrm{~km}$ step up to $50 \mathrm{~km}$ and $2 \mathrm{~km}$ steps between 50 and $70 \mathrm{~km}$. The $2 \mathrm{~km}$ spacing is continued in the MA, UA and NLC setups up to $100 \mathrm{~km}$ (spacing in the nominal setup is $2.5-5 \mathrm{~km}$ ) and increases to $2.5-5 \mathrm{~km}$ above (spacing in the nominal setup is $5-10 \mathrm{~km}$ ). Due to the oversampled retrieval grid compared to the tangent height spacing, the retrieval is regularized by a Tikhonov-type constraint which adds to the objective function of the least squares fit a penalty keeping the temperature differences at adjacent altitudes reasonably small (Tikhonov, 1963; Steck, 2002).

LOS information is retrieved in a identical manner as in the nominal setup, that is, the retrieval vector consists on 
Table 1. Microwindows used in the retrieval of MIPAS v511 temperature. Range of tangent heights for which the microwindows are used are marked with asterisks.

\begin{tabular}{|c|c|c|c|c|c|c|c|c|c|c|c|c|c|c|c|c|c|}
\hline \multirow[t]{2}{*}{ No. } & \multicolumn{2}{|c|}{ Wavelength $\left[\mathrm{cm}^{-1}\right]$} & \multicolumn{15}{|c|}{ Altitude range $[\mathrm{km}]$} \\
\hline & Minimum & Maximum & 18 & 21 & 27 & 30 & 33 & 36 & 39 & 42 & 45 & 48 & 51 & 63 & 69 & 72 & 120 \\
\hline 1 & 686.9375 & 687.3750 & & & & & & & & & $* *$ & $* *$ & & & & & \\
\hline 2 & 687.0000 & 687.3125 & & & & & & & & & & & $* *$ & $* *$ & $* *$ & $* *$ & $* *$ \\
\hline \multirow[t]{3}{*}{3} & 688.5000 & 689.0000 & & & & & & & & & & & $* *$ & $* *$ & $* *$ & $* *$ & $* *$ \\
\hline & 688.5000 & 689.0625 & & & & & & & & & $* *$ & $* *$ & & & & & \\
\hline & 688.8125 & 689.0000 & & & & & & & & $* *$ & & & & & & & \\
\hline \multirow[t]{2}{*}{4} & 690.1250 & 690.6250 & & & & & & & & & $* *$ & $* *$ & & & & & \\
\hline & 690.1875 & 690.5625 & & & & & & & & & & & $* *$ & $* *$ & $* *$ & $* *$ & $* *$ \\
\hline \multirow[t]{3}{*}{5} & 691.7500 & 692.2500 & & & & & & & & & $* *$ & $* *$ & & & & & \\
\hline & 691.8125 & 692.2500 & & & & & & & & & & & $* *$ & $* *$ & $* *$ & $* *$ & $* *$ \\
\hline & 692.0625 & 692.1875 & & & & & & & & $* *$ & & & & & & & \\
\hline \multirow[t]{2}{*}{6} & 699.8750 & 700.1875 & & & & & & & & $* *$ & & & & & & & \\
\hline & 699.8750 & 700.2500 & & & & & & & & & $* *$ & $* *$ & $* *$ & $* *$ & $* *$ & $* *$ & $* *$ \\
\hline 7 & 700.4375 & 700.6875 & & & & & & & & & & & & $* *$ & $* *$ & $* *$ & \\
\hline \multirow[t]{2}{*}{8} & 701.5625 & 701.8125 & & & & & & & & $* *$ & $* *$ & $* *$ & & & & & \\
\hline & 701.5625 & 701.8750 & & & & & & & & & & & $* *$ & $* *$ & $* *$ & $* *$ & $* *$ \\
\hline 9 & 719.6250 & 721.0625 & & & & & & & & $* *$ & $* *$ & $* *$ & $* *$ & $* *$ & $* *$ & $* *$ & $* *$ \\
\hline 10 & 741.4375 & 741.8125 & & & & & & & & $* *$ & $* *$ & $* *$ & $* *$ & $* *$ & $* *$ & & \\
\hline \multirow[t]{3}{*}{11} & 719.6250 & 719.9375 & & & & & $* *$ & & & & & & & & & & \\
\hline & 719.6875 & 720.5625 & & & & & & $* *$ & & & & & & & & & \\
\hline & 719.8750 & 720.6875 & & & & & & & $* *$ & & & & & & & & \\
\hline 12 & 720.8125 & 721.0000 & & & & & $* *$ & & & & & & & & & & \\
\hline 13 & 731.2500 & 731.3750 & & $* *$ & $* *$ & $* *$ & $* *$ & $* *$ & $* *$ & & & & & & & & \\
\hline 14 & 731.5000 & 731.8125 & & $* *$ & $* *$ & $* *$ & $* *$ & $* *$ & $* *$ & & & & & & & & \\
\hline \multirow[t]{3}{*}{15} & 741.2500 & 741.7500 & & & & & & $* *$ & & & & & & & & & \\
\hline & 741.3750 & 741.7500 & & & & & & & $* *$ & & & & & & & & \\
\hline & 741.5000 & 741.6875 & & & & & $* *$ & & & & & & & & & & \\
\hline 16 & 744.3125 & 744.5000 & & $* *$ & $* *$ & $* *$ & $* *$ & $* *$ & $* *$ & & & & & & & & \\
\hline 17 & 745.0625 & 745.5000 & & $* *$ & $* *$ & $* *$ & $* *$ & $* *$ & $* *$ & & & & & & & & \\
\hline 18 & 748.9375 & 749.1250 & $* *$ & $* *$ & & & & & & & & & & & & & \\
\hline 19 & 749.5000 & 749.8125 & $* *$ & $* *$ & $* *$ & $* *$ & $* *$ & $* *$ & $* *$ & & & & & & & & \\
\hline 20 & 765.8750 & 766.0000 & & $* *$ & $* *$ & $* *$ & $* *$ & $* *$ & $* *$ & & & & & & & & \\
\hline 21 & 766.1250 & 766.1875 & & $* *$ & $* *$ & $* *$ & $* *$ & $* *$ & $* *$ & & & & & & & & \\
\hline 22 & 766.3750 & 766.5625 & & $* *$ & $* *$ & $* *$ & $* *$ & $* *$ & $* *$ & & & & & & & & \\
\hline 23 & 780.4375 & 780.6250 & $* *$ & $* *$ & $* *$ & $* *$ & $* *$ & $* *$ & $* *$ & & & & & & & & \\
\hline \multirow[t]{6}{*}{24} & 791.1875 & 791.8750 & $* *$ & & & & & & & & & & & & & & \\
\hline & 791.3750 & 791.5625 & & & & $* *$ & $* *$ & & & & & & & & & & \\
\hline & 791.3750 & 791.6250 & & & $* *$ & & & $* *$ & $* *$ & & $* *$ & $* *$ & $* *$ & $* *$ & & & \\
\hline & 791.3750 & 791.6875 & & & & & & & & $* *$ & & & & & & & \\
\hline & 791.3750 & 791.7500 & & & & & & & & & & & & & & & \\
\hline & 791.5000 & 791.7500 & & $* *$ & & & & & & & & & & & & & \\
\hline 25 & 798.1250 & 798.1875 & & $* *$ & $* *$ & $* *$ & $* *$ & $* *$ & $* *$ & & & & & & & & \\
\hline 26 & 798.4375 & 798.5000 & & $* *$ & $* *$ & $* *$ & $* *$ & $* *$ & $* *$ & & & & & & & & \\
\hline 27 & 810.8125 & 811.0625 & & $* *$ & $* *$ & $* *$ & $* *$ & $* *$ & $* *$ & & & & & & & & \\
\hline 28 & 812.2500 & 812.5625 & & $* *$ & $* *$ & $* *$ & $* *$ & $* *$ & $* *$ & & & & & & & & \\
\hline
\end{tabular}

the tangent altitudes of each limb scan. The LOS retrieval is constrained to engineering pointing information (and uncertainties) using a maximum a posteriori approach (Rodgers, 2000). Since independent spectral information on pressure (and hence LOS) is not contained in mesospheric measurements, only the pointing bias of an entire limb sequence is retrieved, while the pointing increments above $70 \mathrm{~km}$, i.e., the differences between adjacent tangent altitudes, are taken as provided by the engineering information from ESA along with the calibrated spectra. Retrieved LOS information represents a pointing correction to the engineering pointing information provided by ESA. A systematic, orbit-periodic 
pointing bias of ESA's L1b engineering information (version 4.61/62) has been identified from the analysis of the retrieved LOS of nominal observations during 2002-2004 (Kiefer et al., 2007). The pointing mismatch between retrieved and engineering LOS increases with latitude by 1.5$2 \mathrm{~km}$ from pole to pole. Figure 1 shows the average pointing mismatch during December-February as function of tangent height and latitude obtained from MA observations in 20072009. Below $70 \mathrm{~km}$, the observed pattern is very similar to the results of Kiefer et al. (2007) from nominal observations.

A priori temperature information below $60 \mathrm{~km}$ is taken from European Centre for Medium-Range Weather forecasts (ECMWF) reanalysis data. At higher altitudes, the a priori profiles are merged with NRLMSIS-00 model data (Picone et al., 2002) extracted on the location and local time of the MIPAS observations and taking into account actual solar-geomagnetic conditions. A priori profiles for latitudinal and longitudinal temperature gradients are calculated from ECMWF data below $60 \mathrm{~km}$ and are set to zero above. $\mathrm{CO}_{2}$ abundances are assumed to be spatially constant below $35 \mathrm{~km}$ with a volume mixing ratio (vmr) of $376 \mathrm{ppmv}$ at the beginning of 2004 and a linear trend of 1.9 ppmv per year which has been extracted from the graph of monthly mean carbon dioxide globally averaged over marine sites, as issued in September 2007 by NOAA (Pieter Tans, NOAA/ESRL (www.esrl.noaa.gov/gmd/ccgg/trends)). Above $35 \mathrm{~km}$, monthly zonal mean $\mathrm{CO}_{2}$ abundances from WACCM simulations (Garcia et al., 2007), averaged over 2003-2004, are interpolated to the latitude and day of the year of the MIPAS observations. The same trend correction as at lower altitudes is then applied.

\section{$2.1 \quad$ Non-LTE modeling}

Vibrational populations of the six most abundant $\mathrm{CO}_{2}$ isotopes are calculated online during the retrieval with the GRANADA model. This generic non-LTE algorithm provides vibrational and rotational non-LTE populations for relevant atmospheric infrared emitters by solving iteratively the statistical equilibrium (SEE) and radiative transfer equations (RTE) under consideration of radiative, collisional and chemical excitation processes. The iteration scheme, i.e. the order of solutions of SEE and RTE, can be chosen by the user, allowing for Curtis matrix, lambda iteration, or mixed applications. Radiative transfer can be treated either line-by-line or by statistical band methods. The radiative transfer calculations within the GRANADA modeling are performed using KOPRA.

Solar incoming fluxes at the top of the atmosphere are adapted from the SOLAR2000 solar irradiance model (Tobiska et al., 2000), including modulations due to temporal variations of the Sun-Earth distance. Attenuation of the solar flux by Fraunhofer lines is taken into account (Hase et al., 2006). Tropospheric upwelling fluxes are calculated under consideration of surface emissions, tropospheric absorbing

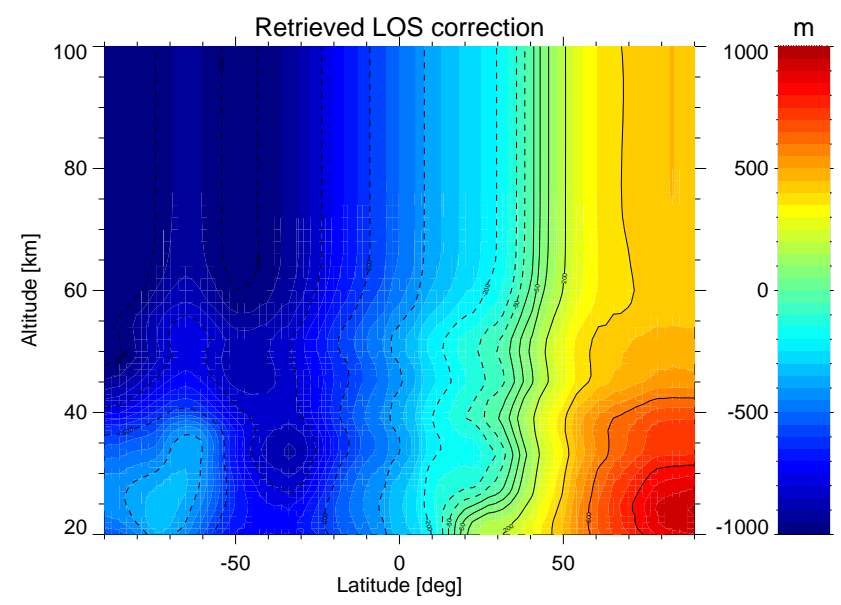

Fig. 1. Average differences between retrieved and engineering tangent altitudes during December-February of 2007-2009.

species and clouds, the latter characterized by the mean cloud top altitude and cloud coverage. Surface and cloud emissions are treated as blackbodies at the temperature of their respective height level.

The current setup of GRANADA for $\mathrm{CO}_{2}$ populations takes into account 134 vibrational levels, including $\mathrm{O}^{16} \mathrm{C}^{12} \mathrm{O}^{16}$ (isotope 626) levels up to (070), (061), (032), and (013); $\mathrm{O}^{16} \mathrm{C}^{12} \mathrm{O}^{17}$ (isotope 627) levels up to (040) and (041); $\mathrm{O}^{16} \mathrm{C}^{12} \mathrm{O}^{18}$ and $\mathrm{O}^{16} \mathrm{C}^{13} \mathrm{O}^{16}$ (isotopes 628 and 636) levels up to (030) and (011); and $\mathrm{O}^{16} \mathrm{C}^{13} \mathrm{O}^{17}$ and $\mathrm{O}^{16} \mathrm{C}^{13} \mathrm{O}^{18}$ (isotopes 637 and 638) levels up to (010) and (001). Because of the strong collisional coupling of $\mathrm{CO}_{2}$ with $\mathrm{N}_{2}(v=1)$ via $\mathrm{V}-\mathrm{V}$ energy transfer, vibrational populations of $\mathrm{N}_{2}(1)$ are also included in the non-LTE model calculations. The $\mathrm{CO}_{2}$ levels are connected by 695 radiative transitions, 39 of them considering full radiative transfer in the atmosphere. These 39 transitions involve vibrational states up to $(041)$ for the 626 isotope, (030) and (021) for the 627 isotope, and (011) for the 628 and 636 isotopes. Above $20 \mathrm{~km}$, radiative transfer is calculated using statistical band methods (i.e. equivalentline approach) in the Curtis matrix formalism, except for the $v_{2}$ and $v_{3}$ fundamental bands (calculated line-by-line). The accuracy of the statistical band method has been assessed to be better than $1 \%$ in terms of resulting populations. Upwelling tropospheric fluxes at $20 \mathrm{~km}$ are calculated line-byline, taking into account absorption by $\mathrm{H}_{2} \mathrm{O}, \mathrm{CO}_{2}, \mathrm{O}_{3}$, and $\mathrm{N}_{2} \mathrm{O}$. For the remaining 656 transitions (without consideration of atmospheric radiative transfer), the radiative field is constrained by a top-of-the-atmosphere solar component and a tropospheric upwelling component at an estimated emission altitude.

The collisional scheme of $\mathrm{CO}_{2}$ levels is based on LópezPuertas and Taylor (2001). Important updates have been included in the current GRANADA setup, benefiting from several analyses of SABER and MIPAS data (LópezPuertas et al., 2004, 2005; García-Comas et al., 2008). The 
collisional deactivation of $\mathrm{CO}_{2}(010)$ level by $\mathrm{O}, k_{\mathrm{O}}$, is still a major uncertainty in the calculation of the populations of $\mathrm{CO}_{2}(010)$ in the upper mesosphere and lower thermosphere. There is a discrepancy of about a factor of 4 between the rates measured in the laboratory and those deduced from atmospheric measurements, see, e.g., (GarcíaComas et al., 2008). In this study we have adopted the value of $6 \times 10^{-12} \mathrm{~cm}^{3} \mathrm{~s}^{-1}$ at $300 \mathrm{~K}$ for this rate (Sharma and Wintersteiner, 1990), maintaining their suggested temperature dependency. This rate is also being used in the current SABER version 1.07 temperature retrievals (García-Comas et al., 2008).

Another aspect which has been deeply revised here is the vibrational-vibrational $(\mathrm{V}-\mathrm{V})$ energy transfer of $v_{2}$ quanta among the $\mathrm{CO}_{2}$ levels of the same isotope and among different $\mathrm{CO}_{2}$ isotopes. A new $\mathrm{V}-\mathrm{V} v_{2}$ collisional scheme has been included, in which we have used the values of Dang et al. (1983) for the V-V exchange between the three $v_{2}=2$ levels and the $v_{2}=1$ level, and have scaled these values using the harmonic oscillator law and an energy gap law for collisions in which more energetic levels or different isotopes take part. In particular, for the 020 triad and for inter-isotopic V-V exchange, that results in a two times faster net exchange rate of $v_{2}$ quanta in $\mathrm{CO}_{2}-\mathrm{CO}_{2} \mathrm{~V}-\mathrm{V}$ collisions $\left(k_{v v}\right)$ than that used in López-Puertas and Taylor (2001).

New rates for the relaxation of $\mathrm{CO}_{2} 2.7 \mu \mathrm{m}$ Fermi levels obtained from the analysis of MIPAS spectra have also been included (López-Puertas et al., 2005). In particular for the processes

$k_{1}: \mathrm{CO}_{2}\left(02^{0} 1,10^{0} 1\right)+\mathrm{M} \rightleftharpoons \mathrm{CO}_{2}\left(02^{2} 1\right)+\mathrm{M}$,

and

$k_{2}: \mathrm{CO}_{2}\left(02^{0} 1\right)+\mathrm{M} \rightleftharpoons \mathrm{CO}_{2}\left(10^{0} 1\right)+\mathrm{M}$,

we were using rates of $1.5 \times 10^{-13}$ and $3 \times 10^{-11} \mathrm{~cm}^{3} \mathrm{~s}^{-1}$, respectively. These rates have been updated to the values found in the MIPAS analysis of $5.5 \times 10^{-13}$ and $8 \times 10^{-13} \mathrm{~cm}^{3} \mathrm{~s}^{-1}$, respectively.

In the same study, they found for the $\mathrm{V}-\mathrm{V}$ coupling of $\mathrm{CO}_{2}\left(v_{3}\right)$ with $\mathrm{N}_{2}$,

$k_{v v 3}: \mathrm{CO}_{2}\left(0, v_{2}, 1\right)+\mathrm{N}_{2} \rightleftharpoons \mathrm{CO}_{2}\left(0, v_{2}, 0\right)+\mathrm{N}_{2}(1)$,

the values of $k_{v v 3}\left(v_{2}=0,1,3\right)=5.0 \times 10^{-13}$ and $k_{v v 3}\left(v_{2}=2,4\right)$ $=6.5 \times 10^{-13} \mathrm{~cm}^{3} \mathrm{~s}^{-1}$. These values have also been included in this study. Previously, López-Puertas and Taylor (2001) used a common value of $5.0 \times 10^{-13} \mathrm{~cm}^{3} \mathrm{~s}^{-1}$ regardless of the $v_{2}$ excitation of the $\mathrm{CO}_{2}\left(0, v_{2}, 1\right)$ level.

A new relaxation scheme for the relaxation of $\mathrm{CO}_{2}(001)$ in collisions with $\mathrm{N}_{2}$ and $\mathrm{O}_{2}$ :

$\mathrm{CO}_{2}(001)+\mathrm{N}_{2}, \mathrm{O}_{2} \rightarrow \mathrm{CO}_{2}\left(v_{1}, v_{2}, 0\right)+\mathrm{N}_{2}, \mathrm{O}_{2}$,

has been included (López-Puertas et al., 2009), resulting in important changes of $\mathrm{CO}_{2}(040)$ populations in the mesosphere.
The value used here for the rates of the collisional relaxation of $\mathrm{CO}_{2}\left(0, v_{2}, 0\right)$ with $\mathrm{N}_{2}$ and $\mathrm{O}_{2}, k_{\text {air }}$, are those of Wintersteiner et al. (1992), including their temperature dependence. However, we assume a temperature-independent value of $10^{-15} \mathrm{~cm}^{3} \mathrm{~s}^{-1}$ below $150 \mathrm{~K}$, where no laboratory measurements are available, instead of extrapolating values from measurements at higher temperatures.

These updates in the collisional scheme for $\mathrm{CO}_{2}$ in the current GRANADA setup introduce changes with respect to López-Puertas and Taylor (2001) in the $\mathrm{CO}_{2}$ vibrational populations which can be summarized as:

- Larger populations for $\mathrm{CO}_{2}\left(v_{2}\right)$ levels at higher altitudes because of the larger $\mathrm{k}\left(\mathrm{CO}_{2}(010)-\mathrm{O}\right)$ collisional deactivation rate.

- $\mathrm{CO}_{2}(001)$ is more populated now in the daytime mesosphere because of weaker collisional reaction of $\mathrm{CO}_{2}(001)$ with $\mathrm{M}\left(\mathrm{N}_{2}\right.$ and $\left.\mathrm{O}_{2}\right)$ to relax to lower $\mathrm{CO}_{2}$ $v_{2}=1,2,3,4$ levels.

- Because of process 4 above, the $\mathrm{CO}_{2}(040)$ levels have also changed significantly their populations in the daytime mesosphere, being now significantly smaller.

- The populations of the $15 \mu \mathrm{m}$ hot and isotopic levels in the summer mesopause are generally closer to LTE and hence smaller because of the larger $k_{v v}\left(v_{2}\right)$ value used now.

The calculation of $\mathrm{CO}_{2}$ vibrational populations requires additional information on atmospheric abundances of $\mathrm{H}_{2} \mathrm{O}$, $\mathrm{O}_{3}, \mathrm{~N}_{2} \mathrm{O}, \mathrm{O}$, and $\left(\mathrm{O}^{1} \mathrm{D}\right)$, as well as tropospheric cloud conditions. $\mathrm{H}_{2} \mathrm{O}$ and $\mathrm{N}_{2} \mathrm{O}$ abundances are taken from the MIPAS IG2 climatology (Raspollini et al., 2006). $\mathrm{O}_{3}$ and $\mathrm{O}$ abundances are taken from 2-D model calculations (Garcia, 1983) and are interpolated in latitude and day of the year to MIPAS measurement locations. $\mathrm{O}$ abundances above $80 \mathrm{~km}$ are taken from NRLMSIS-00. The sum of $\mathrm{O}_{3}$ and $\mathrm{O}$ is then used in simple photochemical box model for the calculation of $\mathrm{O}$ and $\mathrm{O}\left({ }^{1} \mathrm{D}\right)$ abundances adjusted to the local measurement time. National Centers for Environmental Prediction (NCEP) clear-sky and all-sky outgoing longwave radiation (OLR), and cloud fraction data, sampled at the measurement locations, are used for the determination of the effective cloud coverage and top height.

\subsection{MIPAS temperature error analysis and retrieval characterization}

Error estimation is based on linear theory as suggested by Rodgers (2000). The error budget includes the mapping of the measurement noise on the retrieved temperatures, as well as the propagation of uncertainties of model parameters onto the result. The application of a multi-parameter non-linear least squares inversion algorithm implies a redistribution of the altitude-dependent spectral information over the retrieval 
grid which is described by the averaging kernel (AK) matrix (Rodgers, 2000). The vertical resolution of the temperature retrieval can be expressed as the full width at half maximum of the AK rows. Noise-induced retrieval errors and vertical resolutions, discussed in Sect. 2.2.1, are estimated routinely for each individual profile. Systematic errors related to the mapping of uncertain model parameters are estimated for representative profiles only and are discussed in Sect. 2.2.2.

\subsubsection{Precision and vertical resolution}

The temperature random retrieval error for a single scan, i.e., its precision, arises mainly from the propagation of measurement noise through the retrieval. These are calculated by the retrieval algorithm using a wavelength dependent noiseequivalent-spectral-radiance that on MIPAS A band (685$\left.970 \mathrm{~cm}^{-1}\right)$ is on average about $20 \mathrm{nW} /\left(\mathrm{cm}^{2} \mathrm{~cm}^{-1} \mathrm{sr}\right)$. Seasonal averages of zonal mean distributions of single measurement precisions are shown in Fig. 2 together with the corresponding MIPAS zonal mean temperature distributions (middle and left panels, respectively). Typical values are $0.2-$ $0.5 \mathrm{~K}$ below $50 \mathrm{~km}, 0.5-2 \mathrm{~K}$ at $50-70 \mathrm{~km}$, and $2-7 \mathrm{~K}$ above. The average vertical resolution is shown in the right panels of Fig. 2. Typical values are $4 \mathrm{~km}$ below $35 \mathrm{~km}, 3 \mathrm{~km}$ at $35-$ $50 \mathrm{~km}, 4-6 \mathrm{~km}$ at $50-90 \mathrm{~km}$, and $6-10 \mathrm{~km}$ above. The horizontal band structure of the zonal averaged vertical resolution profiles results from the altitude-constant retrieval grid that does not coincide with the tangent altitude sampling. Retrieval grid points close to observed tangent heights show a better vertical resolution than those in between. Precision and vertical resolution vary only marginally with latitude and season despite of the pronounced variations in the retrieved temperature.

\subsubsection{Systematic errors}

There are several sources of systematic errors affecting the non-LTE retrievals of kinetic temperature. The most important in the upper mesosphere and lower thermosphere are due to the modeling of the non-LTE populations of $\mathrm{CO}_{2}$ vibrational levels, in particular, those produced by uncertainties in the collisional rates or in the abundance of other species involved in the non-LTE processes. The largest errors of this type originate from uncertainties in the $\mathrm{CO}_{2}\left(v_{2}\right)$ quenching by atomic oxygen $\left(k_{\mathrm{O}}\right)$, the abundance of the latter $([\mathrm{O}])$, the rate of $v_{2}$ vibrational exchange between $\mathrm{CO}_{2}$ molecules $\left(k_{v v}\right)$ and the quenching of $\mathrm{CO}_{2}\left(v_{2}\right)$ by molecular nitrogen and molecular oxygen $\left(k_{\mathrm{air}}\right)$. The rates $k_{\mathrm{air}}$ and $k_{\mathrm{O}}$ used in the v511, v611 and v711 $T_{\mathrm{k}}$ retrievals are taken from Wintersteiner et al. (1992) and Sharma and Wintersteiner (1990), respectively. For our non-LTE error estimation, we have assumed an uncertainty of $30 \%$ and $50 \%$, respectively, based on the values reported in the literature for these two rates, as summarized in García-Comas et al. (2008). The atomic oxygen used in the retrievals is taken from MSIS (Picone et al., 2002), for which we have assumed an uncertainty of $50 \%$ also based on considerations in García-Comas et al. (2008). The value for $k_{v v}$ used in v511, v611 and v711 is that measured by Dang et al. (1983) and we have assumed their error measurement uncertainty (20\%). Overall, the typical non-LTE systematic error is smaller than $\pm 0.1 \mathrm{~K}$ below $70 \mathrm{~km}, \pm 1.4 \mathrm{~K}$ at $85 \mathrm{~km}, \pm 6 \mathrm{~K}$ at $95 \mathrm{~km}$ and $\pm 11 \mathrm{~K}$ at $100 \mathrm{~km}$. For polar winter conditions, the errors are slightly smaller: $\pm 0.1 \mathrm{~K}$ at $70 \mathrm{~km}, \pm 1.3 \mathrm{~K}$ at $85 \mathrm{~km}, \pm 2 \mathrm{~K}$ at $95 \mathrm{~km}$ and $\pm 7 \mathrm{~K}$ at $100 \mathrm{~km}$. The non-LTE errors are somewhat larger under polar summer conditions, where the $\mathrm{CO}_{2}\left(v_{2}\right)$ levels are further away from LTE. This scenario was also studied in López-Puertas et al. (2009), where they reported overall non-LTE errors of $\pm 0.1 \mathrm{~K}$ at $70 \mathrm{~km}, \pm 5 \mathrm{~K}$ at $85 \mathrm{~km}$, $\pm 19 \mathrm{~K}$ at $95 \mathrm{~km}$ and $\pm 30 \mathrm{~K}$ at $100 \mathrm{~km}$.

Another source of systematic error is the assumed $\mathrm{CO}_{2}$ abundance, which can significantly depart from well-mixed values above around $70 \mathrm{~km}$ (López-Puertas et al., 2000). The $\mathrm{CO}_{2}$ abundance in v511, v611 and v711 $T_{\mathrm{k}}$ retrievals is taken from the WACCM model (Garcia et al., 2007). According to considerations in Remsberg et al. (2008) and comparisons with ACE (Beagley et al., 2010), ATMOS and ISAMS (López-Puertas et al., 2000) measurements, we have assumed a $15 \%$ uncertainty. The induced $T_{\mathrm{k}}$ error is smaller than $\pm 0.1 \mathrm{~K}$ below $70 \mathrm{~km}, \pm 2 \mathrm{~K}$ at $85 \mathrm{~km}, \pm 3 \mathrm{~K}$ at $90 \mathrm{~km}$ and $\pm 2 \mathrm{~K}$ at $100 \mathrm{~km}$. Nevertheless, comparisons of WACCM $\mathrm{CO}_{2}$ with rocket-borne measurements at $90 \mathrm{~km}$ and, particularly, with CRISTA (Kaufmann et al., 2002) at $100 \mathrm{~km}$ point to a slightly larger uncertainty (20\% at $90 \mathrm{~km}$ and $40-50 \%$ at $100 \mathrm{~km}$ ), which would lead to a $T_{\mathrm{k}}$ error smaller than $\pm 0.1 \mathrm{~K}$ below $70 \mathrm{~km}, \pm 3 \mathrm{~K}$ at $85 \mathrm{~km}, \pm 4 \mathrm{~K}$ at $90 \mathrm{~km}$ and $\pm 5 \mathrm{~K}$ at $100 \mathrm{~km}$.

A further systematic error source arises from horizontal temperature inhomogenities. Although horizontal temperature gradients are retrieved simultaneously with temperature, they provide only a linear correction which might not be appropriate in all atmospheric situations, particularly in the presence of located strong temperature anomalies. Kiefer et al. (2010) investigated the impact of horizontal temperature inhomogenities in MIPAS retrievals from nominal observations by looking at differences between ascending and descending orbit branches (i.e., observations at local times 10:00 p.m. and 10:00 a.m., respectively), assuming that the atmosphere does not change significantly within $12 \mathrm{~h}$. This assumption, however, does only hold at altitudes below approximately $60 \mathrm{~km}$ were tidal signatures are small. Figure 3 (left panel) shows these differences obtained from MIPAS MA temperature observations as seasonal zonal mean distributions. Except for the tropical atmosphere, differences are well below $2 \mathrm{~K}$. In the tropics, differences are more pronounced (up to $4 \mathrm{~K}$ ) and show a clear signature of the migrating diurnal tide. In order to assess the degree of tidal contribution in the differences between ascending and descending orbit measurements, we have compared them to similar differences obtained from ECMWF reanalysis data sampled on 

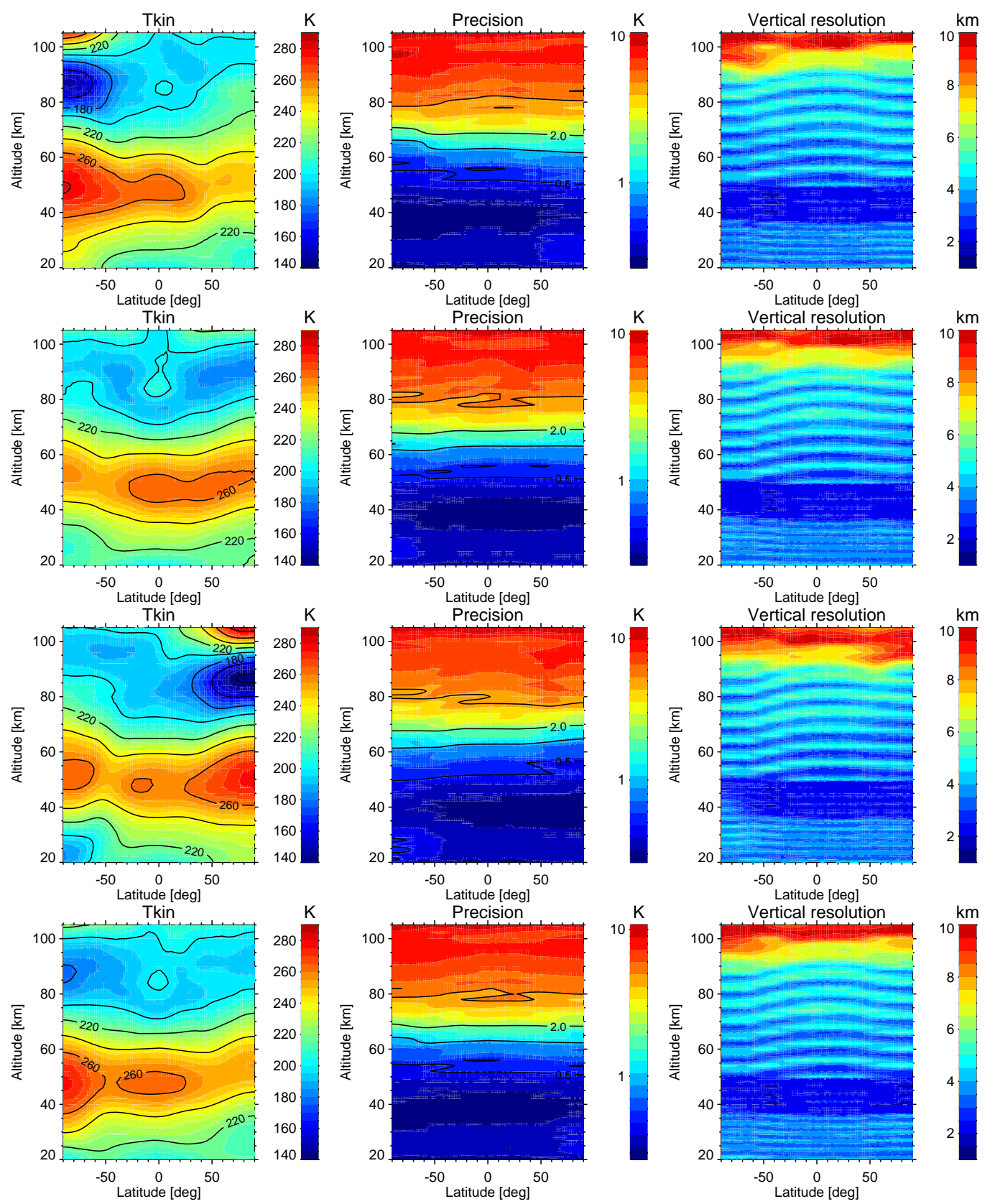

Fig. 2. Seasonal averages of zonal mean distributions of temperature (left), single measurement precision (middle), and vertical resolution (right). Top to bottom: December-February (DJF), March-May (MAM), June-August (JJA), and September-November (SON).

MIPAS locations and times (right panels of Fig. 3). Since ECMWF temperatures include a tidal signature, this comparison allows to separate possible artifacts related to horizontal temperature inhomogenities from tides. The differences obtained from ECMWF data give a very similar picture as the observations, however, with a slightly smaller amplitude of the migrating diurnal tide. Since it is very unlikely that a stronger tidal amplitude in the observations is triggered by horizontal temperature inhomogenities, we conclude that the smaller amplitude in ECMWF is a model-related feature.
Apart of the tidal structures in the ascending - descending differences, MIPAS agrees very well with ECMWF (within $0.5 \mathrm{~K}$ ), and no hint of relevant systematic errors related to horizontal temperature inhomogenities is given.

Other systematic errors arise from uncertainties in the gain calibration (measured radiance uncertainty of $\pm 1 \%$ ), the instrument line shape (uncertainty of $\pm 3 \%$ ), and the spectral shift (which is derived prior to the temperature retrieval). There are also errors coming from the $\mathrm{CO}_{2}$ spectroscopic data used (Flaud et al., 2006), mainly due to uncertainties in 

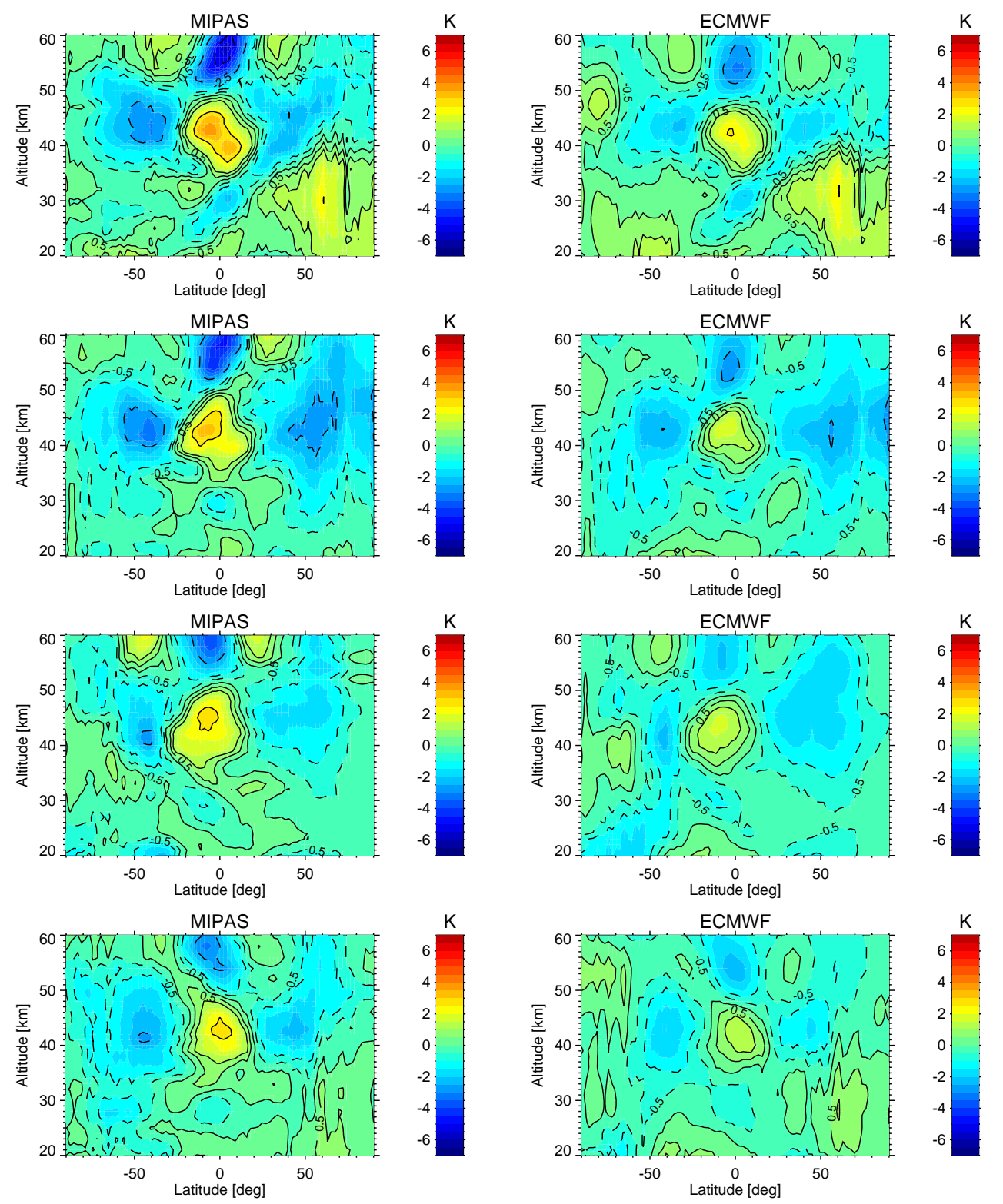

Fig. 3. Seasonal averages of zonal mean temperature differences between descending (10:00 a.m.) and ascending (10:00 p.m.) orbit branch observations of MIPAS (left) and ECMWF sampled at the corresponding MIPAS locations. Top to bottom: December-February (DJF), March-May (MAM), June-August (JJA), and September-November (SON).

the strength, position and width of the emission lines. Based on estimates supplied by J. M. Flaud (personal communication, 2008), we have assumed uncertainties of 3 to $5 \%$ in the intensity (depending on the vibrational band and the rotational quantum numbers) and $6 \%$ in the broadening coefficients. The uncertainties in the abundances of interfering species in the microwindows used for the retrievals (mainly $\mathrm{O}_{3}$ and $\mathrm{N}_{2} \mathrm{O}_{5}$, taken from climatology) are taken from estimates of Remedios et al. (2007). These errors are overall around $1 \mathrm{~K}$ below $70 \mathrm{~km}$ and $1-2 \mathrm{~K}$ above.
Since we compare below temperature profiles, generally as a function of altitude, it is worth mentioning that the pointing errors due to uncertainties in the pressure assumed for the first altitude level are smaller than $\pm 200 \mathrm{~m}$.

A summary of typical estimated systematic errors in MIPAS v511, v611 and v711 kinetic temperature is given in Table 2. The overall systematic error is around $1 \mathrm{~K}$ below $70 \mathrm{~km}, 0.9-3.3 \mathrm{~K}$ from 70 to $85 \mathrm{~km}$ and $3.3-11 \mathrm{~K}$ from 85 to $100 \mathrm{~km}$. In the polar summer, where the non-LTE effect is larger, these values increase to $0.9-5.6 \mathrm{~K}$ from 70 to $85 \mathrm{~km}$ and $5.6-30 \mathrm{~K}$ from 85 to $100 \mathrm{~km}$. 
Table 2. Summary of main systematic and random errors in MIPAS kinetic temperature (in K). Values in parenthesis are the errors in polar summer. "Non-LTE" includes errors due to uncertainties in the collisional rates and the atomic oxygen used in the non-LTE model. "Total Sys." is the root sum square of all the systematic errors.

\begin{tabular}{lrrrrr}
\hline \multirow{2}{*}{ Source } & \multicolumn{5}{c}{ Altitude $[\mathrm{km}]$} \\
\cline { 2 - 6 } & 20 & 55 & 70 & 85 & 100 \\
\hline Systematic & $0.0(0.0)$ & $0.0(0.0)$ & $0.1(0.1)$ & $1.4(4.7)$ & $11(30)$ \\
\hline Non-LTE & 0.03 & 0.01 & 0.12 & 2.3 & 1.6 \\
{$\left[\mathrm{CO}_{2}\right]$} & 0.02 & 0.03 & 0.12 & 0.08 & 0.05 \\
{$\left[\mathrm{~N}_{2} \mathrm{O}_{5}\right]$} & 0.19 & 0.07 & 0.02 & 0.18 & 0.14 \\
{$\left[\mathrm{O}_{3}\right]$} & 0.9 & 1.0 & 0.7 & 0.5 & 0.4 \\
Spectroscopy & 0.01 & 0.02 & 0.1 & 0.3 & 0.2 \\
Shift & 0.09 & 0.3 & 0.2 & 0.4 & 0.7 \\
Gain & 0.14 & 0.3 & 0.4 & 1.7 & 0.9 \\
ILS & $0.9(0.9)$ & $1.1(1.1)$ & $0.9(0.9)$ & $3.3(5.6)$ & $11(30)$ \\
Total Sys. & \multicolumn{7}{c}{} \\
\hline Random & 0.5 & 1.0 & 1.5 & 5.1 & 6.6 \\
\hline Noise (single scan) & \multicolumn{7}{c}{} \\
\hline
\end{tabular}

\section{Validation of MIPAS kinetic temperature}

In order to evaluate possible temperature biases, we have compared MIPAS v511, v611 and v711 kinetic temperature from 2005 to 2009 with co-located measurements from seven other instruments and with a climatology at the northern high latitude summer from falling sphere measurements. This set of instruments includes ground-based, space-borne and in-situ measurements. Out of them, only the SABER instrument provides temperature in the MLT derived from non-LTE emission measurements. The other two space-borne instruments use different techniques to derive temperature: ACE-FTS uses high resolution $\mathrm{CO}_{2}$ absorption spectra with minimized non-LTE effects and MLS measures the oxygen emission in the microwave spectrum. Temperatures derived from the ground measurements are not significantly affected by non-LTE. The lidars use a different spectral region (visible) and measure light scattering. The temperature retrieved from the Davis and SATI spectrometers measurements use the information from the rotational structure from $\mathrm{OH}$ or from $\mathrm{O}_{2}$ emissions that are in rotational LTE. The temperature measured by the falling spheres is inferred indirectly from atmospheric density measurements, derived from the deceleration of the spheres, and is neither affected by nonLTE. This makes the set of instruments well suited to validate MIPAS kinetic temperature in the MLT, for which the largest systematic errors come from non-LTE sources.

We chose pairs of coincident measurements (co-locations) so that MIPAS measurements were taken less than $1000 \mathrm{~km}$ away and $2 \mathrm{~h}$ apart from space-borne measurements, and $1500 \mathrm{~km}$ away and $4 \mathrm{~h}$ apart for ground-based measurements. The reason for taking a larger space and time difference for the ground-based instruments was to increase the number of co-located measurements to have larger statistical signif- icance. We have examined the impact on the comparisons of restricting the spatio-temporal criteria (to $500 \mathrm{~km}$ and $1 \mathrm{~h}$ ) and have found that it is not important, which shows that effects from co-locations mismatch are averaged out.

Prior to the comparison, if the vertical resolution of the instrument is better than that of MIPAS, we have smoothed the instruments individual kinetic temperature profiles $\boldsymbol{T}_{\text {meas }, i}$ using the co-located MIPAS averaging kernel matrix $\mathbf{A}_{i}$ and a priori profile $\boldsymbol{T}_{\mathrm{a}, i}$, and the expression:

$\boldsymbol{T}_{\mathrm{smoo}, i}=\boldsymbol{T}_{\mathrm{a}, i}+\mathbf{A}_{i}\left(\boldsymbol{T}_{\text {meas }, i}-\boldsymbol{T}_{\mathrm{a}, i}\right)$.

The smoothed profile $\boldsymbol{T}_{\mathrm{smoo}, i}$ does not only account for differences in the vertical resolution but also takes into account the fraction of the a priori information used in MIPAS retrievals. In the opposite case, that is, if the MIPAS altitude resolution is significantly higher than that of the comparison instrument, we have smoothed the MIPAS profile accordingly. We have not applied any vertical averaging kernel when both instruments have similar vertical resolutions. We explicitly indicate below when Eq. (5) is applied.

We have estimated MIPAS bias profile $\boldsymbol{b}$ from the average difference of the coincident individual profiles (see, e.g., von Clarmann, 2006), that is:

$\boldsymbol{b}=\frac{\sum_{i}\left(\boldsymbol{T}_{\mathrm{mip}, i}-\boldsymbol{T}_{\mathrm{ins}, i}\right)}{N}$,

where $\boldsymbol{T}_{\text {mip }, i}$ and $\boldsymbol{T}_{\text {ins, } i}$ are, respectively, the MIPAS and the other instrument coincident kinetic temperature profiles (smoothed or not according to the particular case), and $\mathrm{N}$ is the number of coincidences. We have estimated the bias error, $\sigma_{\mathrm{b}}$, with:

$\sigma_{\mathrm{b}}=\sqrt{\frac{\sum_{i}\left(\boldsymbol{T}_{\text {mip }, i}-\boldsymbol{T}_{\text {ins }, i}-\boldsymbol{b}\right)^{2}}{N(N-1)}}$.

Our estimated bias should be smaller than the MIPAS systematic error $\sigma_{\text {sys,mip }}$ (see Sect. 2.2.2) combined with the instrument systematic error $\sigma_{\text {sys, ins }}$, that is, smaller than:

$\sigma_{\text {comb }, \text { sys }}=\sqrt{\sigma_{\text {sys,mip }}^{2}+\sigma_{\text {sys,ins }}^{2}}$

Since the systematic errors depend on the season and latitude, we have divided the comparisons with each instrument in four yearly subsets: two for solstices (December from the previous year, January and February, and June, July and August) and two for equinoxes (March, April and May, and September, October and November). For comparisons with satellite instruments, we also grouped the data in $20^{\circ}$-wide latitude boxes. For each latitude, season and year, we have calculated the zonal mean temperatures for the coincident MIPAS and other instrument profiles and the average differences.

Tables 3 and 5 summarize the comparisons with the spaceborne and the ground-based instruments of MIPAS v511 
Table 3. Summary of comparisons with satellite measurements in solstice. Numbers shown are average temperature differences in K of MIPAS v511 minus the indicated instrument.

\begin{tabular}{lr|rr|rrr|rrr}
\hline Altitude* $^{*}$ & \multicolumn{2}{c}{ Tropics } & \multicolumn{2}{c}{ Mid-latitudes } & \multicolumn{3}{c|}{ Polar Summer } & \multicolumn{3}{c}{ Polar Winter } \\
\cline { 2 - 9 }$[\mathrm{km}]$ & SABER & SABER & MLS & ACE & SABER & MLS & ACE & SABER & MLS \\
\hline 20 & -2.5 & -2.0 & +0.0 & +0.3 & -2.9 & +0.1 & -5.8 & -2.4 & +1.0 \\
30 & -2.6 & -1.4 & +0.8 & -1.3 & -1.3 & +0.8 & -0.7 & -1.5 & +0.3 \\
50 & -0.1 & -0.1 & -0.4 & +0.7 & -2.8 & -4.7 & -1.3 & -0.5 & +1.4 \\
70 & -0.1 & -0.5 & +4.4 & -2.5 & -3.8 & +2.8 & -4.9 & -0.2 & +3.2 \\
80 & -1.7 & -1.7 & -0.8 & -9.6 & -3.1 & -0.7 & +4.7 & +0.6 & +3.6 \\
90 & +0.5 & +1.6 & +8.5 & +0.7 & +7.0 & +22 & +8.8 & +6.3 & +6.6 \\
\hline
\end{tabular}

* For MLS comparisons, the altitude refers to the corresponding MIPAS approximate altitude.

Table 4. Difference (MIPAS-instrument) in altitude $(\Delta z)$ in $\mathrm{km}$ and in temperature $(\Delta T)$ in $\mathrm{K}$ at stratopause and mesopause measured by several satellites. For MLS, $\Delta z$ is the corresponding MIPAS approximate altitude difference.

\begin{tabular}{|c|c|c|c|c|c|c|c|c|c|}
\hline & \multirow{2}{*}{$\begin{array}{c}\text { Tropics } \\
\text { SABER }\end{array}$} & \multicolumn{2}{|c|}{ Mid-latitudes } & \multicolumn{3}{|c|}{ Polar Summer } & \multicolumn{3}{|c|}{ Polar Winter } \\
\hline & & SABER & MLS & ACE & SABER & MLS & ACE & SABER & MLS \\
\hline \multicolumn{10}{|c|}{ Stratopause } \\
\hline$\Delta T[\mathrm{~K}]$ & +0.0 & +0.1 & -2.6 & +0.7 & -2.7 & -4.9 & -2.0 & -0.2 & +0.8 \\
\hline$\Delta z[\mathrm{~km}]$ & -0.1 & -0.3 & +0.5 & -0.5 & -1.7 & -0.0 & -1.5 & +0.4 & +0.9 \\
\hline \multicolumn{10}{|c|}{ Mesopause } \\
\hline$\Delta T[\mathrm{~K}]$ & -1.6 & +0.8 & +5.3 & -7.4 & +5.9 & +11 & +8.8 & +7.9 & +11 \\
\hline$\Delta z[\mathrm{~km}]$ & 0.0 & -1.6 & -3.2 & -1.5 & -0.4 & -3.7 & +0.5 & +1.2 & -1.0 \\
\hline
\end{tabular}

(MA mode) temperatures. Additionally, comparisons of the stratopause and mesopause characteristics as measured by satellite instruments are summarized in Table 4. These results, estimated for the MIPAS MA mode measurements, can be extended to the UA and NLC modes (v611 and v711, respectively) below $102 \mathrm{~km}$ because the retrieval of temperature is performed in the $40-100 \mathrm{~km}$ range in a similar way as for MA. The particularities of the UA and NLC modes observations are only that the lowest tangent height is located at higher altitudes (at $40 \mathrm{~km}$ compared to the $20 \mathrm{~km}$ in the MA mode) and the NLC mode has a denser vertical sampling around the mesopause ( $1.5 \mathrm{~km}$ compared to $3 \mathrm{~km}$ in the MA mode). Thus, the quality (including biases) of the retrieved temperature is similar in the three modes. In the following sections we limit our discussion to MIPAS MA temperatures (v511) because they extend to lower altitudes and the vertical resolution is anyway accounted for through the application of the averaging kernels. We only show comparisons of the UA and the NLC modes temperatures with SABER and compare them with the results for the MA mode.

\subsection{SABER/TIMED}

The Sounding of the Atmosphere using Broadband Emission Radiometry (SABER) has orbited the Earth onboard the NASA's TIMED satellite since the end of 2001. It mea-
Table 5. Summary of comparisons with ground-based measurements of the lidars at Mauna Loa Observatory (MLO) and Table Mountain Facility (TMF), the SATI spectrometer in Granada (Spain), and the $\mathrm{OH}$ spectrometer at Davis (Antarctica). Numbers shown are average temperature differences in $\mathrm{K}$ between MIPAS v511 and the other instruments.

\begin{tabular}{lrrrr}
\hline $\begin{array}{l}\text { Altitude } \\
{[\mathrm{km}]}\end{array}$ & $\begin{array}{r}\text { MLO } \\
\left(30^{\circ} \mathrm{N}\right)\end{array}$ & $\begin{array}{r}\text { TMF } \\
\left(34^{\circ} \mathrm{N}\right)\end{array}$ & $\begin{array}{r}\text { SATI } \\
\left(37^{\circ} \mathrm{N}\right)\end{array}$ & $\begin{array}{r}\text { Davis OH } \\
\left(69^{\circ} \mathrm{S}\right)\end{array}$ \\
\hline 20 & +1.4 & +1.1 & - & - \\
30 & -1.2 & +1.5 & - & - \\
50 & -2.4 & -1.1 & - & - \\
70 & -4.0 & -1.0 & - & - \\
80 & -3.6 & +3.0 & - & - \\
87 & -0.6 & +7.9 & -0.7 & +0.4 \\
95 & +16.6 & - & +16.4 & - \\
\hline
\end{tabular}

sures continuously and almost globally $\left(52^{\circ} \mathrm{S}-82^{\circ} \mathrm{N}\right.$, alternating with $52^{\circ} \mathrm{N}-82^{\circ} \mathrm{S}$ every two months) the daytime and nighttime atmospheric infrared emission in ten broadband channels (Russell III et al., 1999). The kinetic temperature, $T_{\mathrm{k}}$, is derived from about $20 \mathrm{~km}$ up to $105 \mathrm{~km}$ from measurements of the $\mathrm{CO}_{2}$ emission at $15 \mu \mathrm{m}$ using the onionpeeling technique and a Levenberg-Marquardt approach with a retrieval algorithm that considers non-LTE (Mertens et al., 
2004). More details on the temperature retrieval can be found in Remsberg et al. (2008). We have used SABER version 1.07 in our comparisons and applied a quality filter to remove un-physical retrievals (those with pressures exceeding typical values around the mesopause by more than $50 \%$ ). SABER $T_{\mathrm{k}}$ random errors are mainly due to noise $(<0.6 \mathrm{~K}$ below $55 \mathrm{~km}, 1 \mathrm{~K}$ at $70 \mathrm{~km}, 2 \mathrm{~K}$ at $85 \mathrm{~km}$ and $7 \mathrm{~K}$ at $100 \mathrm{~km}$ ) and the systematic errors are mainly due to uncertainties in the $\mathrm{CO}_{2}$ abundance and the non-LTE parameters $(<1.5 \mathrm{~K}$ below $55 \mathrm{~km}, 0.5$ at $70 \mathrm{~km}, 4 \mathrm{~K}$ at $85 \mathrm{~km}$ and $5 \mathrm{~K}$ at $100 \mathrm{~km}$ ) (see further details in García-Comas et al., 2008).

Remsberg et al. (2008) assessed the quality of SABER v1.07 temperatures and they concluded that they are too high by $2-3 \mathrm{~K}$ in the lower stratosphere, and too low by $1 \mathrm{~K}$ in the upper stratosphere and by $2-3 \mathrm{~K}$ in the mid-mesosphere. SABER comparisons with other instruments in the upper mesosphere and lower thermosphere were, however, more variable and showed agreement within $\pm 5 \mathrm{~K}$ at mid-latitudes. They also indicate that SABER locates the mesopause $1.5 \mathrm{~km}$ lower than the falling spheres climatologies.

Using our 2-h and $1000 \mathrm{~km}$ coincidence criterium, there are a large number of co-located measurements of MIPAS and SABER between 2005 and 2009. We grouped the measurements in $20^{\circ}$ latitude boxes and for 3-month seasons of each year. For each of these boxes, we found an average number of coincidences ranging from 800 at the tropics to 2800 at polar latitudes. The total number of coincidences for all years is about 5000 at the tropics and 14000 at the poles.

SABER and MIPAS temperatures are both derived from the $15 \mu \mathrm{m} \mathrm{CO} \mathrm{CO}_{2}$ non-LTE emissions. Both use a non-LTE code to calculate the population of the emitting vibrational states. Both include in the code the same collisional processes. In order to estimate the combined systematic error, we have not taken into account the errors coming from those collisional rate values that are the same in both retrievals. Thus, we only included in the non-LTE error budget the contribution from the $k_{v v}$ rate and the atomic oxygen concentration uncertainties, and, for polar summer, also that of the $k_{\text {air }}$ rate.

Since SABER vertical resolution is about $2 \mathrm{~km}$ (slightly better than that of MIPAS, particularly above the stratopause), we have smoothed SABER kinetic temperature profiles to match MIPAS vertical resolution using MIPAS averaging kernel matrix and a priori profiles following Eq. (5). Figure 4 shows an example of a comparison between two co-located MIPAS and SABER temperature profiles. It corresponds to a nighttime MIPAS measurement at $39^{\circ} \mathrm{N}$ and $56^{\circ} \mathrm{W}$ done during the winter (red line in the figure). SABER (green line) measured $T_{\mathrm{k}}$ almost simultaneously but around $200 \mathrm{~km}$ away. Both profiles show ample vertical structures, particularly in the upper mesosphere. SABER however shows more extreme values at the peaks and troughs of the mesospheric inversion layers. Once the SABER profile is convolved using Eq. (5) (black line in the figure), the profile is smoothed and the agreement is better.

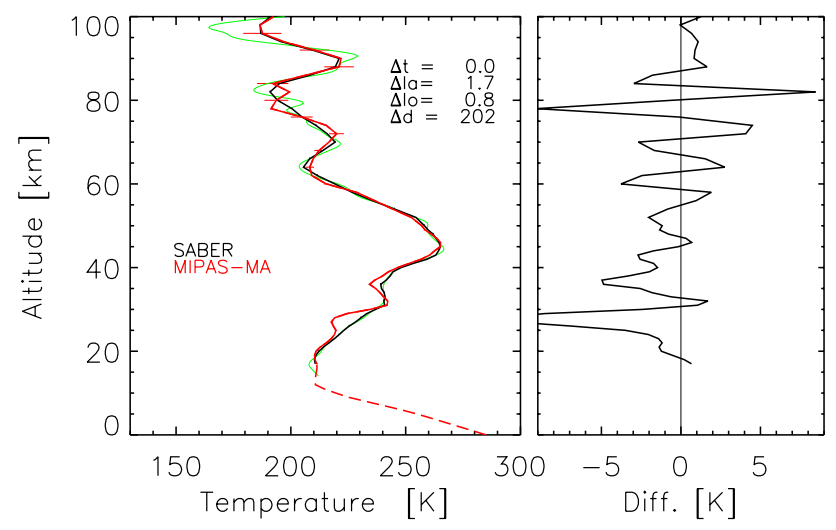

Fig. 4. Left: example of a comparison of an individual MIPAS v511 temperature profile at $39^{\circ} \mathrm{N}$ and $56^{\circ} \mathrm{W}$ in January 2005 (solid red) with a co-located SABER v1.07 measurement (green) and its corresponding smoothed profile using MIPAS averaging kernels and $a$ priori profile as in Eq. (5) (black). The differences in time in hours $(\Delta t)$, latitude $(\Delta \mathrm{la})$ and longitude $(\Delta \mathrm{lo})$ in degrees, and distance $(\Delta d)$ in kilometers between the two measurements are also shown. Red horizontal bars are the MIPAS noise errors. The dashed red line shows the extension of the MIPAS profile with the corresponding ECMWF profile. Right: difference between MIPAS and SABER convolved temperatures (MIPAS-SABER).

Note that the change in the differences is smaller as altitude decreases due to a better MIPAS vertical resolution.

Figure 5 shows the comparison between these two instruments for a $20^{\circ}$-wide latitude box centered at $40^{\circ} \mathrm{S}$ during the winter of 2005. Temperature profiles for MIPAS and SABER have been averaged for the 464 coincidences found in this latitude-time box. The mean time difference between the co-located measurements is about an hour and their average distance is $670 \mathrm{~km}$. This is a typical example of the very good agreement between SABER and MIPAS measurements. SABER temperature is about $3 \mathrm{~K}$ larger in the lower stratosphere, well explained by the known positive bias in SABER measurements at those altitudes. In this example for mid-latitudes, the temperature and altitude of the stratopause compare very well, with differences smaller than $0.5 \mathrm{~K}$ and $0.5 \mathrm{~km}$, respectively. In the lower mesosphere, where vertical gradients are large, the temperature difference is smaller than $1 \mathrm{~K}$. In the upper mesosphere, the differences are slightly larger around $70 \mathrm{~km}(2.5 \mathrm{~K})$ but both instruments show the same structure: a small decrease in the temperature gradient around $75 \mathrm{~km}$. The mesopause is also very similar in both instruments, although that of MIPAS is slightly higher (1$2 \mathrm{~km})$ and colder $(2 \mathrm{~K})$. Temperatures in the lower thermosphere (above $90 \mathrm{~km}$ ) differ up to $9 \mathrm{~K}$. The differences lie within the combined systematic errors of both instruments, indicating a non-significant bias.

We show comparisons for MIPAS and SABER colocations for the summer (left column) and winter (right column) solstices for $20^{\circ}$-wide latitude boxes at the tropics (10- 
$\left.30^{\circ}\right)$, mid-latitudes $\left(30-40^{\circ}\right)$, high-latitudes $\left(50-70^{\circ}\right)$ and the poles $\left(70-90^{\circ}\right)$ in Fig. 6 . The comparisons were done for coincidences during three-month periods: December, January and February for the Northern Hemisphere (NH) winters and Southern Hemisphere (SH) summers, and June, July and August for the NH summers and SH winters.

As in the example in Fig. 5, the differences at all latitudes show 2-3 K colder MIPAS temperatures in the lower and mid-stratosphere, most likely due to the known SABER warm bias at those altitudes. This difference is not dependent on latitude, season nor year.

The atmosphere at altitudes from 40 to $65 \mathrm{~km}$ is generally about $0.5-3 \mathrm{~K}$ colder in MIPAS data during the summers in both hemispheres, with the smallest differences occuring at low latitudes. During the winters, MIPAS temperatures are $0.5-1 \mathrm{~K}$ larger, except for the highest latitudes $\left(50-70^{\circ}\right.$ and $\left.70-90^{\circ}\right)$, where MIPAS is $2-5 \mathrm{~K}$ warmer. The Northern Hemisphere winters show the largest differences, except for the 2008 and 2009, when sudden stratospheric warmings (SSWs) occurred and the differences are smaller than $2 \mathrm{~K}$. Half of the difference in the winters can be due to the SABER cold bias at those altitudes. Both instruments measure similar temperatures at the stratopause at low and mid-latitudes and place it at the same altitude (values estimated from the $\left(T_{\mathrm{k}}, z\right)$ pairs of peak temperatures reached by the instruments between 40 and $60 \mathrm{~km}$ ). The differences at $55-65 \mathrm{~km}$ at high and polar latitudes during the winters can be explained for some years by a higher altitude of the stratopause in MIPAS temperatures, which is located 1-3 km above that of SABER (not shown). In the polar summer, MIPAS stratopause is $2.7 \mathrm{~K}$ colder and almost $2 \mathrm{~km}$ lower than that of SABER (see Table 4).

MIPAS and SABER comparisons in the mid and upper mesosphere are also very good, generally within the estimated systematic error. The mid-mesosphere (up to 80$85 \mathrm{~km}$ ) is slightly colder for MIPAS but the differences are usually smaller than $2 \mathrm{~K}$. The worst case is at latitudes higher than $50^{\circ}$ during the summers, where the difference (in absolute value) reaches $3-5 \mathrm{~K}$, but still the behavior is excellent since the vertical gradient under those conditions is particularly large (see typical polar summer example for the 70$90^{\circ} \mathrm{N}$ summer of 2008 in Fig. 7). The differences in the $\mathrm{NH}$ polar winter of 2009 are significantly larger between 75 and $95 \mathrm{~km}$ than in other seasons and latitudes. That corresponds to altitudes with very large temperatures after the 2009 SSW, where MIPAS measures $10-12 \mathrm{~K}$ larger temperatures than SABER. MIPAS mesopause is generally warmer: on average, $6 \mathrm{~K}$ in the polar summers, $8 \mathrm{~K}$ in the polar winter and $1 \mathrm{~K}$ at mid-latitudes, and the altitude difference with SABER mesopause is $-1.5 \mathrm{~km},+1.2 \mathrm{~km}$ and $-1.5 \mathrm{~km}$, respectively (Table 4). The mesopause altitude difference varies with season for mid-latitudes. Whereas MIPAS mesopause is generally located at almost the same altitude and is about $2 \mathrm{~K}$ colder during the summers (see Fig. 5), it is about $2 \mathrm{~km}$ lower and $5 \mathrm{~K}$ warmer during the winters.

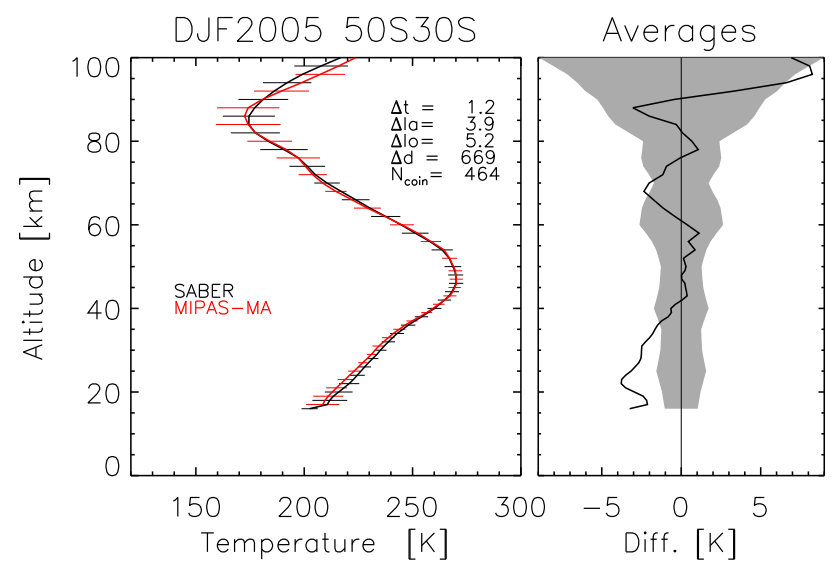

Fig. 5. Average of MIPAS v511 (red) and SABER v1.07 (black) co-located temperature profiles (left) and their difference (MIPASSABER; right) for Southern Hemisphere mid-latitudes $\left(30-50^{\circ} \mathrm{S}\right)$ during January and February of 2005. Horizontal bars are their standard deviation. Average differences in time in hours, latitude and longitude in degrees, distance in kilometers, and number of averaged profiles for each instrument are also shown. The shadowed area in the right panel is the combined systematic error. This is an example of the excellent agreement between SABER and MIPAS measurements. The bias found in the lower stratosphere is mainly due to a well-known positive bias in SABER temperatures at those altitudes (Remsberg et al., 2008).

The temperature differences in the upper mesosphere lie within the combined errors but they occur in both hemispheres and almost every year, seeming systematic. SABER v1.07 retrievals do not account for LOS temperature gradients. That may partly explain the increase of the differences with latitude, that is, since LOS $T_{\mathrm{k}}$ gradients are larger when observing the high latitudes, errors in SABER from not including them are larger there. Additionally, the fact that the differences in the polar summer upper mesosphere are large compared to the tropics and mid-latitudes may be indicative of a non-LTE issue, since non-LTE effects are larger under those conditions. Both MIPAS and SABER $T_{\mathrm{k}}$ retrievals are affected by non-LTE but those of SABER are affected to a larger extent because it uses more information from the hot bands, which are further away from LTE than the fundamental band.

Additionally, some of the non-LTE parameters used in MIPAS and SABER non-LTE retrievals are different. The rate used for the $\mathrm{CO}_{2} v_{2} \mathrm{~V}-\mathrm{V}$ exchange $\left(k_{v v}\right)$ for energy exchange involving the isotopic levels is twice in MIPAS than in SABER. According to García-Comas et al. (2008), equalling this rate to that used for MIPAS $\left(2.4 \times 10^{-11} \mathrm{~cm}^{3} \mathrm{~s}^{-1}\right)$ would increase SABER mesopause temperatures by $3 \mathrm{~K}$ in the polar summer but would barely affect the temperature at mid-latitudes or polar winter. Thus, this would reduce the SABER-MIPAS difference under the conditions where they are larger. 

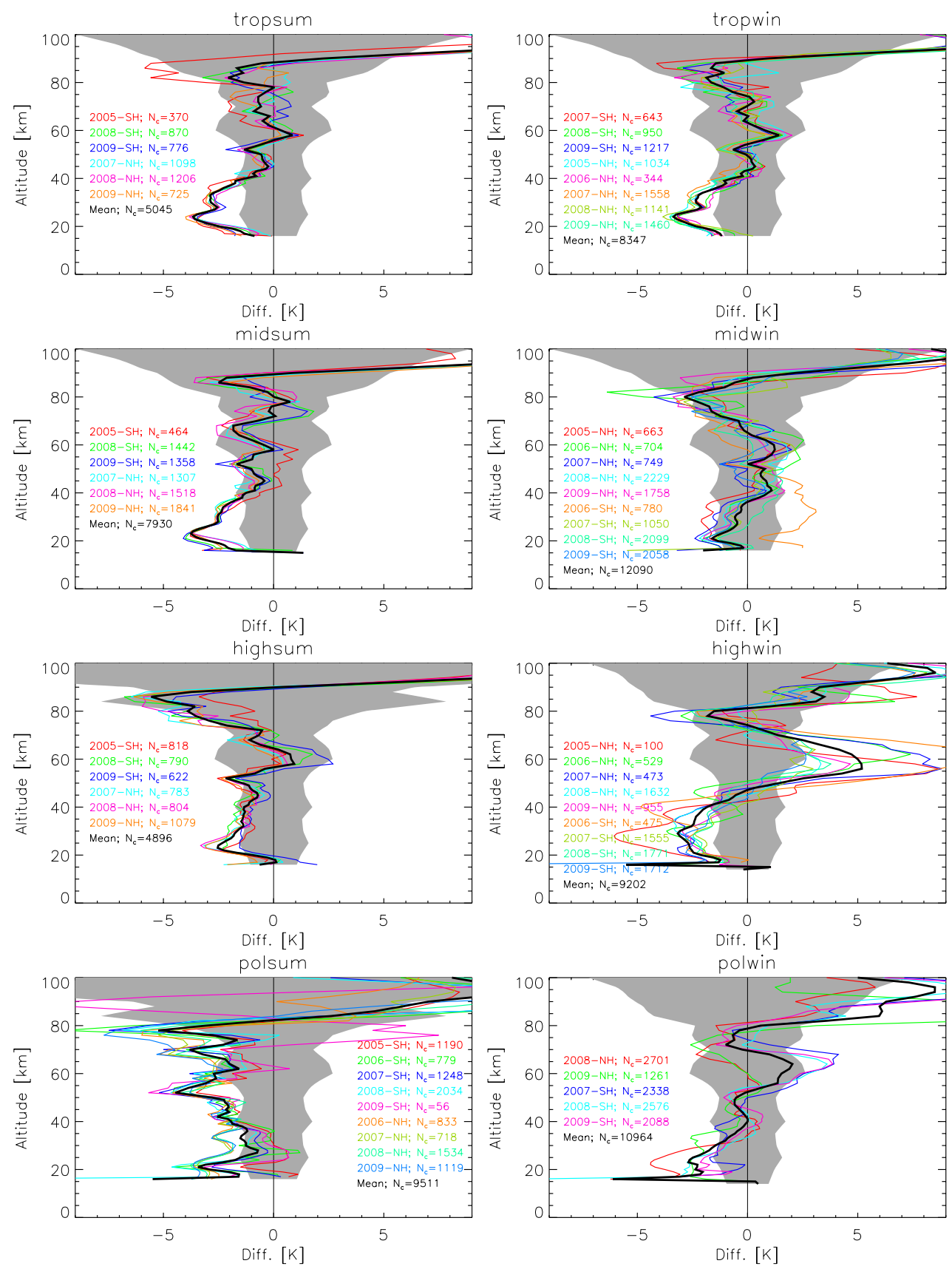

Fig. 6. Mean temperature differences of solstice (left column: summer; right column: winter) co-located measurements of MIPAS v511 minus SABER v1.07 measurements for the tropics $\left(10-30^{\circ}\right.$; 1 st row), mid-latitudes $\left(30-50^{\circ}\right.$; 2nd row), high latitudes $\left(50-70^{\circ} ; 3\right.$ rd row) and the poles $\left(70-90^{\circ}\right.$; 4th row). The differences averaged for the different years and hemispheres (for which the number of co-located measurements are also indicated) are shown in color. Average difference is shown in black. The shadowed area is the MIPAS and SABER combined systematic error.

The quenching rate of the $\mathrm{CO}_{2} v_{2}$ states by $\mathrm{N}_{2}$ and $\mathrm{O}_{2}$ $\left(k_{\text {air }}\right)$ is also slightly different at very low kinetic temperatures. Whereas both MIPAS and SABER retrievals use the same value for temperatures larger than $150 \mathrm{~K}$, MIPAS uses a larger value for lower temperatures ( $15 \%$ larger at $125 \mathrm{~K})$. The use of MIPAS value in SABER retrievals would increase the retrieved temperature by $1 \mathrm{~K}$ around the polar summer mesopause, reducing its difference with MIPAS.

The difference in the mesopause region could also originate from different atomic oxygen abundances used in the non-LTE models. During nighttime, MIPAS and SABER O vmr is taken from the MSIS database at all altitudes but, 


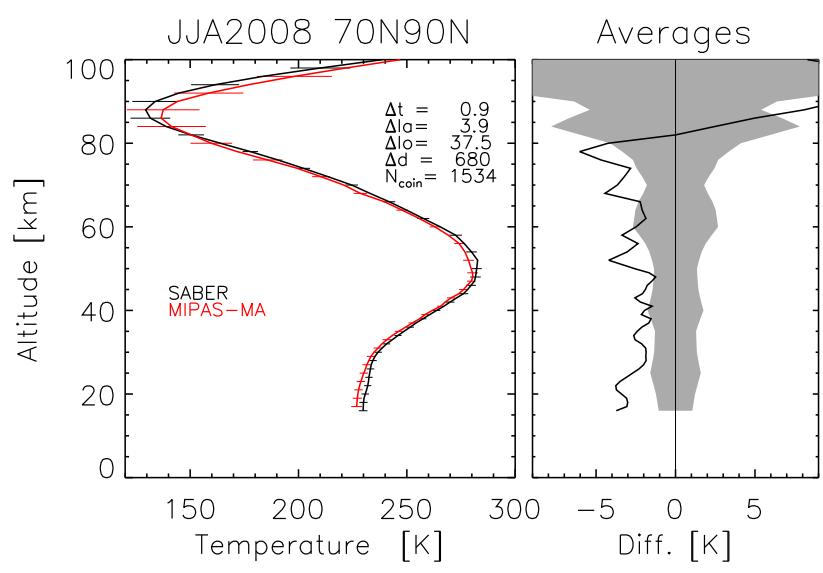

Fig. 7. As in Fig. 5 but for the north pole $\left(70-90^{\circ} \mathrm{N}\right)$. This figure shows the typical behavior over the polar summer, where MIPAS is slightly colder and shows similar gradients up to $80 \mathrm{~km}$ and warmer above. MIPAS stratopause and mesopause is located slightly below SABER's.

during daytime, SABER uses below $90 \mathrm{~km}$ the $\mathrm{O}$ vmr derived from SABER $\mathrm{O}_{3}$ retrieval of $1.27 \mu \mathrm{m}$ measurements and the $\mathrm{O}_{2}\left({ }^{1} \Delta\right)$ model of Mlynczak et al. (2007). The atomic oxygen daytime abundance used in MIPAS retrievals (taken from the MSIS model) in the mesopause region is on average $50 \%$ smaller than the values used in SABER $T_{\mathrm{k}}$ retrievals (as mentioned in Smith et al., 2010), except for polar summer, where it is $50-70 \%$ larger. Using MIPAS midlatitude smaller $[\mathrm{O}]$ in SABER retrievals would increase $1.5 \mathrm{~K}$ the SABER mid-latitude temperature at $90 \mathrm{~km}$ (see García-Comas et al., 2008). Also, the larger MIPAS [O] in the polar summer mesopause would also increase $1.5 \mathrm{~K}$ the SABER mesopause temperature (note that the response of the retrieved temperature to an atomic oxygen change around the cold polar summer mesopause, where an $[\mathrm{O}]$ increase leads to a $T_{\mathrm{k}}$ increase, is opposite to other latitudes and seasons). Therefore, the different atomic oxygen used can explain half of the difference around the mesopause at all latitudes.

In summary, the different non-LTE collisional rates, in particular, $k_{v v}$ and $k_{\text {air }}$, and atomic oxygen abundance in MIPAS and SABER retrievals, explains almost all of the temperature difference. Using the same values in both instruments retrievals would lead to an almost perfect agreement between the instruments at all latitudes, except in the polar winter, where the difference would be reduced to $3 \mathrm{~K}$. Differences in the nighttime [O] used in SABER v1.07 retrievals may explain the larger temperature difference in the dark polar winter. It is worth noting that, at this point, it is not possible to assure what $k_{v v}, k_{\text {air }}$ and [O] values are more accurate.

MIPAS lower thermosphere (altitudes above $85-90 \mathrm{~km}$ ) is also warmer than that of SABER (5-15 K, depending on latitude). On the one hand, a $50 \%$ larger SABER atomic oxygen in v1.07 may explain these differences. On the other hand, the difference is almost constant with altitude, that is, both MIPAS and SABER show similar temperature gradients (see Fig. 7). The differences could thus also be explained by a MIPAS negative altitude shift.

We have also compared MIPAS $T_{\mathrm{k}}$ retrievals from Upper Atmosphere and Noctilucent-Cloud modes with SABER v1.07 retrievals in order to see if there are significant differences with the comparisons in the Middle Atmosphere mode. Figure 8 shows comparisons of the MIPAS-SABER temperature differences for the three modes averaged for the midlatitudes winters and the polar summers of 2008 and 2009, when MIPAS had a better temporal coverage. As expected, the differences for the three modes are very similar at all altitudes. NLC mode comparisons show $1 \mathrm{~K}$ larger differences in mid-latitude winters around $75 \mathrm{~km}$, which slightly increase $(2 \mathrm{~K})$ for the polar summer comparisons. This latter enhanced differences are mainly due to larger differences in the SH polar summer of 2009. Under these conditions, whereas MIPAS does not show large temperature variability in the upper mesosphere between the different modes (which correspond to measurements 2-3 days apart), SABER shows temperature changes as large as $10 \mathrm{~K}$. Comparisons for other seasons (not shown) are also similar for the three modes.

\subsection{ACE-FTS}

The primary instrument on board the Canadian-led scientific satellite SCISAT-1 (also known as the Atmospheric Chemistry Experiment or ACE) is a Fourier transform spectrometer (FTS) with broad spectral coverage (2.2 to $13.3 \mu \mathrm{m})$ and high spectral resolution $\left(0.02 \mathrm{~cm}^{-1}\right.$, unapodized). It is a solar occultation instrument that collects two sets of atmospheric measurements per orbit (one sunrise and one sunset event), for a total of 32 occultation measurements per calendar day. The instrument is self-calibrating because the atmospheric spectra are divided by exoatmospheric solar spectra collected during the same occultation, thereby removing solar and instrumental features from the spectra. The instrument samples a narrow range of latitudes on a given day (latitude coverage depends on the season) but achieves near-global coverage over the course of a year. The vertical sampling of ACE-FTS measurements varies with the angle between the satellite's orbit track and the vector from the satellite to the sun. When this angle is near zero, the vertical sampling for altitudes above the mid-stratosphere is about $6 \mathrm{~km}$. When this angle is large (e.g., greater than $60^{\circ}$ ), the vertical sampling is less than $2 \mathrm{~km}$. A typical spacing is $3-4 \mathrm{~km}$. At lower altitudes, refraction effects compress the vertical sampling, such that the typical measurement spacing in the mid-troposphere is about $1 \mathrm{~km}$. The instrument's circular $1.25 \mathrm{mrad}$ field of view limits the vertical resolution to $3-4 \mathrm{~km}$. Atmospheric temperature profiles are determined through the analysis of $\mathrm{CO}_{2}$ lines in the atmospheric transmittance spectra, employing a Levenberg-Marquardt non-linear least squares global fitting approach. Details of the retrieval algorithm are provided in 

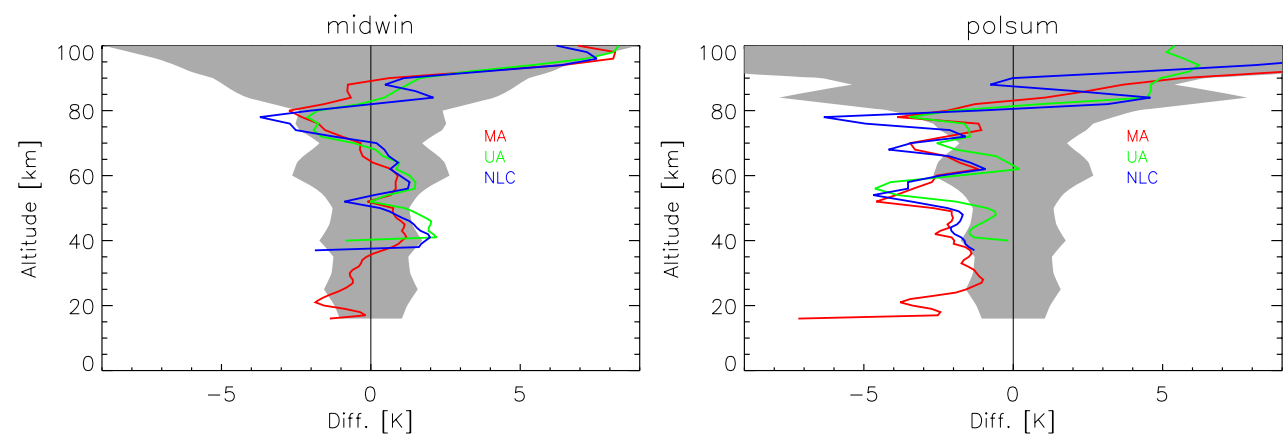

Fig. 8. Average temperature differences between 2008-2009 co-located MIPAS MA (red), UA (green) and NLC (blue) mode measurements and SABER measurements in mid-latitudes winter (left) and polar summer (right). The shadowed areas show the combined systematic error.

Boone et al. (2005). The comparisons shown here use version 2.2 of the ACE-FTS data set. The set of spectral microwindows used in the temperature retrievals is restricted above $70 \mathrm{~km}$ to absorption from common lower-state vibrational bands in order to minimize non-LTE effects. First guess profiles in the retrieval process are generated through a combination of temperature profiles from the MSIS atmospheric model above $30 \mathrm{~km}$ and meteorological data from the Canadian Meteorological Center (CMC) below $30 \mathrm{~km}$. No a priori constraints are employed in the retrievals, but temperatures below $12 \mathrm{~km}$ are fixed to the CMC data, and the temperature profile above the highest analyzed measurement (around $125 \mathrm{~km})$ is a scaling of the MSIS temperature profile. The $\mathrm{CO}_{2} \mathrm{vmr}$ below about $65 \mathrm{~km}$ is fixed in the analysis, but a $\mathrm{CO}_{2}$ vmr profile is fitted (employing an empirical function to ensure smoothness) for higher altitudes. Estimation of ACE-FTS temperature precision from comparisons with lidar measurements provide values around $2 \mathrm{~K}$ (Sica et al., 2008). There are currently no data available regarding systematic errors in the ACE-FTS temperature retrievals.

Sica et al. (2008) comparisons with other instruments show that ACE-FTS temperatures are $2 \mathrm{~K}$ colder in the upper stratosphere and about $5 \mathrm{~K}$ warmer in the lower mesosphere. The latter statement was partially made based on comparisons with SABER v1.06 but SABER is colder than other instruments by $2-3 \mathrm{~K}$ in that region (Remsberg et al., 2008) (note that, although Remsberg et al. (2008) findings were based on SABER v1.07, they point out that temperature differences between v1.06 and v1.07 below $70 \mathrm{~km}$ are not significant). Thus, ACE-FTS warm bias may be reduced to $2-3 \mathrm{~K}$ in the lower mesosphere, as the comparisons with the lidars in Sica et al. (2008) suggest. ACE-FTS temperature profile structures are significantly smoothed out but they generally agree fairly well with measurements from lidars in the upper mesosphere. Nevertheless, the comparisons with lidars and with HALOE show 5-6 K larger ACE-FTS temperatures above $70 \mathrm{~km}$. ACE-FTS temperatures at southern high latitudes at $87 \mathrm{~km}$ during the winter (as shown by comparisons with the Davis $\mathrm{OH}$ spectrometer) are, on the other hand, 5-7 K too cold. Since there is no ACE-FTS systematic error estimation available other than from the comparisons with other instruments presented in Sica et al. (2008), we have used their results to compute the combined systematic error $\left(\sigma_{\text {ins }}\right.$ in Eq. 8).

The number of ACE-FTS and MIPAS coincidences for the period 2005-2009 for each $20^{\circ}$-wide latitude box and 3 months period ranges from 60 , under polar summer conditions $\left(70^{\circ}\right.$ to $\left.90^{\circ}\right)$, to 500 , during winter at latitudes from $50^{\circ}$ to $70^{\circ}$, with averages of 10 and 150 coincidences, respectively, per year. All coincidences are located at latitudes higher than $50^{\circ}$. Since ACE-FTS vertical resolution is similar to that of MIPAS (ACE-FTS vertical sampling is typically 3$4 \mathrm{~km}$ but can be as large as $5-6 \mathrm{~km}$ in the upper mesosphere and lower thermosphere), we have not applied the vertical averaging kernels to either instrument measurement.

Figure 9 shows a typical example of an ACE-FTS and MIPAS temperature comparison for summer. The example is for average temperature profiles for 23 coincident MIPAS and ACE-FTS measurements in the $20^{\circ}$-wide latitude box centered at $60^{\circ} \mathrm{S}$ during the summer of 2007-2008. The mean distance between co-located measurements is $700 \mathrm{~km}$ and they are taken $1 \mathrm{~h}$ apart, on average. Except around $75 \mathrm{~km}$, the differences are within the combined systematic errors. The differences are smaller than $1-2 \mathrm{~K}$ below $55 \mathrm{~km}$. The MIPAS mesosphere is colder, showing differences with ACEFTS of $2-3 \mathrm{~K}$ in the lower mesosphere and up to $5 \mathrm{~K}$ in the upper mesosphere. The mesopause is located at lower altitudes and, in this example, it shows similar temperatures. Nevertheless, other summer comparisons show a MIPAS mesopause colder than ACE-FTS' (see below).

Differences for spring and autumn including all latitudes, and for the winter and summer solstices divided in high $\left(50^{\circ}-70^{\circ}\right)$ and polar $\left(70-90^{\circ}\right)$ latitudes and years from 2005 to 2009 are shown in Fig. 10. Comparisons are very good in the stratosphere. Differences up to $45 \mathrm{~km}$ are smaller than $1 \mathrm{~K}$ (MIPAS temperatures being slightly colder, except in the polar summer) and within the systematic error in most cases, except for the lowest few kilometers of 


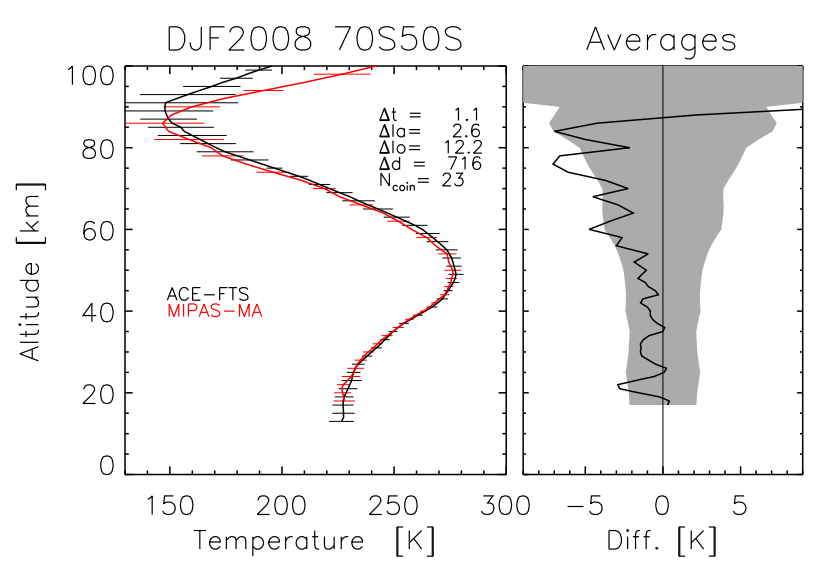

Fig. 9. Average of MIPAS v511 (red) and ACE-FTS v2.2 (black) co-located temperature profiles (left) and their difference (MIPASACE; right) for Southern Hemisphere summer $\left(50-70^{\circ} \mathrm{S}\right)$ in 2008. Horizontal bars are their standard deviation. Average differences in time in hours, latitude and longitude in degrees, distance in kilometers, and number of averaged profiles for each instrument are also shown. The shadowed area in the right panel is the combined error.

MIPAS measurements during the polar winters. Polar winters also show a larger yearly variability than other seasons. Differences at $50 \mathrm{~km}$ are slightly larger and MIPAS is about $2 \mathrm{~K}$ colder, except in the polar summer. The MIPASACE-FTS stratopause temperature difference (measured as the peak temperature difference) is $-3 \mathrm{~K}$ in the polar winter and $+0.7 \mathrm{~K}$ in the polar summer. MIPAS and ACE-FTS stratopause altitude agree within 1.5 and $0.5 \mathrm{~km}$, respectively (see Table 4). MIPAS stratopause at other latitudes is generally colder, with differences with ACE-FTS of around $-1 \mathrm{~K}$.

MIPAS measurements are also colder than ACE-FTS' in the lower and middle mesosphere but the differences are somewhat larger. They range from $2 \mathrm{~K}$ right above the stratopause to $3-4 \mathrm{~K}$ at $70-75 \mathrm{~km}$. In polar summer, the difference is smaller. This result can be explained by the $2-3 \mathrm{~K}$ warm bias detected in ACE-FTS at those altitudes (see Sica et al. (2008) and discussion above).

Between 75 and $85 \mathrm{~km}$, MIPAS is significantly colder, with maximum differences from $4 \mathrm{~K}$ to $12 \mathrm{~K}$, the latter in the polar summer. This occurs at all seasons except during the winter, where the maximum differences range from $5 \mathrm{~K}$ at $50-70^{\circ}$ to $10 \mathrm{~K}$ around the pole (or to $6 \mathrm{~K}$ when excluding the comparison for the $2009 \mathrm{NH}$ winter, when the SSW occurred and MIPAS temperatures at $85 \mathrm{~km}$ are $30 \mathrm{~K}$ warmer). As for the comparisons in the lower mesosphere, these results are also consistent with the 5-6 K ACE-FTS warm bias found in comparisons with other instruments and the 5-7 K cold bias found in the night comparisons for the southern high latitudes. The remaining difference (once those biases previously found in ACE-FTS are subtracted) is then very small (smaller than $1 \mathrm{~K}$ ) for all seasons, except for polar sum- mer, where it is still $-6 \mathrm{~K}$. Nevertheless, the mesopause temperature difference (difference in the minimum temperatures in the upper mesosphere) in the polar summer is $8 \mathrm{~K}$, that is, $4 \mathrm{~K}$ smaller than the maximum temperature difference. Therefore, the $1.5 \mathrm{~K}$ average lower altitude of MIPAS polar summer mesopause could further explain the difference (see Table 4 and example of Fig. 9). The remaining negative differences (MIPAS is colder) around $80-85 \mathrm{~km}$ in the polar summer could also be reduced using a more efficient $\mathrm{CO}_{2}$ $v_{2}$ quenching or faster $\mathrm{CO}_{2}-\mathrm{CO}_{2} v_{2}$ transfer rate in MIPAS non-LTE retrievals, which, regarding the uncertainties in the collisional rates and the atomic oxygen parameters, would lead to a 4-5 K maximum increase of MIPAS temperatures in the polar summer at $85 \mathrm{~km}$ (see Table 2). Nevertheless, the remaining difference could also be due to a further positive bias in ACE-FTS temperatures during this season.

Contrary to the polar summer, the MIPAS-ACE-FTS temperature difference at the mesopause is positive in other seasons, where the mesopause is located at higher altitudes. The temperature difference is $+3 \mathrm{~K}$ in autumn, $+4 \mathrm{~K}$ in spring and $+9 \mathrm{~K}$ in the polar winter. As mentioned above, the difference in the polar winter can be partially explained by the negative bias found in the ACE-FTS comparisons at high southern latitudes. The increase in [O] and $k_{\text {air }}$ in those seasons would lead to smaller MIPAS temperatures, because, opposite to the high latitudes summer mesopause, the non-LTE populations of the $\mathrm{CO}_{2} v_{2}$ levels are smaller than in LTE. The temperature decrease would reach $2 \mathrm{~K}$, reducing the remaining difference to $1-2 \mathrm{~K}$ at all seasons.

In the lower thermosphere, MIPAS shows warmer temperatures. The difference between both instruments is more pronounced during spring and summer. In autumn and winter, the differences are significantly smaller (up to $7-10 \mathrm{~K}$ ). These differences would also be reduced if an atomic oxygen abundance larger than that in the NRLMSIS-00 model is used in the MIPAS $T_{\mathrm{k}}$ retrievals.

\subsection{MLS/Aura}

The Microwave Limb Sounder (MLS) flies in a sunsynchronous near-polar $705-\mathrm{km}$-altitude orbit since its launch on the Aura satellite in mid 2004. MLS continuously observes the limb thermal microwave emission viewing forward along the Aura spacecraft flight direction, scanning its view from the ground to $\sim 90 \mathrm{~km}$ every $\sim 25 \mathrm{~s}$, which provides profiles spaced about $165 \mathrm{~km}$. It measures nearglobally $\left(82^{\circ} \mathrm{S}-82^{\circ} \mathrm{N}\right)$ both day and night and it completes about 14.5 orbits a day. MLS provides temperature of the atmosphere from 316 to $0.001 \mathrm{hPa}$ from retrievals of the oxygen thermal emission at 118 and $190 \mathrm{GHz}$. These microwave measurements are not affected by the presence of ice clouds and aerosols nor non-LTE effects. The MLS data used here is version 2.2. As described in Schwartz et al. (2008), kinetic temperature is retrieved using the optimal estimation theory. The a priori is a merging of the GEOS-5 profiles below $1 \mathrm{hPa}$ 



Fig. 10. Average temperature differences of co-located measurements of MIPAS v511 minus ACE-FTS v2.2 measurements for spring and autumn (upper row), high latitudes $\left(50-70^{\circ}\right)$ summer and winter (middle row) and polar $\left(70-90^{\circ}\right)$ summer and winter (bottom row). The differences averaged for the different years and hemispheres (for which the number of co-located measurements are also indicated) are shown in color. Average difference for each period and latitude box is shown in black. The shadowed area is MIPAS and ACE-FTS combined error.

and the CIRA86 climatology above. MLS $T_{\mathrm{k}}$ vertical resolution is $5 \mathrm{~km}$ from 316 to $100 \mathrm{hPa}, 4 \mathrm{~km}$ from 31 to $3.16 \mathrm{hPa}$, $8 \mathrm{~km}$ from 1 to $0.316 \mathrm{hPa}$, and $14 \mathrm{~km}$ at $0.1 \mathrm{hPa}$. The temperature random error, resulting mainly from radiometric noise, ranges from $0.6 \mathrm{~K}$ in the lower stratosphere to $2.5 \mathrm{~K}$ in the mesosphere. The systematic error, coming mainly from the radiometric and spectral calibration, is about $2 \mathrm{~K}$ at most altitudes, increasing to $3-4 \mathrm{~K}$ in the upper mesosphere.

A comprehensive study of the error budget and validation of MLS kinetic temperature is given in Schwartz et al. (2008). They suggest there is a persistent MLS cold bias in the lower stratosphere of $2 \mathrm{~K}$. Differences with other instruments in the upper stratosphere and mesosphere are more variable but they point to a $2-3 \mathrm{~K}$ warm bias and a $0-7 \mathrm{~K}$ cold bias (larger at the lower and upper limits of the mesosphere), respectively.
The selection of MIPAS measurements taken less than $1000 \mathrm{~km}$ and $2 \mathrm{~h}$ apart from MLS measurements from 2005 to 2009 provides a number of coincidences ranging from 400 for each seasonal $20^{\circ}$-wide latitude box centered at midlatitudes to more than 70000 for that centered at polar latitudes. The average number of coincidences per year range from about 45 to 8000 , respectively. Since MLS temperatures are provided as a function of pressure, the comparisons shown here were done on a pressure grid. MLS vertical resolution is worse than MIPAS, particularly, above the midmesosphere. We have therefore applied MLS averaging kernels and a priori temperatures to MIPAS profiles (according to Eq. 5).

MIPAS and MLS comparison for the 2006 NH polar summer is shown in Fig. 11. The average distance and time difference between measurements are $640 \mathrm{~km}$ and one hour, respectively. The variability within the 1978 averaged profiles 


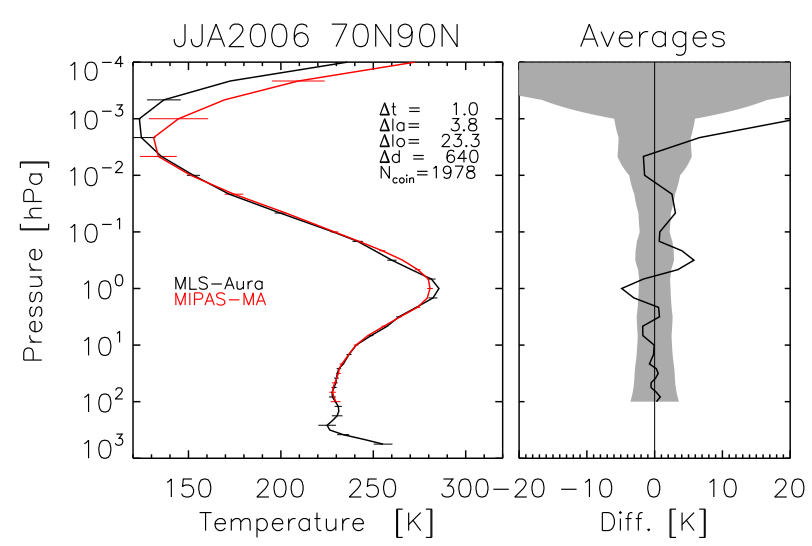

Fig. 11. Average of 1978 temperature profiles of MIPAS v511 (red) and MLS v2.2 (black) co-located measurements (left) and their difference (MIPAS-MLS; right) for Northern Hemisphere polar summer $\left(70-90^{\circ} \mathrm{N}\right)$ in 2006 . MIPAS profiles have been convolved to meet MLS vertical resolution. Horizontal bars are the average profiles standard deviations. Average differences in time of measurements in hours, latitude and longitude in degrees, and distance in kilometers are also shown. The shadowed area in the right panel is the MLS and MIPAS combined systematic error.

for each instrument in this season is very small below the mesopause (the standard deviation ranges from $2 \mathrm{~K}$ to $5-7 \mathrm{~K}$ below and above the mid-mesosphere, respectively). Hence, the resulting bias is typical of thermal profiles similar to the one shown in the figure. The agreement in the temperature from the troposphere to the upper stratosphere is excellent and differences are smaller than $0.5-1 \mathrm{~K}$ and within the combined systematic error. The difference increases 3-4 $\mathrm{K}$ above, where MIPAS and MLS $T_{\mathrm{k}}$ s interweave, MIPAS being colder at $1 \mathrm{hPa}$ and warmer just above (around $0.5 \mathrm{hPa}$ ). The comparison improves again up to the $0.07 \mathrm{hPa}$ level $(\sim 82 \mathrm{~km})$, where the measured mesospheric temperature gradient is similar for both instruments. Differences at that altitude are smaller than $2 \mathrm{~K}$. The mesopause is located at a higher pressure level (lower altitudes) in MIPAS average profile (according to MIPAS altitudes, the $2.1 \mathrm{hPa}$ difference corresponds to about $3 \mathrm{~km}$ ). The mesopause temperature (minimum temperature measured by each instrument) is $\sim 9 \mathrm{~K}$ warmer for MIPAS. This larger difference in the lower and upper mesosphere compared to that in the middle mesosphere is consistent with the known MLS v2.2 0-7 K negative bias. As in the case of SABER, the temperature in the lower thermosphere is larger for MIPAS, which shows a slightly larger gradient than MLS.

The behavior described for the comparison of the $2006 \mathrm{NH}$ polar summer is similar at all latitudes and all year round, both in the solstices (Fig. 12) and the equinoxes (not shown), particularly at altitudes below $10^{-3} \mathrm{hPa}$. The temperatures measured by both instruments differ less than $1 \mathrm{~K}$ below the $5 \mathrm{hPa}$ level, agreeing within the combined systematic error.
The difference is slightly larger (MIPAS being $2 \mathrm{~K}$ warmer) at the winter lower stratosphere (around $50 \mathrm{hPa}$ ), in agreement with the cold MLS bias at those pressures (Schwartz et al., 2008). MIPAS temperature at $1 \mathrm{hPa}$ is colder at all seasons (MIPAS-MLS difference range from $-2 \mathrm{~K}$ at midlatitudes in the summer to $-5 \mathrm{~K}$ in the polar summer). That could be partially explained by the $2-3 \mathrm{~K}$ warm bias in MLS upper stratosphere temperatures. MIPAS stratopause temperature (peak temperature around $1 \mathrm{hPa}$ ) is also $2-5 \mathrm{~K}$ smaller than MLS', except for the polar winters, where it is about $1 \mathrm{~K}$ warmer (see Table 4). Its pressure level agrees very well in both cases, although in the polar winters, it is located slightly above.

MIPAS temperature in the mesosphere (up to $0.005 \mathrm{hPa}$ in the polar summer and $0.001 \mathrm{hPa}$ in the polar winter) is $1-7 \mathrm{~K}$ warmer than MLS'. This difference is within the combined systematic error, except for the MIPAS $1-4 \mathrm{~K}$ colder narrow region at $0.01 \mathrm{hPa}$ in the summers (see Fig. 12). These differences in the mesosphere are almost independent on latitude and season, and can be explained the MLS $0-7 \mathrm{~K}$ cold bias detected by Schwartz et al. (2008).

The variability of the difference between hemispheres is small, except for the summer mid $\left(30-50^{\circ}\right)$ and high (50$70^{\circ}$ ) latitude boxes around $0.01 \mathrm{hPa}$. The larger variability in the latter case corresponds to a pressure level of $0.01 \mathrm{hPa}$, where MIPAS mean temperatures are colder. That negative average difference mainly arises from a larger (in absolute value) Northern Hemisphere negative difference. MLS temperatures during the $\mathrm{NH}$ summers are rather warm at those pressures and, opposite to MIPAS, show a very small variation with respect to the SH high latitude summer temperatures.

The MIPAS-MLS mesopause temperature difference (estimated as the difference between minimum temperatures reached at the mesosphere) is $+5 \mathrm{~K}$ at mid-latitudes (see Table 4). The difference increases towards higher latitudes (up to $+11 \mathrm{~K}$ ). MIPAS shows a $1-4 \mathrm{~km}$ lower altitude of the mesopause. Despite this generally MIPAS warmer mesopause, MIPAS-MLS difference of the polar summer mesopause temperature is larger in the Southern Hemisphere $(+15 \mathrm{~K})$ than in the Northern Hemisphere $(+6 \mathrm{~K})$ (not shown). This comes from the fact that MLS mean polar summer mesopause $T_{\mathrm{k}}$ is $1.5 \mathrm{~K}$ warmer in the $\mathrm{NH}$ than in the $\mathrm{SH}$ whereas MIPAS mesopause is, on average, $8 \mathrm{~K}$ colder in the $\mathrm{NH}$ than in the SH. MIPAS better reproduces the well-known inter-hemispheric difference in the summer mesopause temperature, which is originated by a stronger ascent at the north pole (Brasseur and Solomon, 1986).

The significantly larger differences in the lower thermosphere (altitudes above 0.005 in the polar summer and $0.001 \mathrm{hPa}$ in the polar winter) are due to the larger MIPAS temperatures, which are even larger when the temperature gradient is larger, i.e., during the polar summers. Again, larger atomic oxygen abundance than that provided by the 

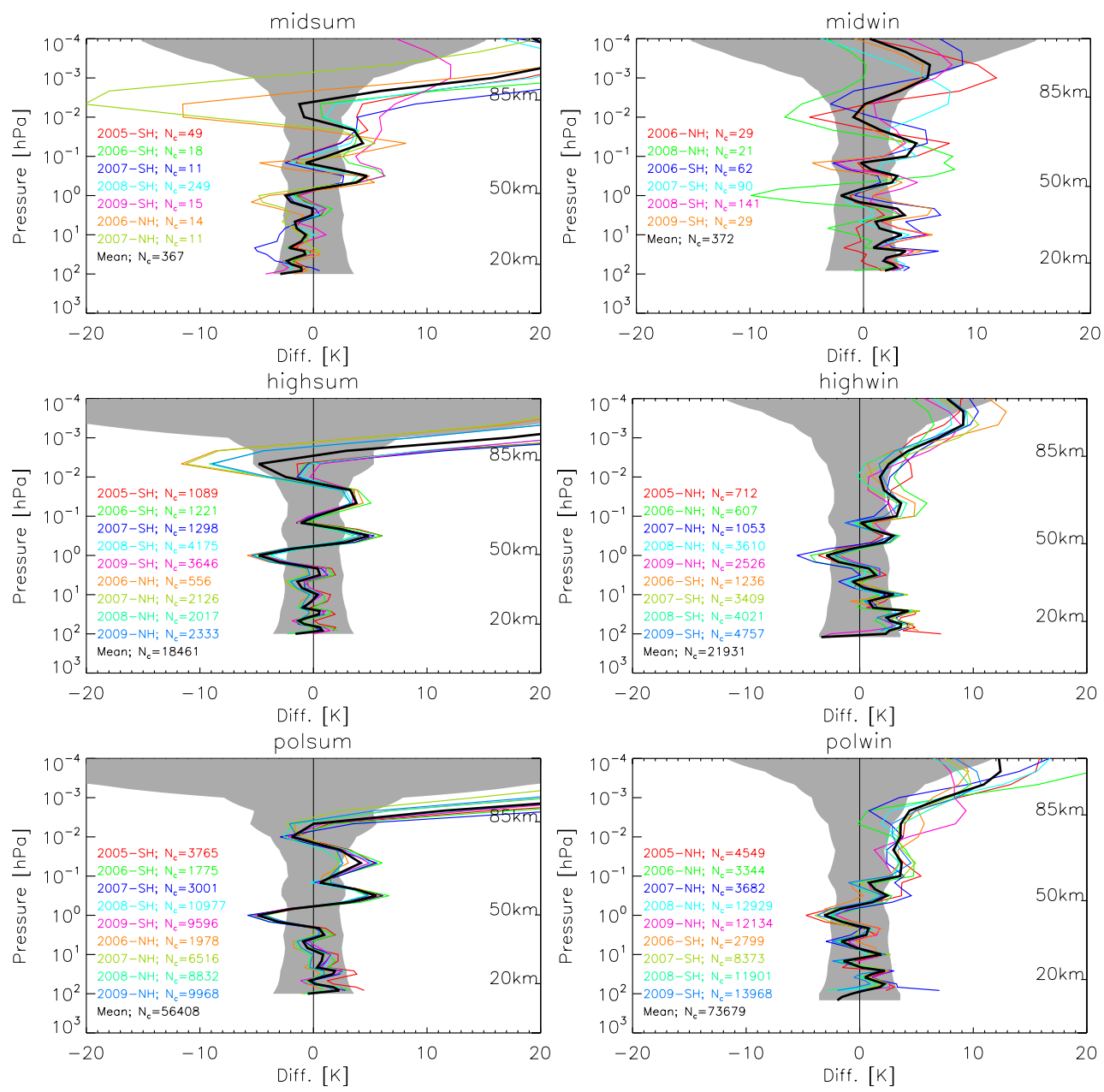

Fig. 12. Average temperature differences of solstice (left: summer; right: winter) co-located measurements of MIPAS v511 minus MLS v2.2 measurements for mid-latitudes ( $30-50^{\circ}$; upper row), high latitudes (50-70 ; middle row) and polar $\left(70-90^{\circ}\right.$; bottom row). Differences averaged for the different years and hemispheres (for which the number of co-located measurements are indicated) are shown in color and average difference for each period and latitude is shown in black. The shadowed area is the combined error. The corresponding mean MIPAS approximate altitude is shown in the vertical right axis.

NRLMSIS-00 model used in MIPAS retrievals or a pressure/altitude shift could mitigate the difference.

\subsection{Table Mountain and Mauna Loa Lidars}

The NASA Jet Propulsion Laboratory runs two Differential Absorption Lidars (DIAL) in the Table Mountain Facility (TMF; $34^{\circ} \mathrm{N}, 118^{\circ} \mathrm{W}$ ) and the Mauna Loa Observatory (MLO; $20^{\circ} \mathrm{N}, 156^{\circ} \mathrm{W}$ ). The systems combine Rayleigh/Mie and nitrogen vibrational Raman scattering techniques, and include 8 receiving channels (4 channels operating at the ozone-absorbed wavelengths of $308 \mathrm{~nm}$ and $332 \mathrm{~nm}$, and 4 channels at the non-absorbed wavelengths of $355 \mathrm{~nm}$ and $387 \mathrm{~nm}$ ). Besides ozone and aerosol backscatter ratio, the combination of its channels allows nighttime temperature retrievals between $12 \mathrm{~km}$ and $90-95 \mathrm{~km}$ with a vertical sampling of $300 \mathrm{~m}$. Their typical temporal resolution ranges from
$5 \mathrm{~min}$ to $2 \mathrm{~h}$ and their measurement frequency from 3 to 5 times per week. Lidar temperature profiles have an effective vertical resolution of $1-2 \mathrm{~km}$ from 10 to $65 \mathrm{~km}, 2-4 \mathrm{~km}$ from 65 to $80 \mathrm{~km}$ and $7 \mathrm{~km}$ at $90 \mathrm{~km}$. The precision (estimated from the statistics of the shot noise for the laser source) is better than $\pm 1 \mathrm{~K}$ at $55 \mathrm{~km}$ and below and $\pm 5 \mathrm{~K}$ at $80 \mathrm{~km}$. More details on the instruments performance and algorithms used to derive temperature can be found in McDermid et al. (1995) and Leblanc et al. (1998). The dataset is publicly available through the Network for the Detection of the Atmospheric Composition Change (NDACC) Data Archive Center (http://www.ndsc.ncep.noaa.gov). Estimates of the errors can be found also in Leblanc et al. (1998), who determined systematic errors of $4 \mathrm{~K}$ below $25 \mathrm{~km}$, smaller than $1 \mathrm{~K}$ from $30 \mathrm{~km}$ to $60 \mathrm{~km}, 10 \mathrm{~K}$ at $80 \mathrm{~km}$ and $15 \mathrm{~K}$ at $90 \mathrm{~km}$. 
Comparisons of the TMF lidar and the Goddard Space Flight Center (GSFC) mobile lidar showed differences of $5 \mathrm{~K}$ at $30 \mathrm{~km}, 1 \mathrm{~K}$ at $40 \mathrm{~km}$ and $3 \mathrm{~K}$ at $50 \mathrm{~km}$, although measurements were not made at the same time and some effect from tides might have been present. Indirect comparisons with other ground-based instruments located at different places may be inferred from cross-comparisons with satellite instrument or using climatological model data as a geographical transfer reference. That yielded differences with the Observatoire de Haute Provence and the GSFC lidars of 1-2 K around the stratopause and $3-4 \mathrm{~K}$ at $80 \mathrm{~km}$, although tidal effects were not removed. These results are summarized in Keckhut et al. (2004).

The selection of MIPAS measurements taken less than $4 \mathrm{~h}$ and $1500 \mathrm{~km}$ apart from the lidar measurements over Mauna Loa provided a total of 163 coincidences, out of which 103 were taken during solstice and 60 during equinox. The total number of coincidences with the Table Mountain lidar are 142 , from which 74 correspond to solstice and 68 to equinox. Taking into account their better vertical resolution, we have degraded the lidars temperature profiles using Eq. (5) for the comparisons with MIPAS measurements.

Figure 13 shows an example of a comparison of individual profiles of MIPAS and the MLO lidar for December 2006. The effect of the convolution of the lidar profile using MIPAS kernels is clearly seen in the figure, significantly smoothing out profile structures with a vertical phase smaller than MIPAS vertical resolution. Good examples are the small oscillations in the lidar profile detected around 60 or $75 \mathrm{~km}$, which are $2-3 \mathrm{~km}$ wide and that almost disappear once the convolution is applied. Wider structures in the smoothed profile remain and MIPAS also shows them. Nevertheless, it seems that MIPAS structures are more pronounced (larger temperature amplitude). That happens particularly in the inversion layer revealed at $85 \mathrm{~km}$ and not only in this example but very often when mesospheric inversion layers are present. The difference remains even if the lidar profile is not smoothed (green line in the figure). MIPAS measurements are colder in the troughs and warmer in the crests (more than $5 \mathrm{~K}$ in this example). This could be due to three reasons. First, the lidar has large temperature errors at these altitudes, which can be $10-15 \mathrm{~K}$. The lidar profile clearly displays the structure but the smooth density profile used for its determination could subdue its amplitude. Second, it could be due to a co-location mismatch because, although MIPAS measurements were done only $20 \mathrm{~min}$ after the lidar, they were taken $1400 \mathrm{~km}$ away from MLO. Third, the amplified errors due to non-LTE effects around inversion layers could also explain that behavior. Non-LTE errors are larger when the population of the emitting states are further away from LTE. This happens around an inversion layer, where the non-LTE population is larger than the LTE population in the troughs of the inversion layer but smaller in the crests (see Fig. 14 in GarcíaComas et al., 2008). Typical uncertainties in the quenching of the $v_{2}$ states by atomic oxygen can produce $5 \mathrm{~K}$ errors un-

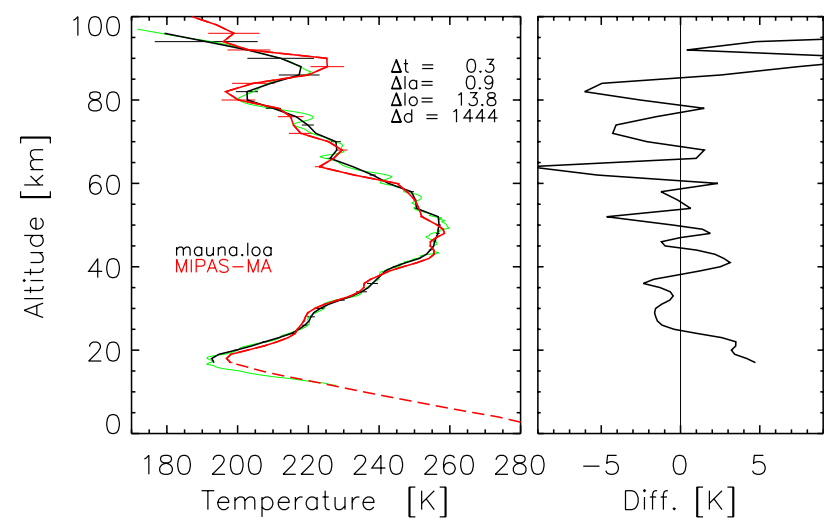

Fig. 13. Example of a comparison on December 2006 of individual nighttime profiles of temperature (left) and their difference (MIPAS-lidar; right) measured by MIPAS v511 (red - dashed line correspond to an extended profile with ECMWF values) and the lidar at the Mauna Loa Observatory $\left(20^{\circ} \mathrm{N}, 156^{\circ} \mathrm{W}\right)$ (black: convolved with MIPAS averaging kernels; green: not-convolved). The horizontal bars are the noise errors. Differences between both measurements in time in hours, latitude and longitude in degrees and distance in kilometers are also shown. Note MIPAS ability to reproduce vertical structures shown in the lidar measurements.

der these circumstances, even at mid-latitudes. Specifically, increasing the atomic oxygen abundance would drive MIPAS temperatures closer to the lidar values around the layer.

The average differences between MIPAS and the lidar at MLO for the solstices and the equinoxes, also grouped in 3-month periods from 2005 to 2009, are shown in Fig. 14. Both seasons exhibit similar values: MIPAS is $1-2 \mathrm{~K}$ warmer around $20 \mathrm{~km}$ and $1-2 \mathrm{~K}$ colder from 25 to $65 \mathrm{~km}$. The difference increases (in absolute value) to $-5 \mathrm{~K}$ around $75 \mathrm{~km}$ in solstice and $70 \mathrm{~km}$ in equinox. The difference slightly exceeds the combined error between $40 \mathrm{~km}$ and the midmesosphere $(70 \mathrm{~km})$, where the non-LTE effects are not important. At $85 \mathrm{~km}$, the difference rapidly becomes positive (MIPAS is warmer) and is $+5 \mathrm{~K}$ in solstice and $+10 \mathrm{~K}$ in equinox at $90 \mathrm{~km}$. This change of sign around that altitude is related to the lower altitude of the mesopause in MIPAS profiles compared to the lidar, whose mesopause is generally located above $90 \mathrm{~km}$ or even does not show up in the lidar altitude range. The average differences are within the combined errors at those altitudes. The comparison does not change dramatically from year to year but the variability for the solstices is larger than for the equinoxes.

The comparison between MIPAS and TMF lidar colocated temperature measurements (a total of 15) during the spring of 2008 is shown in Fig. 15. Mean distance between measurements was $1200 \mathrm{~km}$ and they were taken, on average, about an hour apart. This is an example of the very good agreement between their measurements. The gradients are very similar in both cases, the stratopause and the mesopause are located at the same altitudes and reveal temperatures 

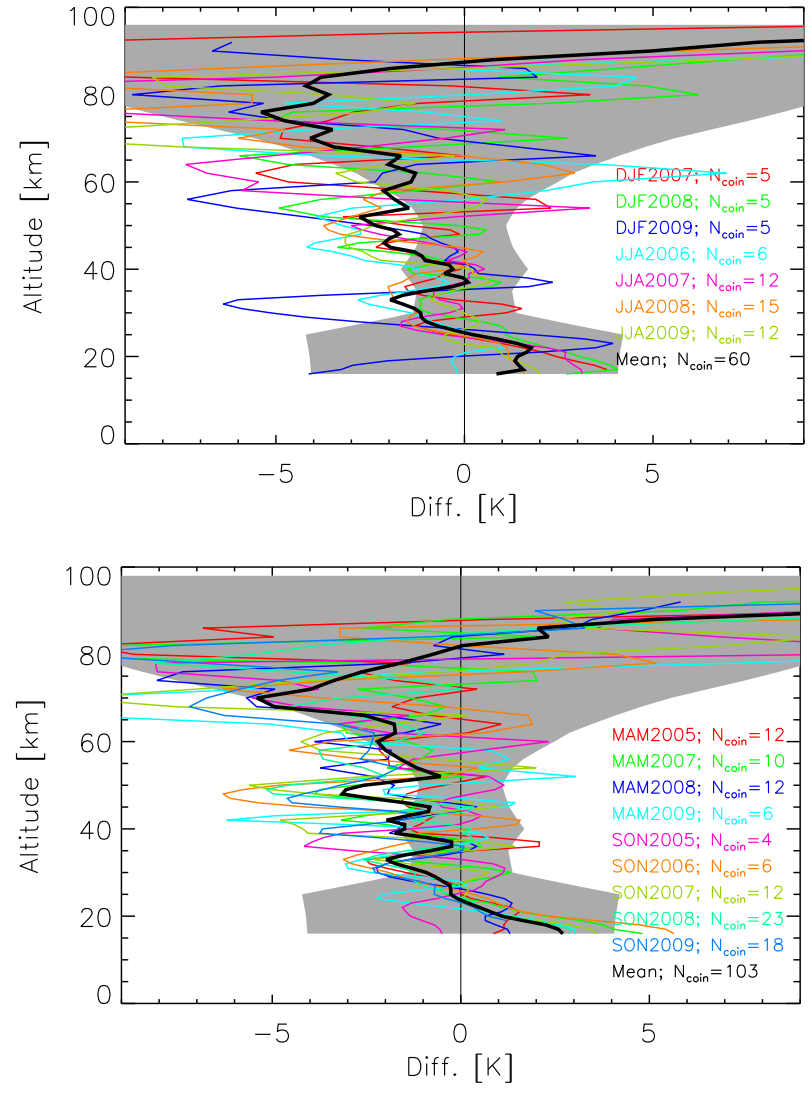

Fig. 14. Top: mean temperature differences (MIPAS-lidar) of solstice co-located measurements of MIPAS v511 and Mauna Loa Observatory lidar $\left(20^{\circ} \mathrm{N}, 156^{\circ} \mathrm{W}\right)$ (the seasons, years and number of coincidences are indicated in color). Average difference is shown in black. The total number of co-locations is 60 . The shadowed area is the combined systematic error. Bottom: as in top panel but for comparisons over MLO during equinox. The total number of colocations is 103 .

differing only a few $\mathrm{K}$ ( $2 \mathrm{~K}$, being warmer for MIPAS). Even the subtle change of slope around $30 \mathrm{~km}$ is very similarly detected by both instruments.

Figure 16 shows the average differences between MIPAS and TMF lidar co-located temperature measurements for all solstices and equinoxes from 2005 to 2009. As with the comparisons with the MLO lidar, MIPAS is also warmer (1-2 K) than the TMF lidar at the lower limit of MIPAS profiles (below $30 \mathrm{~km}$ ). As mentioned above, lidar comparisons with GSFC mobile lidar at those altiudes showed differences of $5 \mathrm{~K}$. The agreement from the mid-stratosphere to the midmesosphere is very good. From 40 to $60 \mathrm{~km}$ in the solstice and from 40 to $70 \mathrm{~km}$ in the equinox, MIPAS is $1 \mathrm{~K}$ colder. Around $65 \mathrm{~km}$ in the solstice, it is about $1 \mathrm{~K}$ warmer. Differences at $75 \mathrm{~km}$ slightly increase in absolute value in the solstice also over TMF (to $-3 \mathrm{~K}$ ) but $2 \mathrm{~K}$ less than at MLO. The differences above $80 \mathrm{~km}$ also change in sign (although at a lower altitude than at MLO), become positive and reach 5-

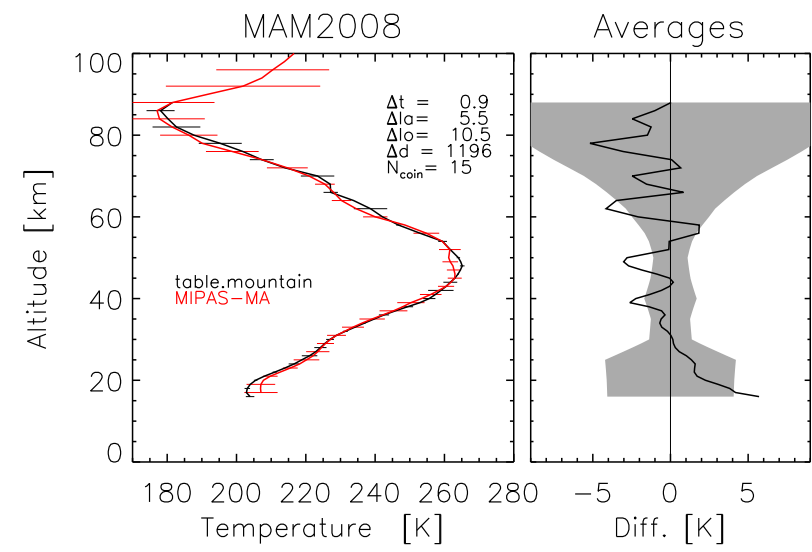

Fig. 15. Mean of co-located profiles of MIPAS v511 and Table Mountain Facility lidar $\left(34^{\circ} \mathrm{N}, 118^{\circ} \mathrm{W}\right)$ temperatures (left) and their difference (MIPAS-lidar; right) for the spring in 2008 (March, April and May). The total number of averaged profiles is 15 . Horizontal bars are their standard deviation. Average differences in time in hours, latitude and longitude in degrees and distance in kilometers are also shown. The shadowed area in the right panel is the combined systematic error.

$7 \mathrm{~K}$ at $90 \mathrm{~km}$. All differences are within the systematic errors at all altitudes, except at the stratopause during the equinox, where MIPAS is $1.5 \mathrm{~K}$ colder. In summary, comparisons with the TMF lidar show the same pattern and slightly improve those with the MLO lidar, particularly in the middle mesosphere $(70 \mathrm{~km})$.

In both mid-latitude comparisons (with MLO and TFM lidars), non-LTE errors could account for a 1-3 K bias from 80 to $90 \mathrm{~km}$. The results support to use a larger atomic oxygen in MIPAS retrievals, although the expected error in the [O] currently used in MIPAS retrievals (50\%) can only account for an increase of $1-2 \mathrm{~K}$ at those altitudes at mid-latitudes.

\subsection{Sierra Nevada's SATI}

The Spectral Airglow Temperature Imager (SATI) installed at the Sierra Nevada Observatory $\left(37.06^{\circ} \mathrm{N}, 3.38^{\circ} \mathrm{W}\right)$, Granada, Spain, is a spatial and spectral imaging Fabry-Perot spectrometer in which the etalon is a narrow band interference filter and the detector is a CCD camera. The SATI instrumental concept and optical configuration is described in detail by Sargoytchev et al. (2004). The instrument uses two interference filters, one centered at $836.813 \mathrm{~nm}$ (in the spectral region of the $\mathrm{OH}$ Meinel (6-2) band) and another one centered at $867.689 \mathrm{~nm}$ (in the spectral region of the $\mathrm{O}_{2}$ Atmospheric (0-1) band), from which the nighttime $T_{\mathrm{OH}}$ and $T_{\mathrm{O}_{2}}$ rotational temperatures are derived, respectively. The performance of the Sierra Nevada SATI is described in LópezGonzález et al. (2005). Since, up to date, there is not any study of SATI temperatures errors available, we estimated its precision from the standard deviation of temperatures 

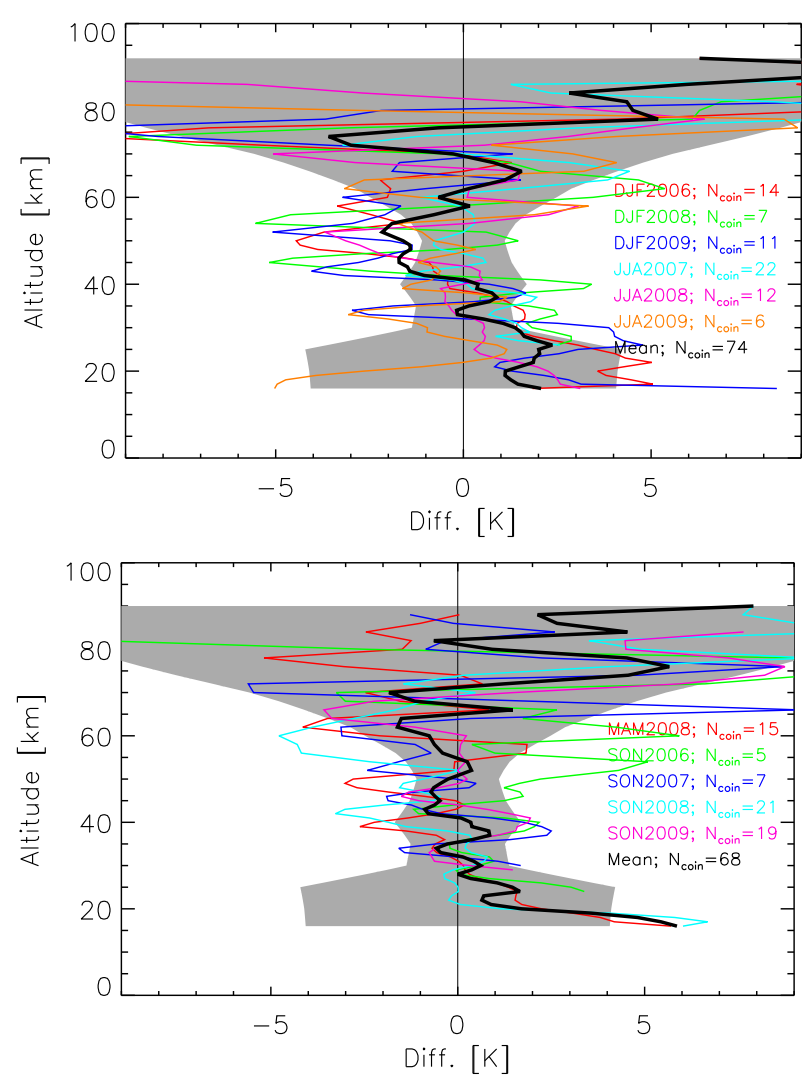

Fig. 16. Top: mean temperature differences of soltice MIPAS v511 and Table Mountain Facility lidar $\left(34^{\circ} \mathrm{N}, 118^{\circ} \mathrm{W}\right)$ co-located measurements (the seasons, years and number of coincidences are indicated in color). The total number of co-locations is 74. Average difference is shown in black. The shadowed area is the combined error. Bottom: as in top panel but for comparisons over TMF during equinox. The total number of co-locations is 68 .

measured during one hour, in about 5-10 min steps. By doing so, we assume that the spread obtained that way is dominated by random errors more than atmospheric variability. The values estimated this way give a $5.5 \mathrm{~K}$ and and $3.5 \mathrm{~K}$ precisions for the $\mathrm{OH}$ and the $\mathrm{O}_{2}$ temperatures, respectively. Regarding the systematic errors, there is no direct way to estimate them and, thus, we did not take them into account for the calculation of the combined systematic errors.

Effort has been made in the past to validate SATI temperatures (López-González et al., 2007; Remsberg et al., 2008). The comparisons with the SABER v1.06 measurements for the 2002-2006 showed SATI $6 \mathrm{~K}$ lower temperatures at $87 \mathrm{~km}$ and $2.5 \mathrm{~K}$ higher temperatures at $95 \mathrm{~km}$. The comparisons with SABER v1.07 for 2002 showed $2 \mathrm{~K}$ larger temperatures for SATI at $87 \mathrm{~km}$ and $5 \mathrm{~K}$ at $95 \mathrm{~km}$.

We have selected MIPAS measurements taken over a circle of $1500 \mathrm{~km}$ around Sierra Nevada and within $4 \mathrm{~h}$ of SATI measurements. We have compared a total of 19 nights from 2005 to 2009, with a total of 173 MIPAS co-locations. SATI was out of order for more than a year (2008 and half 2009) and, thus, there is a lack of coincidences for that period. For our comparison, we have averaged SATI measurements for each night. We have assumed that they peak at $87 \mathrm{~km}$ for $T_{\mathrm{OH}}$ and at $95 \mathrm{~km}$ for $T_{\mathrm{O}_{2}}$, respectively, and have a full width at half maximum (FWHM) of $10 \mathrm{~km}$. This value is based on results from Remsberg et al. (2008), where the estimation of the SATI $T_{\mathrm{k}}$ kernel peak was derived from simultaneous SABER measurements of the $\mathrm{OH}$ emission. With those parameters, we have convolved MIPAS $T_{\mathrm{k}}$ profiles and compared them with SATI measurements.

The results of the MIPAS-SATI comparisons are shown in Figs. 17 and 18 . MIPAS $T_{\mathrm{k}}$ at $87 \mathrm{~km}$ is in very good agreement with SATI OH temperature. Both instruments show a similar seasonal pattern, with a colder mesopause during the summer in both cases. MIPAS $T_{\mathrm{k}}$ is on average $0.7 \mathrm{~K}$ colder than SATI rotational temperatures. The result is similar to the difference between SABER v1.07 and SATI. The average difference in the whole period is within MIPAS estimated systematic error. The differences do not show any clear seasonal dependence. MIPAS temperatures in late 2009, when SATI was reinitialize after its failure, point to a larger positive bias $(+7 \mathrm{~K})$, although the statistics are then poor to reach a clear conclusion.

The comparisons with SATI $\mathrm{O}_{2}$ temperatures reveal $16 \mathrm{~K}$ larger MIPAS temperatures at $95 \mathrm{~km}$. That supports the results from comparisons with other instruments, typically showing higher MIPAS lower thermosphere temperatures, although, the difference with SATI is somewhat larger than in other comparisons at mid-latitudes conditions (see e.g., lidars). The difference does not follow any clear seasonal pattern. Although the temporal coverage of the co-locations is not continuous, the differences in the summers are always positive whereas they are usually negative in the equinoxes (except for 2009, after the recovery of SATI).

\subsection{Davis station spectrometer}

Hydroxyl rotational temperature over Davis Station (DS; $69^{\circ} \mathrm{S}, 78^{\circ} \mathrm{E}$ ), Antartica, is derived from measurements with a Czerny-Turner scanning grating spectrometer. The temperature is derived from emissions in the (6-2) band (approximately at $87 \mathrm{~km}$ ). A detailed description of the performance of the instrument and its temperature measurements is given in French et al. (2000) and Burns et al. (2002). The temperatures used here were determined from nighttime scans collected in about $7.5 \mathrm{~min}$. Temperature errors are usually less than $15 \mathrm{~K}$ and the vertical resolution is estimated to be about $8.7 \mathrm{~km}$ (French and Mulligan, 2010).

Comparisons of the DS spectrometer $\mathrm{OH}$ temperatures with SABER and MLS are described in French and Mulligan (2010). Over the $8 \mathrm{yr}$ the comparisons spanned for, they found an average SABER bias of $+2 \mathrm{~K}$ when weighting SABER temperatures using SABER OH volume emission rate profile and $-1 \mathrm{~K}$ when weighting SABER temperatures 

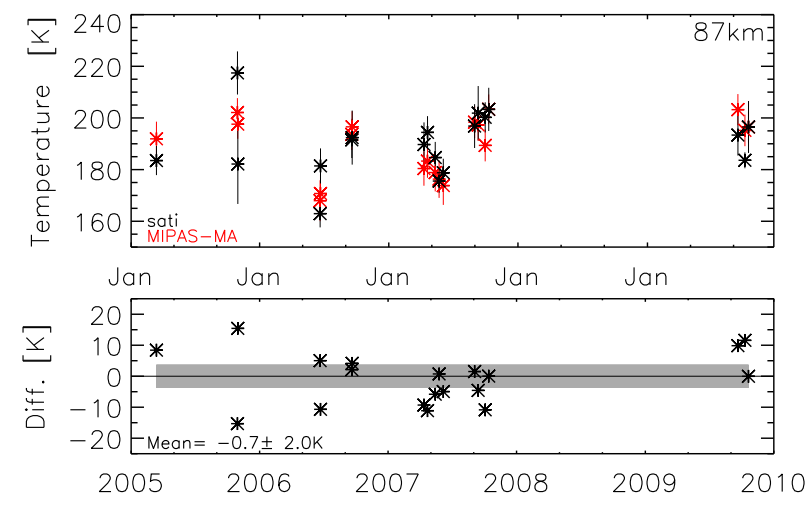

Fig. 17. Nightly mean MIPAS v511 temperature at $87 \mathrm{~km}$ (red) and SATI $\mathrm{OH}$ rotational temperatures $\left(37^{\circ} \mathrm{N}, 3^{\circ} \mathrm{W}\right)$ (black) and their standard deviation (vertical bars) from 2005 to 2009 (top panel) and their difference (MIPAS-SATI). The shadowed area is MIPAS systematic error. The mean difference and its error are also indicated.

using a Gaussian with FWHM of $8 \mathrm{~km}$ centered at $87 \mathrm{~km}$ (more comparable to the weighting we use in this work; see below). French and Mulligan (2010) also reported a $0.7 \mathrm{~K} \mathrm{yr}^{-1}$ trend in the SABER-DS bias. MLS measurements provided $10 \mathrm{~K}$ lower temperatures than the DS spectrometer (weighting MLS temperatures with a Gaussian with FWHM of $8.7 \mathrm{~km}$ centered at $87 \mathrm{~km}$ ) but this bias showed no trend along the $6 \mathrm{yr}$ the comparisons were extended for.

Based on the same considerations used for the comparison with SATI OH temperatures, we have compared the temperature measured by MIPAS centered at $87 \mathrm{~km}$ with the Davis station spectrometer $\mathrm{OH}$ rotational temperatures. We have convolved vertically MIPAS temperatures using a gaussian of $10 \mathrm{~km} \mathrm{FWHM.} \mathrm{As} \mathrm{in} \mathrm{comparisons} \mathrm{with} \mathrm{other} \mathrm{ground-}$ based instruments, we selected MIPAS measurements within $1500 \mathrm{~km}$ around Davis and taken $4 \mathrm{~h}$ apart. The comparison covers measurements taken from 2005 to 2009 , both inclusive, for which we found 121 nights with coincidences. Due to the high latitude of the Davis station, measurements are restricted to nights from March to November because of the continuous daylight during the summers. Therefore, the comparisons do not cover the polar summer.

Figure 19 shows DS OH and MIPAS temperatures averaged for all coincidences found in each night. Both measurements show a similar seasonal pattern. The difference between MIPAS and DS spectrometer averaged for all colocations found is $+0.4 \mathrm{~K}$, without any noticeable seasonal dependence. That value is well within the expected MIPAS systematic error. This result is consistent with the MIPASMLS and MIPAS-SABER differences at $87 \mathrm{~km}$ in the high latitude winters estimated in this work $(+6-7 \mathrm{~K}$ and $+3 \mathrm{~K}$, respectively) and the DS-MLS and DS-SABER differences $(+10 \mathrm{~K}$ and $+1 \mathrm{~K}$, respectively, from French and Mulligan (2010) results using their weighting with a Gaussian). That is, MIPAS and DS temperatures are warmer than those of

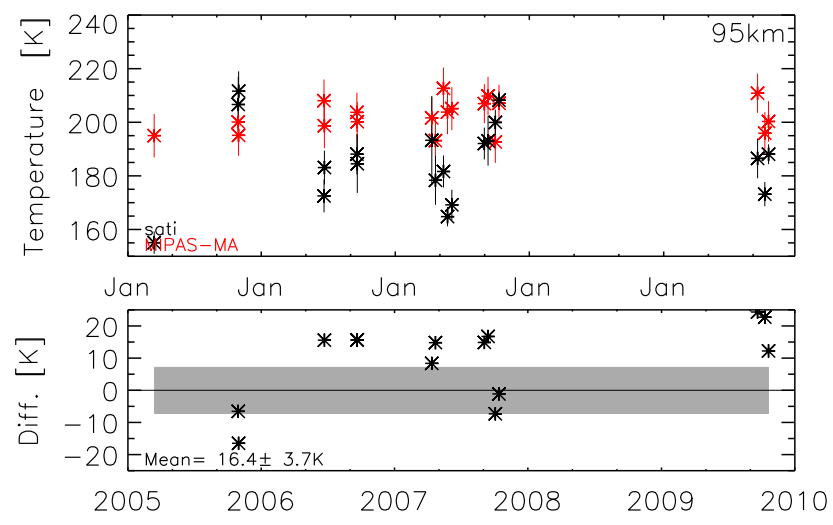

Fig. 18. Nightly mean MIPAS v511 temperature at $95 \mathrm{~km}$ (red) and SATI $\mathrm{O}_{2}$ rotational temperatures $\left(37^{\circ} \mathrm{N}, 3^{\circ} \mathrm{W}\right)$ (black) and their standard deviation (vertical bars) from 2005 to 2009 (top panel) and their difference (MIPAS-SATI). The shadowed area is MIPAS systematic error. The mean difference and its error are also indicated.
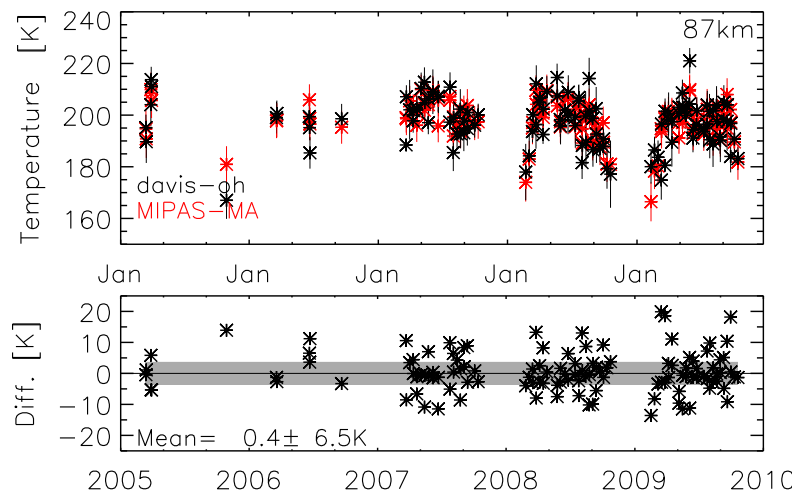

Fig. 19. Nightly mean MIPAS v511 temperature at $87 \mathrm{~km}$ (red) and Davis $\mathrm{OH}$ rotational temperatures $\left(69^{\circ} \mathrm{S}, 78^{\circ} \mathrm{E}\right)$ (black) and their standard deviation (vertical bars) from 2005 to 2009 (top panel) and their difference (MIPAS-DS; bottom panel). The shadowed area is the combined error.

MLS and SABER at the OH layer. The differences between the biases found between DS and MIPAS and the other two instruments (taking into account that MIPAS and DS temperatures differ in less than $0.5 \mathrm{~K}$ ) can be explained by the different co-location criteria used (which is $8 \mathrm{~h}$ and $500 \mathrm{~km}$ in the DS-MLS and DS-SABER comparisons of French and Mulligan (2010) compared to our $4 \mathrm{~h}$ and $1500 \mathrm{~km}$ ).

French and Mulligan (2010) detected a $0.7 \mathrm{~K} \mathrm{yr}^{-1}$ positive trend in the 2002-2008 SABER-DS bias, which they attributed to an inaccurate representation of the $\mathrm{CO}_{2}$ or O natural variability, in particular, their long term variations. Given that SABER uses a similar technique to MIPAS to measure temperature and is affected by similar inaccuracies in the $\mathrm{CO}_{2}$ or atomic oxygen abundances variability (they are taken from the same databases), we expect a similar trend in the bias. The extension in time of our MIPAS-DS comparisons 
is not as long (our comparisons extend only for $5 \mathrm{yr}$ compared to the $8 \mathrm{yr}$ of SABER-DS comparisons) and, thus the resulting bias trend is not as representative, but, still, we fitted the MIPAS-DS differences to a straight line and found $\mathrm{a}-0.5 \pm 0.3 \mathrm{~K} \mathrm{yr}^{-1}$ slope. The bias is even almost negligible $\left(0.1 \pm 0.1 \mathrm{~K} \mathrm{yr}^{-1}\right)$ when it is estimated considering only measurements from 2007 to 2009 (where the number of coincidences is larger). Therefore, MIPAS-DS bias trend does not agree with that of SABER. That suggests that the bias trend is not due to the $\mathrm{CO}_{2}$ or $\mathrm{O}$ natural long term variability, which is not accounted for either in MIPAS nor SABER temperature retrievals. This statement should, however, be confirmed with MIPAS-DS comparisons further extended in time.

\subsection{Falling sphere climatology}

After measurements taken at high northern latitudes from falling spheres (FS) launched from 1987 to 1997 in eight different campaigns, mainly over Andoya $\left(69^{\circ} \mathrm{N}\right)$ and Kiruna $\left(68^{\circ} \mathrm{N}\right)$, Lübken (1999) constructed a climatology from 35 to $95 \mathrm{~km}$. The climatology covers periods from April to September with a 7 days temporal grid. The measurement technique consists in the determination of the atmospheric density profile from the deceleration of the spheres and the determination of the temperature by integration of the density profile assuming hydrostatic equilibrium. The upper boundary temperature was taken generally from CIRA-1986 or rocket-borne measurements when available. Its uncertainty is the factor producing the largest errors in the derived temperature. The total $T_{\mathrm{k}}$ errors are $1.5,3$ and $7 \mathrm{~K}$ at 70,80 and $90 \mathrm{~km}$, respectively, and the smallest scales detectable (related to the vertical resolution) are $0.8,3$ and $8 \mathrm{~km}$ at 40,60 and $85 \mathrm{~km}$, respectively.

Since the high latitude summer non-LTE retrievals have the largest systematic errors, we also compared the MIPAS temperatures under those conditions with this in-situ measurements climatology. We used MIPAS v511 measurements for 2008 and 2009, when the temporal coverage is better than in other years. We compared the FS temperatures corresponding to weekly periods with the MIPAS zonal mean temperatures of scans in $10^{\circ}$ latitude box centered at $68.5^{\circ} \mathrm{N}$ measured within three and a half days before and after the FS profile date.

Figure 20 shows the comparisons of the temperature profiles and the FS profile for 22 April, 16 May, 1 June, 22 June, 16 July, 1 August, 16 August and 22 September. The number of MIPAS averaged profiles for each week of comparisons vary from 45 to 110 . The MIPAS and FS temperatures agree within $1-3 \mathrm{~K}$ in the upper stratosphere in all seasons. MIPAS stratopause is located $3-5 \mathrm{~km}$ below that of FS. Temperature in the lower mesosphere (from the stratopause to $70 \mathrm{~km}$ ) is from 5 to $15 \mathrm{~K}$ smaller for MIPAS, the difference being smaller (in absolute value) in April and September and larger during the other months.
The agreement in the upper mesosphere is generally better and the differences decrease to $\pm 5 \mathrm{~K}$. The mesopause temperature agrees very well in May and the beginning of June and August. At the end of June, MIPAS mesopause temperatures are $3 \mathrm{~K}$ colder than those measured by FS. During July and mid-August, MIPAS mesopause is located slightly below that of FS and is 2 to $10 \mathrm{~K}$ warmer. Since, except for April and end of June, MIPAS mesopause (measured more than a decade after the FS measurements) is warmer than that of FS, there is no evidence of any mesopause cooling trend. These comparisons do not show either the expected colder FS temperatures around $70 \mathrm{~km}$ (about $10 \mathrm{~K}$ colder according to Lübken et al., 1994) due to the discontinuity in the drag coefficient around Mach 1. Particularly noticeable is the upper mesosphere structure during September, which is present in both datasets with similar vertical and temperature amplitudes.

\section{Summary and conclusions}

The MIPAS instrument measures the $15 \mu \mathrm{m} \mathrm{CO}_{2}$ non-LTE emission with a high spectral resolution $\left(0.0625 \mathrm{~cm}^{-1}\right)$ up to the lower thermosphere in three special modes of observations: the Middle Atmosphere (MA), the Upper Atmosphere (UA) and the NoctiLucent Cloud (NLC) modes. Measurements are taken day and night and have a global coverage. Kinetic temperature and line of sight are derived from the $15 \mu \mathrm{m}$ region using a dedicated non-LTE retrieval algorithm developed and operated by the Institute of Meteorology and Climate Research (IMK) in Karlsruhe together with the Instituto de Astrofísica de Andalucía (IAA) in Granada. The nonLTE populations of the $\mathrm{CO}_{2}$ vibrational levels are modeled with the Generic RAdiative traNsfer AnD non-LTE population Algorithm (GRANADA). Temperature and line of sight are retrieved from the radiance measured in 28 narrow spectral microwindows $\left(0.1-0.5 \mathrm{~cm}^{-1}\right.$ wide). These microwindows have been carefully selected and contain the $\mathrm{CO}_{2}$ emission lines most sensitive to temperature changes in the altitude range from 20 to $120 \mathrm{~km}$.

The temperature retrieval is performed on an $1 \mathrm{~km}$ step altitude grid from the ground to $50 \mathrm{~km}, 2 \mathrm{~km}$ step from 50 to $100 \mathrm{~km}$ and increased to $2.5-5 \mathrm{~km}$ up to $120 \mathrm{~km}$. The retrieval is regularized by a first-order Tikhonov-type constraint and uses a priori information from ECMWF merged with NRLMSIS-00 model data. Horizontal temperature gradients are simultaneously retrieved using a priori profiles from ECMWF below $60 \mathrm{~km}$ and set to zero above. The $\mathrm{CO}_{2}$ abundances used are constant below $35 \mathrm{~km}$ and taken from the WACCM model above, and a trend correction is applied.

The temperature random errors mainly arise from the propagation of measurement noise through the retrieval. Typical values are $0.2-0.5 \mathrm{~K}$ below $50 \mathrm{~km}, 0.5-2 \mathrm{~K}$ at $50-70 \mathrm{~km}$, and $2-7 \mathrm{~K}$ above. Typical values of the retrieved temperature vertical resolution are $4 \mathrm{~km}$ below $35 \mathrm{~km}, 3 \mathrm{~km}$ from 

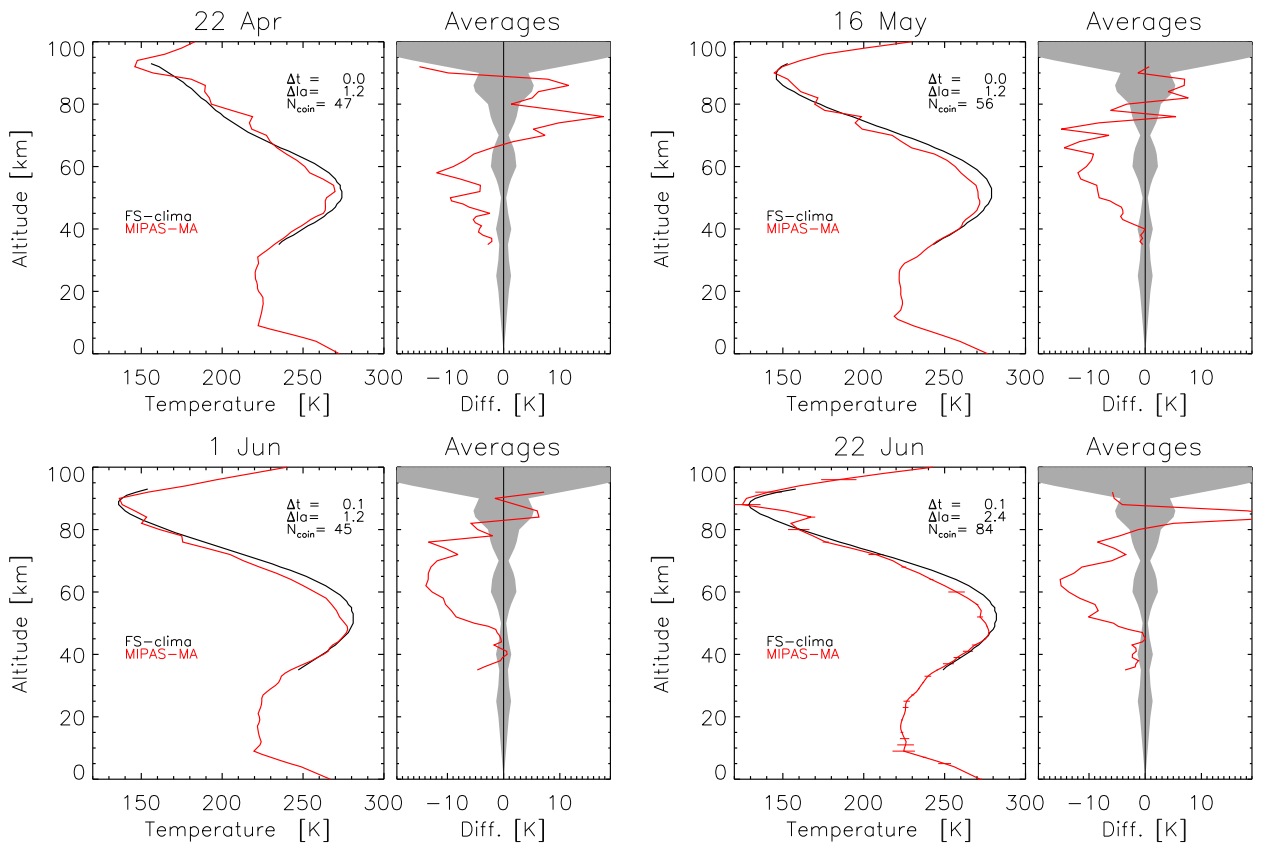

Averages
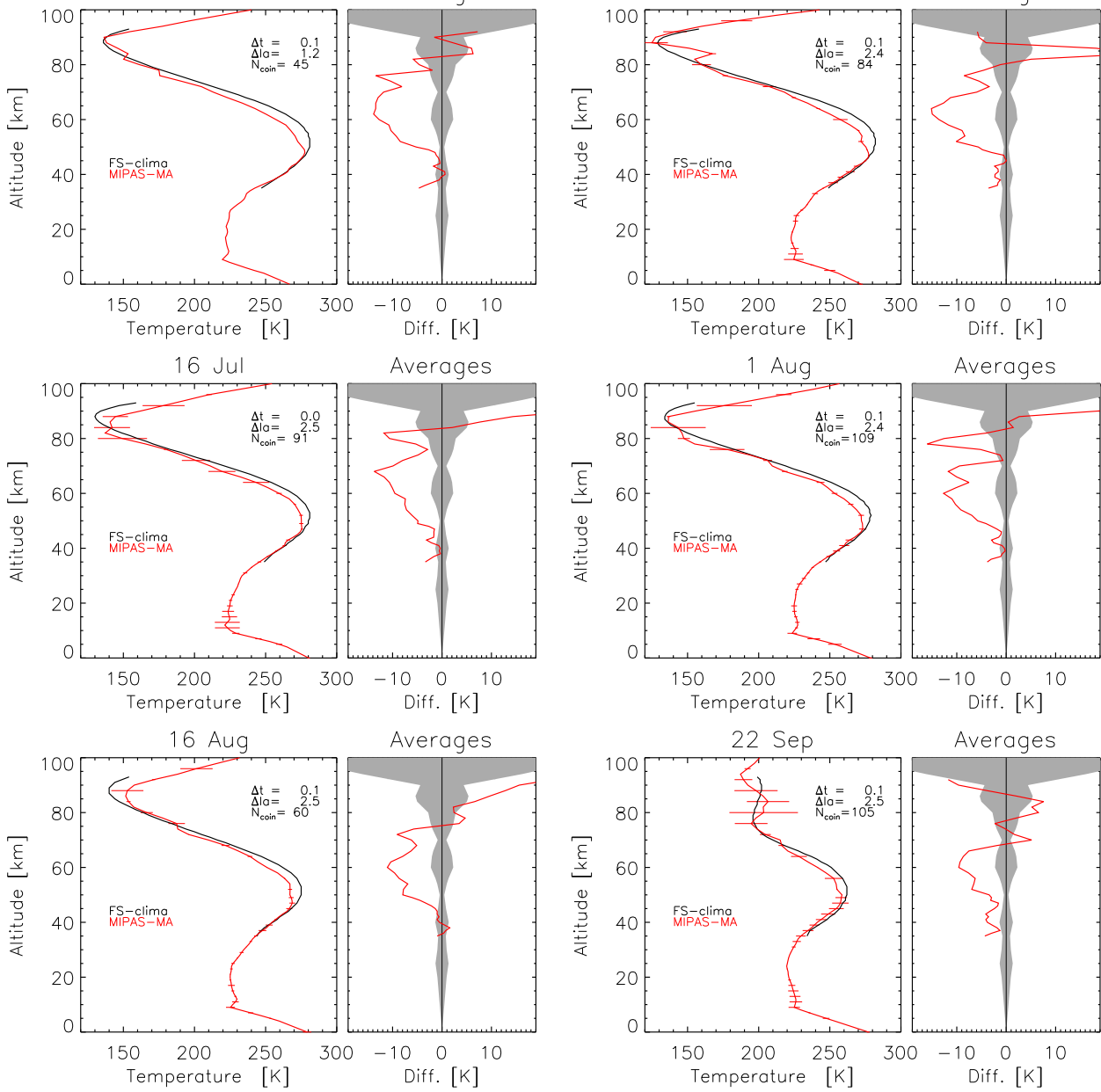

Fig. 20. Comparison between the temperature profiles of the Lübken (1999) falling sphere climatology and weekly MIPAS zonal mean profiles in a $10^{\circ}$ latitude box centered at $68.5^{\circ} \mathrm{N}$ for eight dates (shown in the title of each plot) from April to September. MIPAS profiles have been averaged for measurements taken in 2008 and 2009 three and a half days after and before the date shown. The right panels show the differences (MIPAS-FS) (red line) and the MIPAS total systematic error (grey shadow).

35 to $50 \mathrm{~km}, 4-6 \mathrm{~km}$ from 50 to $90 \mathrm{~km}$, and $6-10 \mathrm{~km}$ above. Both random errors and vertical resolution do not vary significantly with latitude and season.

The systematic temperature errors above the midmesosphere arise mainly from uncertainties in the non-LTE parameters. Additionally, the carbon dioxide abundance un- certainty contribute to the systematic error in this region. Uncertainties in the spectroscopy, the gain calibration, the instrument line shape and the interfering species introduce systematic errors particularly below the mid-mesosphere. The overall estimated systematic error is $1 \mathrm{~K}$ below $70 \mathrm{~km}, 1-3 \mathrm{~K}$ from 70 to $85 \mathrm{~km}$ and $3-11 \mathrm{~K}$ from 85 to $100 \mathrm{~km}$. Due to 

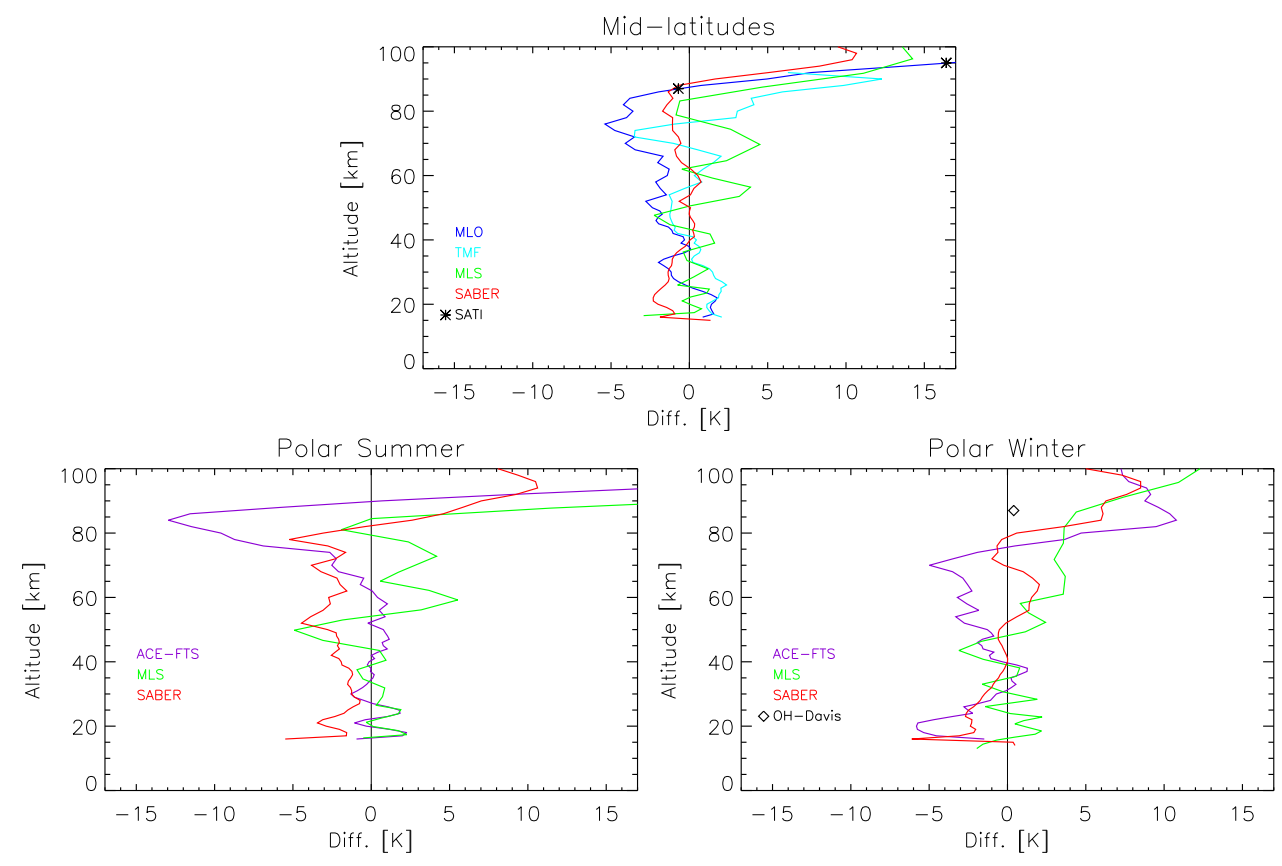

Fig. 21. Mean temperature difference between MIPAS and SABER (red), ACE-FTS (purple), Aura-MLS (green), MLO lidar (dark blue), TMF lidar (light blue), SATI (asterisk), and the Davis Spectrograph (diamond) for mid-latitudes (top), polar summer (bottom left) and polar winter (bottom right).

the larger non-LTE effects in the polar summer, these values increase to $1-6 \mathrm{~K}$ from 70 to $85 \mathrm{~km}$ and $6-30 \mathrm{~K}$ from 85 to $100 \mathrm{~km}$ under those conditions.

We have compared the results of our MA temperature nonLTE retrievals (v511) with independent co-located measurements of seven instruments from 2005 to 2009. As our extension of the comparison with SABER to the UA (v611) and NLC (v711) mode measurements show, the results and conclusions for MA mode temperatures reported here can be applied to the UA and NLC modes. Figure 21 and Tables 3 and 5 summarize the comparisons between kinetic temperature measured by MIPAS and the space-borne instruments TIMED-SABER, Aura-MLS and ACE-FTS, and the groundbased instruments MLO lidar, TMF lidar, Sierra Nevada's SATI and the Davis spectrograph in mid-latitudes, polar summer and polar winter. Table 4 summarizes the differences in the stratopause and the mesopause temperatures and altitudes between MIPAS and the space-borne instruments.

MIPAS MA v511 temperature compares very well with the other instruments measurements. MIPAS agrees with all instruments within $1-2 \mathrm{~K}$ from 20 to $70 \mathrm{~km}$, within $4-10 \mathrm{~K}$ from 80 to $90 \mathrm{~km}$ and within $15-20 \mathrm{~K}$ above $95 \mathrm{~km}$. This suggests that the systematic errors mentioned above are probably overestimated. MIPAS v511 temperatures reproduce other instruments' average profile vertical structure very well. The individual profile vertical structures are reproduced fairly well and MIPAS, in some occasions, shows larger temperature amplitudes in inversion layers, which may point to a too low atomic oxygen used in MIPAS non-LTE retrievals. The differences do not strongly depend on season but are somewhat larger in the high latitude summers, particularly around the mesopause.

In the lower and mid-stratosphere, MIPAS agreement with other instruments at all seasons is better than $1 \mathrm{~K}$, except with SABER. MIPAS is there $2-3 \mathrm{~K}$ colder than SABER but the latter has a well known warm bias of similar magnitude.

MIPAS temperatures are generally $1-2 \mathrm{~K}$ colder at $45-$ $50 \mathrm{~km}$. The comparison with SABER at mid-latitudes and polar winter (not at polar summer, however) show a better agreement at these altitudes but SABER also has a known $1-2 \mathrm{~K}$ cold bias around the stratopause. The comparisons at $50 \mathrm{~km}$ in polar summer with ACE-FTS also show better agreement but ACE-FTS might also have a $2 \mathrm{~K}$ negative bias in the upper stratosphere. Comparisons of the stratopause altitude show very good agreement, except for the polar summer with SABER, where MIPAS stratopause is about $2 \mathrm{~km}$ below SABER's.

MIPAS agreement with other instruments in the lower mesosphere (up to $70 \mathrm{~km}$ ) is better than $2 \mathrm{~K}$ at all seasons, MIPAS being generally colder. MIPAS-MLS differences provide positive values there but MLS comparisons with other instruments showed a negative MLS bias in the mesosphere $(0-7 \mathrm{~K})$. The agreement at those altitudes with SABER and the TMF lidar is particularly good (differences $<1 \mathrm{~K}$ ).

Above the mid-mesosphere, the comparisons slightly worsen in some cases. Additionally, the variability of the 
differences with season in the upper mesosphere and lower thermosphere are larger than below $70 \mathrm{~km}$. Except for the polar winter, (and also comparisons with the TMF lidar and Aura-MLS), MIPAS temperatures from 75 to $85 \mathrm{~km}$ also show colder values. Mid-latitude differences (in absolute value) range from 1 to $2 \mathrm{~K}$ ( $4 \mathrm{~K}$ for the MLO lidar) and polar summer differences from 1 to $10 \mathrm{~K}$. Polar winter MIPAS temperatures are $3 \mathrm{~K}$ warmer at those altitudes. The larger (in absolute value) polar summer and polar winter difference with ACE-FTS from 75 to $85 \mathrm{~km}(-10 \mathrm{~K}$ and $+10 \mathrm{~K}$, respectively) are consistent with differences found in previous ACE-FTS comparisons with other instruments.

MIPAS temperatures are generally warmer around the mesopause and above in mid-latitudes and in the polar winter, specifically, above 88 and $80 \mathrm{~km}$, respectively. Comparisons with the $\mathrm{OH}$ ground-based instruments (SATI at midlatitudes and Davis spectrograph at high latitudes) show excellent agreement (within $1 \mathrm{~K}$ at $87 \mathrm{~km}$ ). In the polar summer, MIPAS is up to $10 \mathrm{~K}$ colder than ACE-FTS between 85 and $90 \mathrm{~km}$ (around the mesopause) and warmer everywhere else. The large positive differences with MLS at $85-90 \mathrm{~km}$ in the polar summer are generally associated to a mismatch in the mesopause altitude, located $4 \mathrm{~km}$ higher in MLS. Compared to other instruments, MLS polar summer mesopause shows too small variability between the $\mathrm{NH}$ and SH high latitude mesopause and too low temperatures. MIPAS difference with SABER in the polar summer mesopause would be reduced if both MIPAS and SABER used the same $\mathrm{CO}_{2} v_{2}$ exchange, $\mathrm{CO}_{2}-\mathrm{N}_{2}$ and $\mathrm{CO}_{2}-\mathrm{O}_{2}$ quenching rates and the same atomic oxygen, which is not the case currently.

Although the known negative ACE-FTS bias in the upper mesosphere may account for part of the differences, the remaining higher ACE-FTS polar summer mesopause temperatures may point to wrong collisional rates or [O] used in MIPAS non-LTE retrievals. However, the MIPAS comparisons with the FS climatology shows good agreement there (or even a MIPAS too warm mesopause during particular periods, e.g., end of the summer), which suggests that MIPAS-ACE-FTS negative difference at the polar summer mesopause is likely due to a further bias in ACE-FTS temperatures, instead of a too small [O] and/or too slow $k_{v v}$ and/or $k_{\text {air }}$.

Except for the polar summer, the comparisons around the mesopause point to a too low atomic oxygen abundance used in MIPAS retrievals (taken from the NRLMSIS-00 model). The warmer MIPAS lower thermosphere also support that result. In the case of the polar summer mesopause, the opposite occurs. Smaller mesopause [O] during the polar summer would decrease the MIPAS temperature there, leading to a better agreement with SABER and with the FS-climatology, for which comparisons for some months in the summer showed a MIPAS warmer mesopause. A smaller $k_{v v}$ rate of $v_{2}$ exchange between $\mathrm{CO}_{2}$ isotopic levels and/or a smaller rate for the quenching of $\mathrm{CO}_{2}\left(v_{2}\right)$ by $\mathrm{N}_{2}$ and/or $\mathrm{O}_{2}$ would also act in the same direction and would barely affect the temperatures at other latitudes and seasons.

Given the excellent performance and quality, and the broad spatial and temporal coverage of MIPAS kinetic temperature non-LTE retrievals, MIPAS temperature from versions 511, 611 and 711 of MA, UA and NLC modes, respectively, embody a suitable dataset for studies aiming to the understanding of the physics of the MLT region, and for the retrieval of atmospheric species abundances from measurements at IR wavelengths.

Acknowledgements. MGC was supported by ESA within the framework of the Changing Earth Science Network Initiative. The IAA team was supported by the Spanish MICINN, under project AYA2008-03498/ESP, and EC FEDER funds. The Atmospheric Chemistry Experiment mission is funded primarily by the Canadian Space Agency. The Davis $\mathrm{OH}$ data used within this paper were obtained from the Australian Antarctic Data Centre (IDN Node AMD/AU), a part of the Australian Antarctic Division (Commonwealth of Australia). These data are described in the metadata record "Rotational temperature studies of the hydroxyl airglow layer above Davis, Antarctica" of Burns, G. and French, J. (2002, updated 2009) at the Australian Antarctic Data Centre - CAASM Metadata (http://data.aad.gov.au/aadc/metadata/). The Davis program is supported by the Antarctic Science Advisory committee under project 701 .

Edited by: W. Ward

\section{References}

Beagley, S. R., Boone, C. D., Fomichev, V. I., Jin, J. J., Semeniuk, K., McConnell, J. C., and Bernath, P. F.: First multi-year occultation observations of $\mathrm{CO}_{2}$ in the MLT by ACE satellite: observations and analysis using the extended CMAM, Atmos. Chem. Phys., 10, 1133-1153, doi:10.5194/acp-10-1133-2010, 2010.

Boone, C. D., Nassar, R., Walker, K. A., Rochon, Y., McLeod, S. D., Rinsland, C. P., and Bernath, P. F.: Retrievals for the atmospheric chemistry experiment Fourier-transform spectrometer, Appl. Opt., 44, 7218-7231, 2005.

Brasseur, G. and Solomon, S.: Aeronomy of the Middle Atmosphere, Atmospheric Science Library, D. Reidel Publishing Company, Dordrecht, Holland, second edn., 1986.

Burns, G. B., French, W. J. R., Greet, P. A., Phillips, F. A., Williams, P. F. B., Finlayson, K., and Klich, G.: Seasonal variations and inter-year trends in 7 years of hydroxyl airglow rotational temperatures at Davis station $\left(69^{\circ} \mathrm{S}, 78^{\circ} \mathrm{E}\right)$, Antarctica, Journal of Atmospheric and Solar-Terrestrial Physics, 64, 11671174, doi:10.1016/S1364-6826(02)00066-4, 2002.

Dang, C., Reld, J., and Garside, B. K.: Dynamics of the $\mathrm{CO}_{2}$ lower laser levels as measured with a tunable diode laser, Appl. Phys. B, 31, 163-172, doi:10.1007/BF00688838, 1983.

Dudhia, A. and Livesey, N.: Validation of temperature measurements from the improved stratospheric and mesospheric sounder, J. Geophys. Res., 101, 9795-9809, 1996.

Echle, G., von Clarmann, T., Dudhia, A., Flaud, J.-M., Funke, B., Glatthor, N., Kerridge, B., López-Puertas, M., Martín-Torres, 
F. J., and Stiller, G. P.: Optimized spectral microwindows for data analysis of the Michelson Interferometer for Passive Atmospheric Sounding on the Environmental Satellite, Appl. Opt., 39, 5531-5540, doi:10.1364/AO.39.005531, 2000.

Fischer, H., Birk, M., Blom, C., Carli, B., Carlotti, M., von Clarmann, T., Delbouille, L., Dudhia, A., Ehhalt, D., Endemann, M., Flaud, J. M., Gessner, R., Kleinert, A., Koopman, R., Langen, J., López-Puertas, M., Mosner, P., Nett, H., Oelhaf, H., Perron, G., Remedios, J., Ridolfi, M., Stiller, G., and Zander, R.: MIPAS: an instrument for atmospheric and climate research, Atmos. Chem. Phys., 8, 2151-2188, doi:10.5194/acp-8-2151-2008, 2008.

Flaud, J.-M., Brizzi, G., Carlotti, M., Perrin, A., and Ridolfi, M.: MIPAS database: Validation of $\mathrm{HNO} 3$ line parameters using MIPAS satellite measurements, Atmos. Chem. Phys., 6, 5037-5048, doi:10.5194/acp-6-5037-2006, 2006.

French, W. J. R. and Mulligan, F. J.: Stability of temperatures from TIMED/SABER v1.07 (2002-2009) and Aura/MLS v2.2 (2004-2009) compared with OH(6-2) temperatures observed at Davis Station, Antarctica, Atmos. Chem. Phys., 10, 1143911446, doi:10.5194/acp-10-11439-2010, 2010.

French, W. J. R., Burns, G. B., Finlayson, K., Greet, P. A., Lowe, R. P., and Williams, P. F. B.: Hydroxyl (6-2) airglow emission intensity ratios for rotational temperature determination, Ann. Geophys., 18, 1293-1303, doi:10.1007/s00585-000-1293-2, 2000.

Funke, B., Stiller, G. P., von Clarmann, T., Echle, G., and Fischer, H.: $\mathrm{CO}_{2}$ Line Mixing in MIPAS Limb Emission Spectra and its Influence on Retrieval of Atmospheric Parameters, J. Quant. Spectrosc. Ra., 59, 215-230, doi:10.1016/S00224073(97)00121-0, 1998.

Funke, B., López-Puertas, M., Stiller, G. P., von Clarmann, T., and Höpfner, M.: A new non-LTE Retrieval Method for Atmospheric Parameters From MIPAS-ENVISAT Emission Spectra, Adv. Space Res., 27, 1099-1104, doi:10.1016/S0273-1177(01)001697, 2001.

Funke, B., López-Puertas, M., García-Comas, M., Stiller, G. P., von Clarmann, T., Höpfner, M., Glatthor, N., Grabowski, U., Kellmann, S., and Linden, A.: Carbon monoxide distributions from the upper troposphere to the mesosphere inferred from $4.7 \mu \mathrm{m}$ non-local thermal equilibrium emissions measured by MIPAS on Envisat, Atmos. Chem. Phys., 9, 2387-2411, doi:10.5194/acp-92387-2009, 2009.

Garcia, R. R.: A Numerical Model of the Zonally Averaged Dynamical and Chemical Structure of the Middle Atmosphere, J. Geophys. Res., 88, 1379-1400, 1983.

Garcia, R. R., Marsh, D. R., Kinnison, D. E., Boville, B. A., and Sassi, F.: Simulation of secular trends in the middle atmosphere, J. Geophys. Res., 112, D09301, doi:10.1029/2006JD007485, 2007.

García-Comas, M., López-Puertas, M., Marshall, B., Wintersteiner, P. P., Funke, B., Bermejo-Pantaléon, D., Mertens, C. J., Remsberg, E. E., Gordley, L. L., Mlynczak, M., and Russell, J.: Errors in SABER kinetic temperature caused by non-LTE model parameters, J. Geophys. Res., 113, D24106, doi:10.1029/2008JD010105, 2008.

Grossmann, K. U., Offermann, D., Gusev, O., Oberheide, J., Riese, M., and Spang, R.: The CRISTA-2 mission, J. Geophys. Res., 107, 8173, doi:10.1029/2001JD000667, 2002.

Gusev, O., Kaufmann, M., Grossmann, K.-U., Schmidlin, F., and Shepherd, M. G.: Atmospheric neutral temperature distribution at the mesopause altitude, J. Atmos. Solar-Terr. Phys., 68, 16841697, doi:10.1016/j.jastp.2005.12.010, 2006.

Hase, F., Demoulin, P., Sauval, A. J., Toon, G. C., Bernath, P. F., Goldman, A., Hannigan, J. W., and Rinsland, C. P.: An empirical line-by-line model for the infrared solar transmittance spectrum from 700 to $5000 \mathrm{~cm}^{-1}$, J. Quant. Spectrosc. Ra., 102, 450-463, doi:10.1016/j.jqsrt.2006.02.026, 2006.

Kaufmann, M., Gusev, O. A., Grossmann, K. U., Roble, R. G., Hagan, M. E., Hartsough, C., and Kutepov, A. A.: The vertical and horizontal distribution of $\mathrm{CO}_{2}$ densities in the upper mesosphere and lower thermosphere as measured by CRISTA, J. Geophys. Res., 107, 8182, doi:10.1029/2001JD000704, 2002.

Keckhut, P., McDermid, S., Swart, D., McGee, T., GodinBeekmann, S., Adriani, A., Barnes, J., Baray, J., Bencherif, H., Claude, H., di Sarra, A., Fiocco, G., Hansen, G., Hauchecorne, A., Leblanc, T., Lee, C., Pal, S., Megie, G., Nakane, H., Neuber, R., Steinbrecht, W., and Thayer, J.: Review of ozone and temperature lidar validations performed within the framework of the Network for the Detection of Stratospheric Change, J. Environ. Monit., 6, 721-733, 2004.

Khosravi, R., Lambert, A., Lee, H., Gille, J., Barnett, J., Francis, G., Edwards, D., Halvorson, C., Massie, S., Craig, C., Krinsky, C., McInerney, J., Stone, K., Eden, T., Nardi, B., Hepplewhite, C., Mankin, W., and Coffey, M.: Overview and characterization of retrievals of temperature, pressure, and atmospheric constituents from the High Resolution Dynamics Limb Sounder (HIRDLS) measurements, J. Geophys. Res.-Atmos., 114, D20304, doi:10.1029/2009JD011937, 2009.

Kiefer, M., von Clarmann, T., Grabowski, U., De Laurentis, M., Mantovani, R., Milz, M., and Ridolfi, M.: Characterization of MIPAS elevation pointing, Atmos. Chem. Phys., 7, 1615-1628, doi:10.5194/acp-7-1615-2007, 2007.

Kiefer, M., Arnone, E., Dudhia, A., Carlotti, M., Castelli, E., von Clarmann, T., Dinelli, B. M., Kleinert, A., Linden, A., Milz, M., Papandrea, E., and Stiller, G.: Impact of temperature field inhomogeneities on the retrieval of atmospheric species from MIPAS IR limb emission spectra, Atmos. Meas. Tech., 3, 1487-1507, doi:10.5194/amt-3-1487-2010, 2010.

Leblanc, T., McDermid, I. S., Keckhut, P., Hauchecorne, A., She, C. Y., and Krueger, D. A.: Temperature climatology of the middle atmosphere from long-term lidar measurements at middle and low latitudes, J. Geophys. Res., 103, 17191-17204, 1998.

López-González, M. J., Rodríguez, E., Shepherd, G. G., Sargoytchev, S., Shepherd, M. G., Aushev, V. M., Brown, S., García-Comas, M., and Wiens, R. H.: Tidal variations of $\mathrm{O}_{2}$ Atmospheric and $\mathrm{OH}(6-2)$ airglow and temperature at midlatitudes from SATI observations, Ann. Geophys., 23, 35793590, doi:10.5194/angeo-23-3579-2005, 2005.

López-González, M. J., García-Comas, M., Rodríguez, E., LópezPuertas, M., Shepherd, M. G., Shepherd, G. G., Sargoytchev, S., Aushev, V. M., Smith, S. M., Mlynczak, M. G., Russell, J. M., Brown, S., Cho, Y., and Wiens, R. H.: Groundbased mesospheric temperatures at mid-latitude derived from $\mathrm{O}_{2}$ and $\mathrm{OH}$ airglow SATI data: Comparison with SABER measurements, J. Atmos. Solar-Terr. Phys., 69, 2379-2390, doi:10.1016/j.jastp.2007.07.004, 2007.

López-Puertas, M. and Taylor, F. W.: Non-LTE radiative transfer in the Atmosphere, World Scientific Pub., Singapore, 2001. 
López-Puertas, M., López-Valverde, M. Á., Garcia, R. R., and Roble, R. G.: A review of $\mathrm{CO}_{2}$ and $\mathrm{CO}$ abundances in the middle atmosphere, in: Atmospheric Science Across the Stratopause, edited by: Siskind, D. E., Eckermann, S. D., and Summers, M. E., vol. 123 of Geophysical Monograph Series, p. 83, American Geophysical Union, 2000.

López-Puertas, M., García-Comas, M., Funke, B., Picard, R. H., Winick, J. R., Wintersteiner, P. P., Mlynczak, M. G., Mertens, C. J., Russell III, J. M., and Gordley, L. L.: Evidence for an $\mathrm{OH}(v)$ excitation mechanism of $\mathrm{CO}_{2} 4.3 \mu \mathrm{m}$ nighttime emission from SABER/TIMED measurements, J. Geophys. Res., 109, D09307, doi:10.1029/2003JD004383, 2004.

López-Puertas, M., Funke, B., Gil-López, S., López-Valverde, M. A., von Clarmann, T., Fischer, H., Oelhaf, H., Stiller, G. P., Kaufmann, M., Koukouli, M. E., and Flaud, J.-M.: Atmospheric non-local thermodynamic equilibrium emissions as observed by the Michelson Interferometer for Passive Atmospheric Sounding (MIPAS), Comptes Rendus Physique, 6, 848-863, doi:10.1016/j.crhy.2005.07.012, 2005.

López-Puertas, M., Funke, B., García-Comas, M., BermejoPantaleón, D., Kaufmann, M., and Dudhia, A.: Extension of the Reference atmospheres and Vibrational Temperatures (WP9220). Support to MIPAS Level 2 product validation (MIPAS L2), Report ESA ESRIN contract no 21719/08/i-ol, European Space Agency, 2009.

López-Puertas, M., García-Comas, M., Funke, B., BermejoPantaleón, D., Höpfner, M., Grabowski, U., Stiller, G. P., von Clarmann, T., and von Savigny, C.: Measurements of polar mesospheric clouds in infrared emission by MIPAS/ENVISAT, J. Geophys. Res., 114, D00I07, doi:10.1029/2009JD012548, 2009.

Lübken, F.-J.: Thermal structure of the arctic summer mesosphere, J. Geophys. Res., 104, 9135-9150, doi:10.1029/1999JD900076, 1999.

Lübken, F.-J., Hillert, W., Lehmacher, G., von Zahn, U., Bittner, M., Offermann, D., Schmidlin, F. J., Hauchecorne, A., Mourier, M., and Czechowsky, P.: Intercomparison of density and temperature profiles obtained by lidar, ionizatoin gauges, falling spheres, datasondes and radiosondes during the DYANA campaign, J. Atmos. Terr. Phys., 56, 1969-1984, 1994.

McDermid, I. S., Walsh, T. D., Deslis, A., and White, M. L.: Optical Systems Design for a Stratospheric Lidar, Appl. Opt., 34, 62016210, 1995.

Mertens, C. J., Schmidlin, F. J., Goldberg, R. A., Remsberg, E. E., Pesnell, W. D., Russell III, J. M., Mlynczak, M. G., LópezPuertas, M., Wintersteiner, P. P., Picard, R. H., Winick, J. R., and Gordley, L. L.: SABER observations of mesospheric temperatures and comparisons with falling sphere measurements taken during the 2002 summer MaCWAVE campaign, Geophys. Res. Lett., 31, L03105, doi:10.1029/2003GL018605, 2004.

Miller, S. M., Snell, H. E., and Moncet, J.-L.: Simultaneous retrieval of middle atmospheric temperature and trace gas species volume mixing ratios from Cryogenic Infrared Radiance Instrumentation for Shuttle (CIRRIS 1A), J. Geophys. Res., 104, 18697-18714, 1999.

Mlynczak, M. G., Martin-Torres, F. J., Marshall, B. T., Thompson, R. E., Williams, J., Turpin, T., Kratz, D. P., Russell III, J. M., Woods, T., and Gordley, L. L.: Evidence for a solar cycle influence on the infrared energy budget and radiative cooling of the thermosphere, J. Geophys. Res., 112, A12302,
doi:10.1029/2006JA012194, 2007.

Nadile, R. M., Wheeler, N. B., Stair, A. T., Frodsham, D. C., and Wyatt, D. J.: SPIRE-Spectral Infrared Experiment, Proc. Soc. Photo. Opt. Instrum. Eng., 24, p. 18, 1977.

Picone, J., Hedin, A., Drob, D., and Aikin, A.: NRLMSISE00 empirical model of the atmosphere: Statistical comparisons and scientific issues, J. Geophys. Res., 107, 1468, doi:10.1029/2002JA009430, 2002.

Raspollini, P., Belotti, C., Burgess, A., Carli, B., Carlotti, M., Ceccherini, S., Dinelli, B. M., Dudhia, A., Flaud, J.-M., Funke, B., Höpfner, M., López-Puertas, M., Payne, V., Piccolo, C., Remedios, J. J., Ridolfi, M., and Spang, R.: MIPAS level 2 operational analysis, Atmos. Chem. Phys., 6, 5605-5630, doi:10.5194/acp6-5605-2006, 2006.

Raspollini, P., Carli, B., Ceccherini, S., Forzieri, G., Sgheri, L., Ridolfi, M., Carlotti, M., Papandrea, E., Arnone, E., Dinelli, B. M., Castelli, E., Remedios, J., Sembhi, H., Dudhia, A., Lopez-Puertas, M., Funke, B., Flaud, J.-M., von Clarmann, T., Hoepfner, M., Oelhaf, H., Fischer, H., Kiefer, M., Kleinert, A., Chipperfield, M., .Perron, G., Aubertin, G., Birk, M., Wagner, G., Gessner, R., Mosner, P., Schmitt, M., Fehr, T., D’Alba, L., and Niro, F.: Level 2 near-real-time analysis of MIPAS measurements on ENVISAT, in: Eight years of MIPAS measurements, vol. SP-686, 011-d2, ESA Publication Division, 2010.

Remedios, J. J., Leigh, R. J., Waterfall, A. M., Moore, D. P., Sembhi, H., Parkes, I., Greenhough, J., Chipperfield, M. P., and Hauglustaine, D.: MIPAS reference atmospheres and comparisons to V4.61/V4.62 MIPAS level 2 geophysical data sets, Atmos. Chem. Phys. Discuss., 7, 9973-10017, doi:10.5194/acpd-79973-2007, 2007.

Remsberg, E. E., Marshall, B. T., García-Comas, M., Krueger, D., Lingenfelser, G. S., Martin-Torres, J., Mlynczak, M. G., Russell, J. M., I., Smith, A. K., Zhao, Y., Brown, C., Gordley, L. L., López-Gonzalez, M. J., López-Puertas, M., She, C.-Y., Taylor, M. J., and Thompson, R. E.: Assessment of the quality of the Version 1.07 temperature-versus-pressure profiles of the middle atmosphere from TIMED/SABER, J. Geophys. Res., 113, D17101, doi:10.1029/2008JD010013, 2008.

Ridolfi, M., Carli, B., Carlotti, M., von Clarmann, T., Dinelli, B., Dudhia, A., Flaud, J.-M., Höpfner, M., Morris, P. E., Raspollini, P., Stiller, G., and Wells, R. J.: Optimized Forward and Retrieval Scheme for MIPAS Near-Real-Time Data Processing, Appl. Opt., 39, 1323-1340, 2000.

Riese, M., Spang, R., Preusse, P., Ern, M., Jarnish, M., Offermann, D., and Grossmann, K. U.: Cryogenic Infrared Spectrometers and Telescopes for the Atmosphere (CRISTA) data processing and atmospheric temperature and trace gas retrieval, J. Geophys. Res., 104, 16349-16367, 1999.

Rodgers, C. D.: Inverse Methods for Atmospheric Sounding: Theory and Practice, vol. 2 of Series on Atmospheric, Oceanic and Planetary Physics, edited by: Taylor, F. W., World Scientific Publishing Co. Pte. Ltd, Singapore, 2000.

Rosenkranz, P. W.: Shape of the $5 \mathrm{~mm}$ Oxygen Band in the Atmosphere, IEEE Trans. Antennas Propag., AP-23, 498-506, 1975.

Russell III, J. M., Mlynczak, M. G., Gordley, L. L., Tansock, J., and Esplin, R.: An overview of the SABER experiment and preliminary calibration results, Proc. SPIE, 3756, 277-288, 1999.

Sargoytchev, S. I., Brown, S., Solheim, B. H., Cho, Y.-M., Shepherd, G. G., and López-González, M. J.: Spectral airglow tem- 
perature imager (SATI): a ground-based instrument for the monitoring of mesosphere temperature, Appl. Opt., 43, 5712-5721, 2004.

Schwartz, M. J., Lambert, A., Manney, G. L., Read, W. G., Livesey, N. J., Froidevaux, L., Ao, C. O., Bernath, P. F., Boone, C. D., Cofield, R. E., Daffer, W. H., Drouin, B. J., Fetzer, E. J., Fuller, R. A., Jarnot, R. F., Jiang, J. H., Jiang, Y. B., Knosp, B. W., Krüger, K., Li, J., Mlynczak, M. G., Pawson, S., Russell, J. M., Santee, M. L., Snyder, W. V., Stek, P. C., Thurstans, R. P., Tompkins, A. M., Wagner, P. A., Walker, K. A., Waters, J. W., and Wu, D. L.: Validation of the Aura Microwave Limb Sounder temperature and geopotential height measurements, J. Geophys. Res.Atmos., 113, D15S11, doi:10.1029/2007JD008783, 2008.

Sharma, R. D. and Wintersteiner, P. P.: Role of carbon dioxide in cooling planetary thermospheres, Geophys. Res. Lett., 17, 22012204, 1990.

Sica, R. J., Izawa, M. R. M., Walker, K. A., Boone, C., Petelina, S. V., Argall, P. S., Bernath, P., Burns, G. B., Catoire, V., Collins, R. L., Daffer, W. H., De Clercq, C., Fan, Z. Y., Firanski, B. J., French, W. J. R., Gerard, P., Gerding, M., Granville, J., Innis, J. L., Keckhut, P., Kerzenmacher, T., Klekociuk, A. R., Kyrö, E., Lambert, J. C., Llewellyn, E. J., Manney, G. L., McDermid, I. S., Mizutani, K., Murayama, Y., Piccolo, C., Raspollini, P., Ridolfi, M., Robert, C., Steinbrecht, W., Strawbridge, K. B., Strong, K., Stübi, R., and Thurairajah, B.: Validation of the Atmospheric Chemistry Experiment (ACE) version 2.2 temperature using ground-based and space-borne measurements, Atmos. Chem. Phys., 8, 35-62, doi:10.5194/acp-8-35-2008, 2008.

Smith, A. K., Marsh, D. R., Mlynczak, M. G., and Mast, J. C.: Temporal variations of atomic oxygen in the upper mesosphere from SABER, J. Geophys. Res., 115, D18309, doi:10.1029/2009JD013434, 2010.

Stair, T., Pritchard, J., Coleman, I., Bohne, C., Williamson, W., Rogers, J., and Rawlins, W. T.: Rocketborne cryogenic (10 K) high-resolution interferometer spectrometer flight HIRIS: auroral and atmospheric IR emission spectra, Appl. Opt., 22, 10561069, 1983.

Steck, T.: Methods for determining regularization for atmospheric retrieval problems, Appl. Opt., 41, 1788-1797, 2002.
Stiller, G. P., von Clarmann, T., Funke, B., Glatthor, N., Hase, F., Höpfner, M., and Linden, A.: Sensitivity of trace gas abundances retrievals from infrared limb emission spectra to simplifying approximations in radiative transfer modelling, J. Quant. Spectrosc. Ra., 72, 249-280, doi:10.1016/S0022-4073(01)00123-6, 2002.

Tikhonov, A.: On the solution of incorrectly stated problems and method of regularization, Dokl. Akad. Nauk. SSSR, 151, 501504, 1963.

Tobiska, W. K., Woods, T., Eparvier, F., Viereck, R., Floyd, L., Bouwer, D., Rottman, G., and White, O. R.: The SOLAR2000 empirical solar irradiance model and forecast tool, J. Atmos. Solar-Terr. Phys., 62, 1233-1250, 2000.

von Clarmann, T.: Validation of remotely sensed profiles of atmospheric state variables: strategies and terminology, Atmos. Chem. Phys., 6, 4311-4320, doi:10.5194/acp-6-4311-2006, 2006.

von Clarmann, T., Glatthor, N., Grabowski, U., Höpfner, M., Kellmann, S., Kiefer, M., Linden, A., Mengistu Tsidu, G., Milz, M., Steck, T., Stiller, G. P., Wang, D. Y., Fischer, H., Funke, B., Gil-López, S., and López-Puertas, M.: Retrieval of temperature and tangent altitude pointing from limb emission spectra recorded from space by the Michelson Interferometer for Passive Atmospheric Sounding (MIPAS), J. Geophys. Res., 108, 4736, doi:10.1029/2003JD003602, 2003.

von Clarmann, T., Höpfner, M., Kellmann, S., Linden, A., Chauhan, S., Funke, B., Grabowski, U., Glatthor, N., Kiefer, M., Schieferdecker, T., Stiller, G. P., and Versick, S.: Retrieval of temperature, $\mathrm{H}_{2} \mathrm{O}, \mathrm{O}_{3}, \mathrm{HNO}_{3}, \mathrm{CH}_{4}, \mathrm{~N}_{2} \mathrm{O}, \mathrm{ClONO}_{2}$ and $\mathrm{ClO}$ from MIPAS reduced resolution nominal mode limb emission measurements, Atmos. Meas. Tech., 2, 159-175, doi:10.5194/amt-2-159-2009, 2009.

Wintersteiner, P. P., Picard, R. H., Sharma, R. D., Winick, J. R., and Joseph, R. A.: Line-by-line Radiative Excitation Model for the Non-Equilibrium Atmosphere: Application to $\mathrm{CO}_{2} 15-\mu \mathrm{m}$ Emission, J. Geophys. Res., 97, 18083-18117, 1992. 